NUREG/CR-1957

PNL-3692

\title{
Evaluation of ASME Section XI Reference Level Sensitivity for Initiation of Ultrasonic Inspection Examination
}

Prepared by T. T. Taylor, G. P. Selby

Pacific Northwest Laboratory

Operated by

Battelle Memorial Institute

Prepared for

U.S. Nuclear Regulatory

Commission 


\section{NOTICE}

This report was prepared as an account of work sponsored by an agency of the United States Government. Neither the United States Government nor any agency thereof, or any of their employees, makes any warranty, expressed or implied, or assumes any legal liability or responsibility for any third party's use, or the results of such use, of any information, apparatus product or process disclosed in this report, or represents that its use by such third party would not infringe privately owned rights.

GPO Sales Program

Division of Technical Information and Document Control

U. S. Nuclear Regulatory Commission

Washington, D. C. 20555

Printed copy price: $\$ 4.00$

and

National Technical Information Service

Springfield, Virginia 22161 


\section{Evaluation of ASME Section XI Reference Level Sensitivity for Initiation of Ultrasonic Inspection Examination}

Manuscript Completed: February 1981

Date Published: Aprił 1981

Prepared by

T. T. Taylor, G. P. Selby

Pacific Northwest Laboratory

Fichland, WA 99352

\section{Prepared for}

Division of Engineering

Office of Nuclear Reactor Regulation U.S. Nuclear Regulatory Commission Washington, D.C. 20555

NRC FIN B2157 


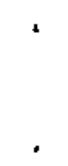




\section{ABSTRACT}

This report evaluates the change in inspection sensitivity resulting in major changes of ASME Boiler and Pressure Vessel Code Section XI between 1974 and 1977 Editions. It was found that the inspection sensitivity resulting from requirements of the 1977 Edition of Section $X I$ were not adequate to detect minimum flaws referenced by same Code. 


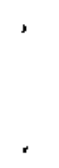




\section{TABLE OF CONTENTS}

\section{Page}

I. INTRODUCTION I

II. PROGRAM OBJECTIVE 2

III. TECHNICAL APPROACH 3

IV. PROCEDURE AND RESULTS 4

V. DISCUSSION 6

VI. CONCLUSIONS 18

APPENDIX I I-]

APPENDIX II II-1

APPENDIX III III-] 


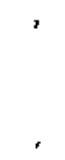




\section{LIST OF FIGURES}

Page

$\begin{array}{lll}\text { Figure 1. Reporting Convention } & 6\end{array}$

Figure 2. Effect of Increasing Wall Thickness on EMERGING Sound

Figure 3. Frequency Spectrum of Reflection from 0.100 inch Vertical Notch in 0.6 Inch Thick Stainless Steel

Figure 4. Instrument A Receiver Bandpass at 2.25 $\mathrm{MHz}$ Setting

Figure 5. Instrument B Receiver Bandpass at 2.0 $\mathrm{MHz}$ Setting

Figure 6. Measured and Theoretical Reduction in Ultrasonic Piping Inspection Sensitivity of the 1977 Edition of Section XI (notch), as compared to the 1974 Edition (side drilled holes, SDH)

KEY WORDS:

Evaluation: As used in Section XI Editions of ASME Boiler and Pressure Vessel Code refers to the "sizing" indications with respect to acceptance and rejection standards specified by Section XI.

Recording: As used in Section XI Editions of ASME Boiler and Pressure Vessel Code, recording an indication simply denotes the presence of the indications. Disposition of the flaw in terms of acceptance or rejection is not required. 


\section{LIST OF TABLES}

Page

Table I. Piping Used for Test Samples

Table II. Sumrnary of Flaw Response Using Criteria of 1977 Edjtion/Summer 1978 Addenda IWA-2232

Table III. Summary of Flaw Response Using 20\% Reference Leve] Evaluation Criteria 


\section{ACKNOWLEDGEMENTS}

The authors would like to acknowledge the guidance of G. J. Posakony and F. L. Becker in developing the technical approach of this project. 


\section{EVALUATION OF ASME SECTION XI REFERENCE LEVEL. SENSITIVITY FOR INITIATION OF ULTRASONIC INDICATION EVALUATION}

\section{INTRODUCTION}

A recent state-of-practice survey ${ }^{(1)}$ indicates that there is considerable difference in opinion over the amplitude of reference level ${ }^{(2)}$ at which indications from an ultrasonic test should be recorded and evaluated during inservice weld examinations.

The 1974 Edition through Summer 1975 Addenda of Section XI of ASME Boiler and Pressure Vessel code ${ }^{(3)}$ for ultrasonic examination of nuclear power plant piping welds states:
"All indications which produce a response greater than $20 \%$ of the reference level shall be investigated to the extent that the operator can evaluate the shape, identity, and location of all such reflectors in terms of the acceptance-rejection standards of the reference code section."

After the $20 \%$ reference level criteria became effective, the nuclear industry determined that many of the reflectors that exceeded the $20 \%$ reference level resulted from geometric reflectors such as weld root, counter bore and weld crown areas. Recording these "nonrelevant"

\footnotetext{
${ }^{1}$ Quarterly report dated August 27, 1979, "Integration of Nondestructive Examination Reliability and Fracture Mechanics," RSR Fin. Budget No. B2289-9; RSR Contact, J. Muscara.

${ }^{2}$ Appendix II page II- 1 lists the calibration procedure and defines the primary reference level for both the 1974 and 1977 Editions of Section $X I$.
}
${ }^{3} 1974$ Edition through Summer 1975 Addenda Section XI which references the same edition of Article 5, Section V of ASME Boiler and Pressure Vessel code.


indications resulted in increased inspection time, increased manpower requirements and increased personnel exposure. Consequently, industry questioned the necessity for using a $20 \%$ reference level recording criterion. Subsequent addenda to the 1974 Edition of Section XI have reflected industry concerns; and the current recording criteria is $50 \%$ reference level while actual flaw evaluation criteria is $100 \%$ reference level response.

As subsequent editions and addenda to 1974 Edition began referencing recording levels greater than $20 \%$ reference level, utility inservice weld inspection programs began requesting relief from the $20 \%$ reference level recording criteria required by the 1974 Edition of Section XI.

In response to requests from the nuclear inclustry for relief from the $20 \%$ reference level criteria, the NRC develcped the following criteria: ${ }^{(5)}$

- Indications 50\% of DAC or greater shall be recorded.

- An indication 100\% of DAC or greater shall be investigated by a Level II or Level III examiner to the extent necessary to determine the shape, identity and location of the reflector.

- Any non-geometric indication $20 \%$ of DAC or greater discovered during the ultrasonic (UT) examination of piping welds and base metal shall be recorded and investigated by the Level II or Leve] III examiner to the extent necessary to determine the shape, identity and location of the reflector.

\section{PROGRAM OBJECTIVE}

The objective of this program is to produce engineering data that define the relative ability of various reference level criteria to detect

\footnotetext{
${ }^{4} 1977$ Edition through Summer 1978 Addenda Section XI, ASME Boiler and Pressure Vessel Code.

5 This position is referenced in the Safety Evaluations of Inservice Inspection Programs for St. Lucie Unit 1, Prairie Island Units 1 and 2, Turkey Point 4 , and Palasides.
} 
minimum Code unacceptable flaws as defined by Tables IWB-3514-2 and -3 of the 1977 Edition of Section XI, including addenda through Sunmer 1978.

\section{II1. TECHNICAL APPROACH}

Tables IWB-3514-2 and -3 define the minimum rejectable flaw sizes for carbon and stainless steel pipe. A selection of these flaws have been fabricated as EDM slots in unwelded sections of carbon and stainless steel pipe. In order to limit the size of the experiment, three nominal pipe diameters and three flaw aspect ratios ${ }^{(6)}$ were selected for study.

The aspect ratios chosen were $0.05,0.25$, and 0.5 . The 0.5 aspect ratio was chosen because flaws of that shape (semicircular) are the smallest, and presumably therefore the most difficult to detect of all the rejectable flaws. The other two aspect ratios, 0.05 and 0.25 , are more representative of actual cracks grown in reactor piping, both inservice and under laboratory conditions. The shapes of all these slots are segments of circles; that is, the part of a circle that is cut off by the construction of a chord.

The pipe sections were selected to cover a representative range of diameters and thicknesses, and to include both carbon and stainless steels. All are in widespread use in nuclear facilities. The pipe sections used for test samples were as follows:

\section{$\underline{\text { TABLE I }}$}

\section{Piping Used for Test Samples}

Nominal

Diameter

$20^{\prime \prime}$

$20^{\prime \prime}$
Nominal

Thickness

Sch. 80/1.033 inch

Sch. $80 / 1.033$ inch
Material

Stainless

Ferritic

6 Aspect ratio as defined by the Code is the ratio of flaw throughwall depth over length. Aspect ratio=a/1; a=throughwall depth, $]=1$ ength. 
TABLE I

(continued)

Piping Types Used for Test Samples

Nomina 1

Diameter

$12^{\prime \prime}$

$4 "$
Nominal

Thickness

Sch. 80/0.688 inch

Sch. $80 / 0.344$ inch
Material

Stainless

Ferritic

Flaw orientation was also varied, in order to represent crack propagation at a non-vertical angle through the weld heat affected zone. Flaw angles used (measured from normal to the pipe surface) were $0^{\circ}, 15^{\circ}$ and $25^{\circ}$.

Calibration reflectors were fabricated into each pipe section. Both the side-drilled hole (Section XI 1974) and the end-mill notch (1977) were installed, though only the notch was used in data acquisition.

Each pipe section used in this experiment contained nine EDM slots of minimum Code-rejectable size, representing all combinations of the selected flaw aspect ratios and orientations. The slots were all fabricated on the inside pipe surface, oriented parallel to the pipe circumference. In addition, each pipe section contained code calibration reflectors. A typical pipe section is shown in Appendix I, page I-1.

Finally, in an attempt to determine possible effects of instrument variations, measurements were made using two different ultrasonic inspection instruments. These instruments are typical, and among the most commion, of the portable UT instruments currently being used in industry.

IV. PROCEDURE AND RESULTS

The method used to measure the response of each flaw was as follows: 
The inspection system $(7)$ was caljbrated as required by Appendix III of the 1977 Edition through Summer 1978 Addenda of Section XI. (8) The peak amplitude of reflection from each flaw was measured in decibels (dB) and recorded. Peak ampljtudes were then calculated relative to the reference level established by calibration. The transducers used in this program were:

- 0.25 inch diameter, 2.25 MHz

- 0.50 inch diameter, $2.25 \mathrm{MHz}$

- 1.00 inch diameter, 2.25 MHz

The measurements outlined above were made at $1 / 2$ Vee and $3 / 2$ Vee paths using $45^{\circ}$ inspection beam angles and $1 / 2$ Vee using $60^{\circ}$ inspection angle.

The peak amplitude reflections were measured using each transducer, except in the case of the 4-inch diameter pipe, which was examined with .25 -inch and .5-inch diameter transducers only. The angled notches were examined from both beam directions because the reflection geometry is direction-dependent. The vertical notches were inspected from both sides to average any fabrication curvature.

Since each flaw was inspected from both sides and some flaws were angled, a $(+)$ was used to indicate inspection from the obtuse side and a (-) was used to indicate inspection from the acute side. This convention is shown in Figure 1 (page 6).

The results of the measurements made from this program are given in graphic form in Appendix III, pages III-1 through III-31.

\footnotetext{
7 The inspection system as defined by code includes search units, shoes, couplants, cables, ultrasonic instruments, and recording devices. 1977 Edition Section XI, ASME Boiler and Pressure Vessel Code, page 153.

${ }^{8}$ Appendix II, page II-1 lists calibration requirements of Section XI, Appendix III.
} 


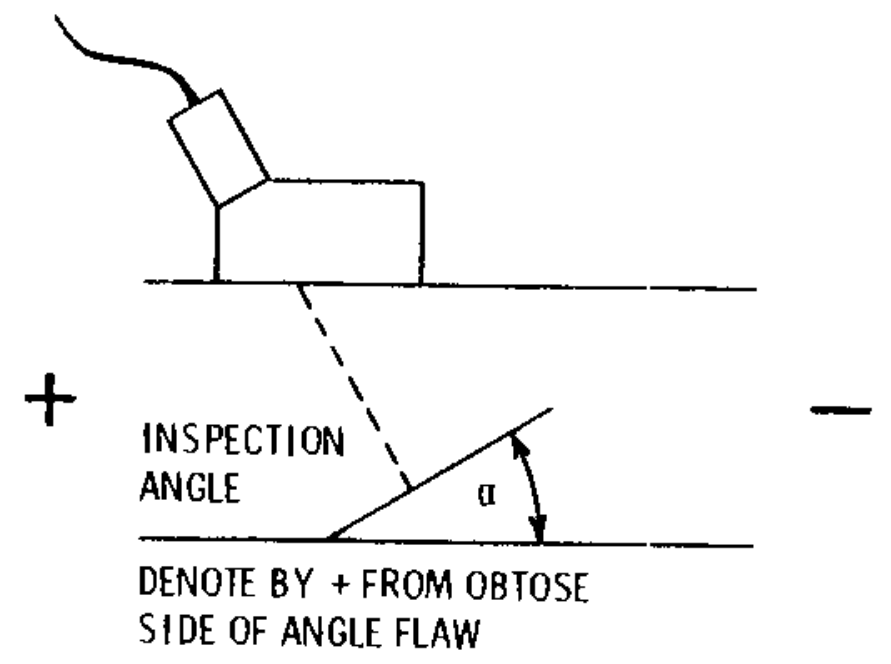

Figure 1. Reporting Convention.

\section{DISCUSSION}

The primary observation of this report is that the inspection sensitivity resulting from the calibration and recording/evaluation requirements of Appendix III, Section XI, is not adequate to detect minimum unacceptable flaws as defined by the same code. Table 1 it (page 7) shows a summary of the measurements resulting from inspections using both instruments. The results are tabulated according to pipe dianeter, inspection angle and beam path using the recording and evaluation criteria of the 1977 Edition, Surmmer 1978 Addenda, Section XI, IWA-2232.

Examination of Table II shows that approximately $26 \%$ of the inspections produced a response greater than or equal to the reference established by calibration according to Appendix III. Since the 1977 Edition of Section $X I$ requires only those flaws producing a response greater than 


\section{TABLE II}

Sumary of Flaw Response Using

Criteria of 1977 Edjtion/IWA-2232

Summer 1978 Addenda, Section XI

\begin{tabular}{|c|c|c|c|c|}
\hline Pipe Diameter & $\begin{array}{c}\text { Inspection } \\
\text { Angle / } \\
\text { Beam Path }\end{array}$ & $\begin{array}{l}\text { Number of } \\
\text { Flaws Pro- } \\
\text { ducing Re- } \\
\text { cordable } \\
\text { Response } \\
\end{array}$ & $\begin{array}{c}\text { Number of } \\
\text { Flaws Pro- } \\
\text { ducing } \\
\text { Evaluation } \\
\text { Response } \\
\end{array}$ & $\begin{array}{l}\text { Total } \\
\text { Measure- } \\
\text { ments } \\
\text { Made } \\
\end{array}$ \\
\hline $\begin{array}{l}4 " \text { Sch. } 80 \\
\text { Carbon Steel }\end{array}$ & $\begin{array}{l}45^{\circ} / 1 / 2 V \\
45^{\circ} / 3 / 2 V \\
60^{\circ} / 1 / 2 V\end{array}$ & $\begin{array}{l}72 \\
65 \\
59\end{array}$ & $\begin{array}{l}37 \\
19 \\
40\end{array}$ & $\begin{array}{l}72 \\
72 \\
72\end{array}$ \\
\hline $\begin{array}{l}12^{\prime \prime} \text { Sch. } 80 \\
304 \text { Stainless } \\
\text { Stee? }\end{array}$ & $\begin{array}{l}45^{\circ} / 1 / 2 v \\
45^{\circ} / 3 / 2 v \\
60^{\circ} / 1 / 2 v\end{array}$ & $\begin{array}{r}86 \\
86 \\
105\end{array}$ & $\begin{array}{l}25 \\
39 \\
57\end{array}$ & $\begin{array}{l}108 \\
108 \\
108\end{array}$ \\
\hline $\begin{array}{l}20 " \text { Sch. } 80 \\
\text { Carbon Steel }\end{array}$ & $\begin{array}{l}45^{\circ} / 1 / 2 v \\
45^{\circ} / 3 / 2 v \\
60^{\circ} / 1 / 2\end{array}$ & $\begin{array}{l}67 \\
48 \\
74\end{array}$ & $\begin{array}{r}24 \\
9 \\
40\end{array}$ & $\begin{array}{l}108 \\
108 \\
108\end{array}$ \\
\hline $\begin{array}{l}20^{\prime \prime} \text { Sch. } 80 \\
304 \text { Stainless } \\
\text { Steel }\end{array}$ & $\begin{array}{l}45^{\circ} / 1 / 2 V \\
45^{\circ} / 3 / 2 V \\
60^{\circ} / 1 / 2 V\end{array}$ & $\begin{array}{l}17 \\
\text { Sound attenu- } \\
\text { ated; no flaw } \\
\text { response. } \\
10\end{array}$ & 0 & 108 \\
\hline Totals & & 689 & 284 & 1,080 \\
\hline Percentage & & $63.8 \%$ & $26.3 \%$ & \\
\hline
\end{tabular}


or equal to reference level to be evaluated, only $26 \%$ of the flaws examined would be evaluated in terms of acceptance or rejection. Approximately $64 \%(9)$ of the inspections produced a response greater than $50 \%$ of the reference level. Since the 1977 Edition of Section XI requires flaws producing a response $50 \%$ of the reference level to be recorded, $64 \%$ of the flaws inspected would have been recorded. At this point it must be noted that according to the 1977 Edition Section XI even though a flaw produces a response large enough to be recorded (e.g., $50 \%$ reference leve1), only those flaws producing a response greater than or equal to the reference level (e.g., 100\% reference level) are evaluated. Less than a third of the rejectable defects in this study produced such a response requiring evaluation. In addition, pipe cracks similar in size will likely produce lower amplitude responses due to their roughness, tightness, and possibly their location (on counterbore, on far side of weld with one-sided access, etc.). Table III (page 9) summarizes measurement results using a $20 \%$ reference level evaluation criteria. The results shown in Table III are not surprising; increasing inspection sensitivity increases the assurance of flaw detection.

One final observation of Tables II and III is that the results show, as one would expect, the ability to detect flaws in carbon steel is much higher (roughiy 2 to 1 ) than stainless steel. This is especially true of thick walled stainless steel piping. The data in Tables II and III also show that increasing pipe wall thickness seems to have a negative effect on reflection amplitudes. The 4 -inch pipe data show very little amplitude change as a function of flaw angle, while the 20-inch pipe data fluctuated considerably. This is attributed to two effects. First, the flaws in the 4 -inch pipe are about $0.6 \lambda$ through-wall, where $\lambda$ represents the acoustic wavelength; and the 20-inch pipe flaws are about $1.9 \lambda$ through-wall. The greater through-wall dinension causes the reflected beam to be more directional. Since the reflected beam in a thick wall

${ }^{9}$ This number includes any response greater than $50 \%$ reference level (i.e., includes those flaws that would also be evaluated). 


\section{TABLE III}

Summary of Flaw Response Using

20\% Reference Level Evaluation Criteria

\begin{tabular}{|c|c|c|c|c|}
\hline Pipe Diameter & $\begin{array}{c}\text { Inspection } \\
\text { Angle / } \\
\text { Beam Path } \\
\end{array}$ & $\begin{array}{l}\text { Number of } \\
\text { Flaws Pro- } \\
\text { ducing Re- } \\
\text { cordable } \\
\text { Response } \\
\end{array}$ & $\begin{array}{l}\text { Number of } \\
\text { Flaws Pro- } \\
\text { ducing } \\
\text { Evaluation } \\
\text { Response } \\
\end{array}$ & $\begin{array}{l}\text { Total } \\
\text { Measure- } \\
\text { ments } \\
\text { Made } \\
\end{array}$ \\
\hline $\begin{array}{l}\text { 4" Sch. } 80 \\
\text { Carbon Steel }\end{array}$ & $\begin{array}{l}45^{\circ} / 1 / 2 V \\
45^{\circ} / 3 / 2 V \\
60^{\circ} / 1 / 2 V\end{array}$ & $\begin{array}{l}72 \\
72 \\
72\end{array}$ & $\begin{array}{l}72 \\
72 \\
72\end{array}$ & $\begin{array}{l}72 \\
72 \\
72\end{array}$ \\
\hline $\begin{array}{l}12^{\prime \prime} \text { Sch. } 80 \\
304 \text { Stajnless } \\
\text { Steel }\end{array}$ & $\begin{array}{l}45^{\circ} / 1 / 2 V \\
45^{\circ} / 3 / 2 V \\
60^{\circ} / 1 / 2 V\end{array}$ & $\begin{array}{l}108 \\
108 \\
108\end{array}$ & $\begin{array}{l}108 \\
108 \\
108\end{array}$ & $\begin{array}{l}108 \\
108 \\
108\end{array}$ \\
\hline $\begin{array}{l}20^{\prime \prime} \text { Sch. } 80 \\
\text { Carbon Steel }\end{array}$ & $\begin{array}{l}45^{\circ} / 1 / 2 V \\
45^{\circ} / 3 / 2 V \\
60^{\circ} / 1 / 2 \vee\end{array}$ & $\begin{array}{r}102 \\
98 \\
108\end{array}$ & $\begin{array}{r}102 \\
98 \\
108\end{array}$ & $\begin{array}{l}108 \\
108 \\
108\end{array}$ \\
\hline $\begin{array}{l}20 " \text { Sch. } 80 \\
304 \text { Stainless } \\
\text { Steel }\end{array}$ & $\begin{array}{l}45^{\circ} / 1 / 2 V \\
45^{\circ} / 3 / 2 V \\
60^{\circ} / 1 / 2 V\end{array}$ & $\begin{array}{l}101 \\
\text { Sound attenu- } \\
\text { ated; no flaw } \\
\text { response. } \\
72\end{array}$ & 101 & 108 \\
\hline Total & & 1,021 & 1,021 & 1,080 \\
\hline Percentage & & $94.5 \%$ & $94.5 \%$ & \\
\hline
\end{tabular}


has farther to travel to reach the surface. Clearly, if the reflected beam is more directional and does not retrace the path of the incident beam, then the farther it travels the greater the separation between insertion and emergence points. For the 4-inch pipe, the reflected beam does not travel far enough to deviate much from the incident beam path. When it reaches the surface, the reflected beam illuminates an area that is at least partially but probably mostly covered by the transducer. For the 20-inch pipe, the more directional reflected beam travels farther and deviates more from the incident beam path. Therefore, the reflected beam may illuminate an area of the pipe surface that may be far from the search unit, resulting in lower amplitude and more variation of amplitude with varying flaw angle. This concept is shown graphically in Figure 2 (page 11).

Comparison of aspect ratios yields few surprises. A longer flaw generally produces an equal or higher amplitude than a similar shorter flaw. This result is to be expected because flaws shorter than the calibration notch have less reflective area horizontally. Close scrutiny of the data shows some exceptions--the longest flaw produced a lower response than the medium length flaw--which may be due to variations in attenuation from point to point within the metal or beam directionly.

Analysis of the data in Appendix III also snows that differences in performance can be expected between different inspection systems. The data produced by this program show a clear trend between Instrument $A$ and Instrument $B$. In nearly all inspections, Instrument $A$ shows less varjation in response to angled flaws than Instrument $B$. To understand this trend requires, the authors believe, knowledge of the inspection frequency of each inspection system (i.e., pulser/transducer output) and the recejver bandpass. Figure 3 (page 12) shows the frequency spectrum produced by the reflection of ultrasound from a . I-inch vertical notch in .6-inch stainless steel test specimen using the same .5-inch diameter search unit, cable, $45^{\circ}$ shoe, and coupling using both instruments. The beam path is $1 / 2$ Vee. Figures 4 and 5 (page 13 and 14) show the frequency 


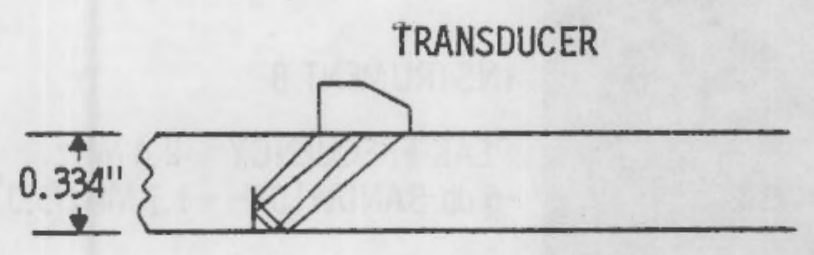

TRANSDUCER

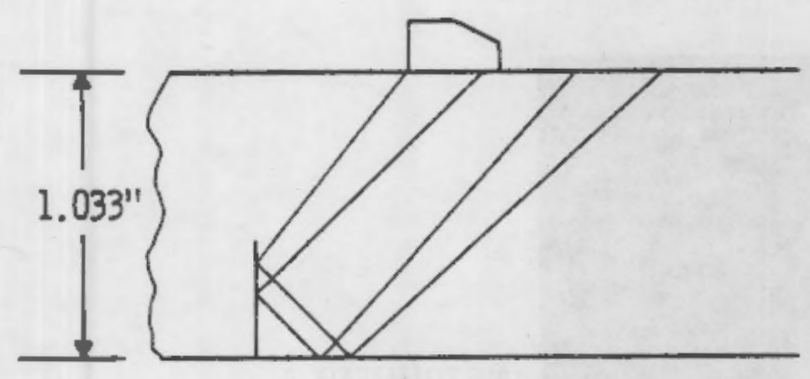

EMERGING BEAM NEARLY RETRACES INCIDENT PATH AND PARTIALLY ECLIPSED BY TRANSDUCER

EMERGING BEAM DEVIATES FROM INCIDENT PATH AND IS NOT ECLIPSED BY TRANSDUCER

EFFECT OF INCREASING WALL

THICKNESS ON EMERGING SOUND

BEAM

Figure 2. 


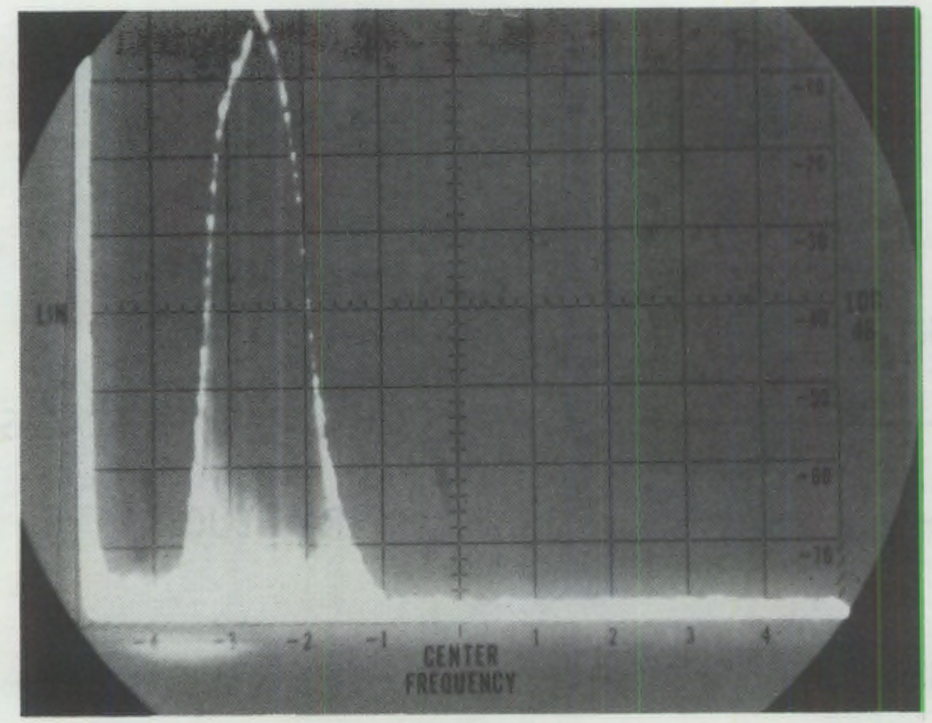

INSTRUMENT B

PEAK FREQUENCY $\quad 2.4 \mathrm{MHz}$

$6 \mathrm{db}$ BANDWIDTH $=1.7 \mathrm{MHz} / 3.0 \mathrm{MHz}$

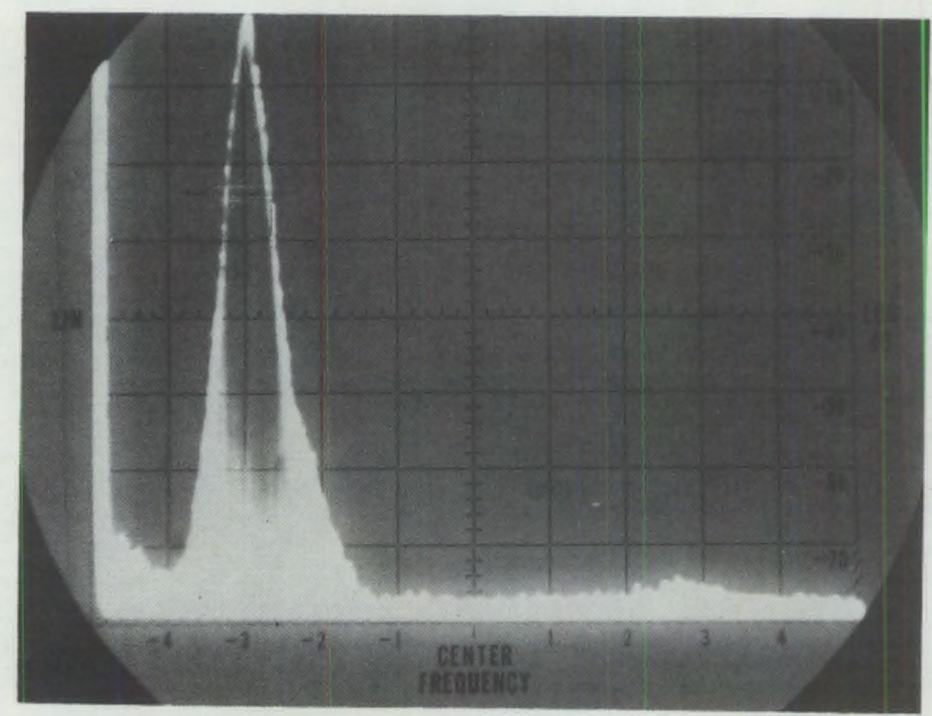

INSTRUMENT A

PEAK FREQUENCY $2.0 \mathrm{MHz}$

$6 \mathrm{db}$ BANDWIDTH $=1.6 \mathrm{MHz} / 2.5 \mathrm{MHz}$

FREQUENCY SPECTRUM OF REFLECTION FROM 0.100 INCH VERTICAL NOTCH IN 0.6 INCH THICK STAINLESS STEEL

Figure 3. Actual Inspection Frequency of Instruments A and B. 


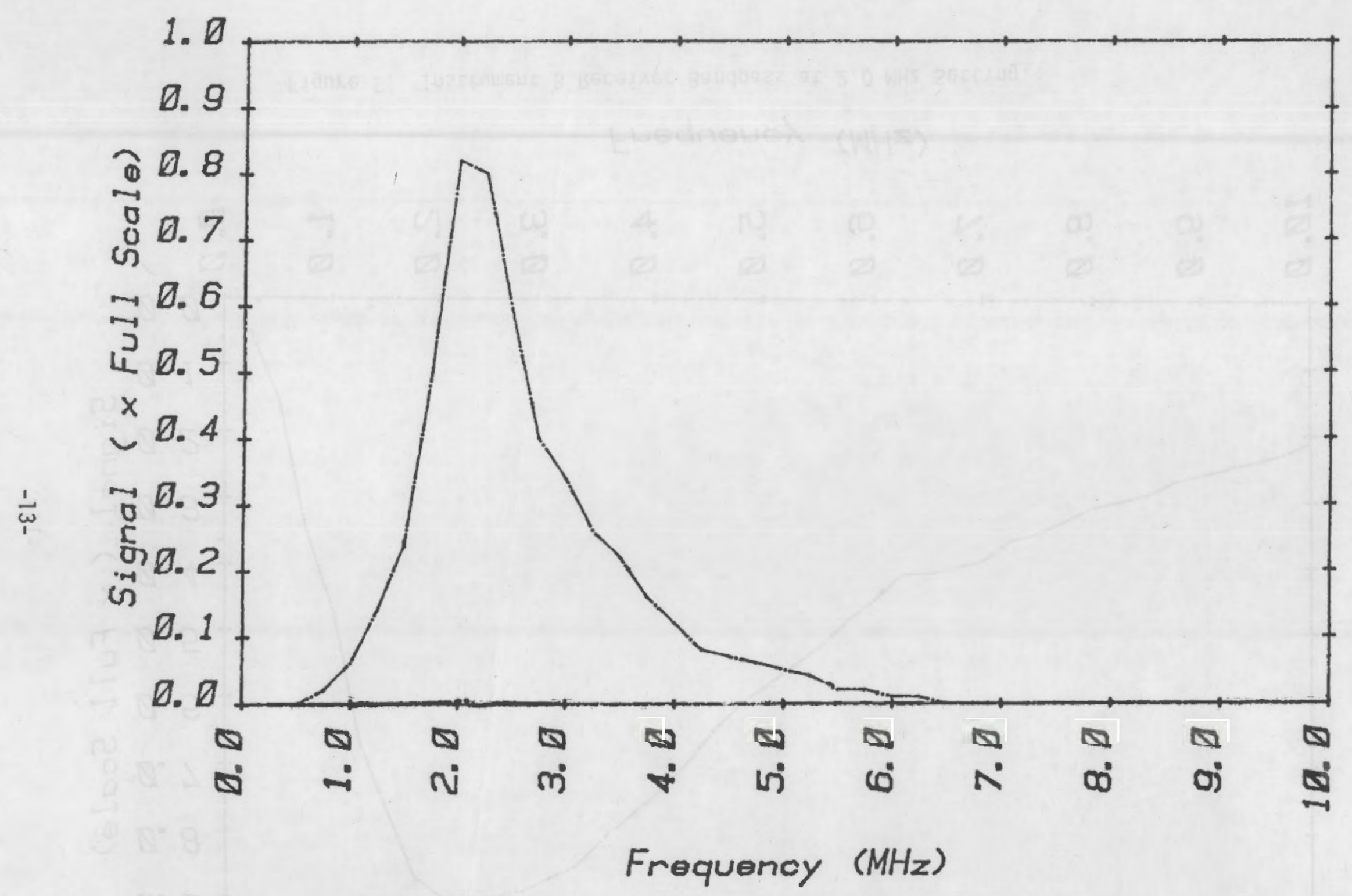

Figure 4. Instrument A Receiver Bandpass at $2.25 \mathrm{MHz}$ Setting. 


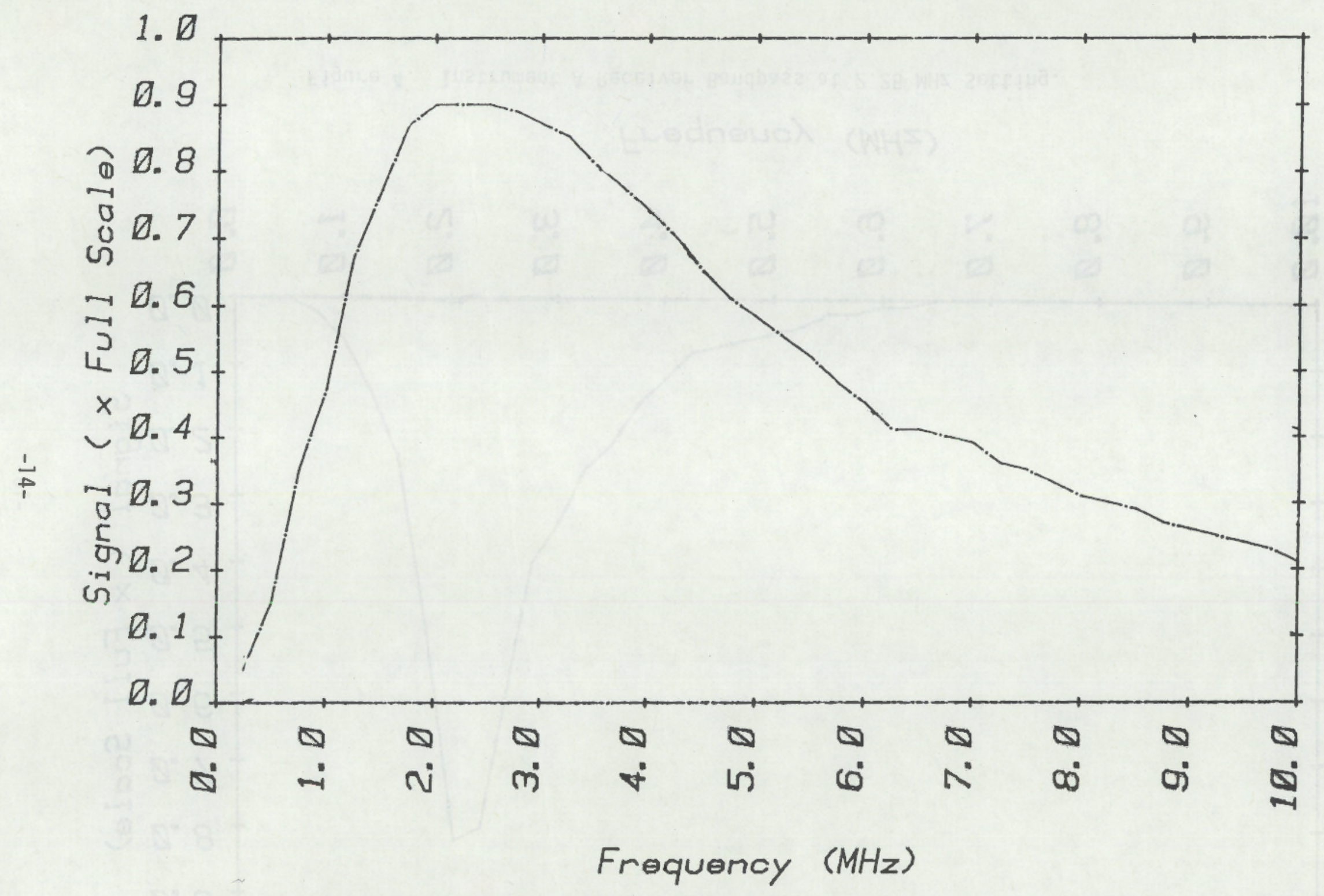

Figure 5. Instrument B Receiver Bandpass at $2.0 \mathrm{MHz}$ Setting. 
bands of the receivers from both instruments. When one compares the inspection frequency and receiver bandpass of Instrument $A$ with the inspection frequency and receiver bandpass of Instrument $B, c l e a r l y$ the inspection system of Instrument A (i.e., combination of pulser/ transducer output, receiver bandpass, etc.) operates at a lower frequency (approximately 2.0 MHz) than Instrument B (approximately 2.4 $\mathrm{MHz}$ ). Ultrasonic theory shows that lower frequencies are less affected by flaw angle. The lower operating frequency of inspection system $A$ should produce a more uniform response to angled flaws than inspection system $B$.

Under another Nuclear Regulatory Commission (NRC) sponsored ultrasonic ISI research program, (10) Pacific Northwest Laboratory described the impact of change in calibration reflectors in the 1977 Edition, Summer 1978 Addenda (end mill notch) versus the 1974 Edition, Summer 1975 Addenda (side drilled hole).

The measurement program to determine the impact of the change in calibration reflectors consisted of approximately 540 measurements on 34 piping calibration standards. The standards were from a boiling water reactor (BWR) presently under construction and ranged in wall thickness from 0.237 to 2.343 inches with diameters from 4 to 30 inches. Twentysix of the samples were ferritic and eight were stainless steel. The samples contained both side-drilled holes and notch reflectors according to the applicable codes. Measurements were performed using $0.25-$, $0.5-$ and 1.0-inch diameter, $2.25 \mathrm{MHz}$ search units with $45^{\circ}$ and $60^{\circ}$ shear wave contact shoes. The 0.25 -inch search unit was used for thicknesses up to 0.75 inch; the 1.0-inch unit, for thicknesses greater than 0.75 inch; and the 0.5-inch unit, for the total range. A Sonic Mark I flaw detector was used for the measurements, and a Nortec-1310 flaw detector was used for verification on four of the samples.

${ }^{10}$ RSR Fin. Budget No. B2289-0; RSR Contact, J. Muscara. 
The measurements were performed by establishing a distance amplitude correction (DAC) curve for the side-drilled holes and measuring the notch response relative to the DAC curve. Measured results for $45^{\circ}$ shear waves--the principal angle used for piping inspection--are shown in Figure 6 . The notches produce higher reflected amplitudes than the side-drilled holes. A calibration performed using the notches (1977 Code) will, therefore, provide a less sensitive inspection than the side-drilled hole calibration (1974 Code). The reduction in inspection sensitivity is dependent on pipe wall thickness ranging from $-6 \mathrm{~dB}$ (a factor of 2) at 0.4 inch to $-16 \mathrm{~dB}$ (a factor of 6.3) at a wall thickness of 2.4 inches. The error bars on the measured curve of Figure 6 are the $\pm 2 \sigma$ error bars for the measurements $(\sigma=2 \mathrm{~dB})$.

Theoretical calculations were performed according to Ermolov (11) and Werneyer $(12)$ to assure that the measured results in Figure 6 were reasonable. These calculations, shown in Figure 6 as Theory, are in close agreement with the measured results. The calculations were performed for the far-field conditions that are satisfied for thicknesses greater than 1.0 inch; however, the differences below 1 inch are not great. It should be noted that the theoretical curve has not been adjusted to fit the data; it is the total dB difference predicted by the theory--the agreement is remarkable.

For $60^{\circ}$ shear wave inspection, there was not a statistically significant difference between the side-drilled hole and the notch calibration sensitivities although the response from the side-drilled hole calibration was quantitatively slightly less sensitive. This difference between the

11 Ermolov, I. N., April 1972. "The Reflection of U1trasonic Waves from Targets of Simple Geometry." Nondestructive Testing 5:2(87-91).

12 Werneyer, R., F. Walt and M. Klein, 1977. Mathematisches Model Zur Fehlerrekonstruktion bei der UTtraschall - Impulsecho und Tandimprung und Ergenbisse aud Modellversuchen. Report No. 770212-TW, Institut fur Zestrungsfreie Prufrefahren (IZfP), Saarbrucken, West Germany, P. 6. 


\section{REDUCTION IN ULTRASONIC INSPECTION SENSITIVITY \\ 77 CODE RELATIVE TO 74 CODE \\ CLASS 1 AND 2 PIPING}

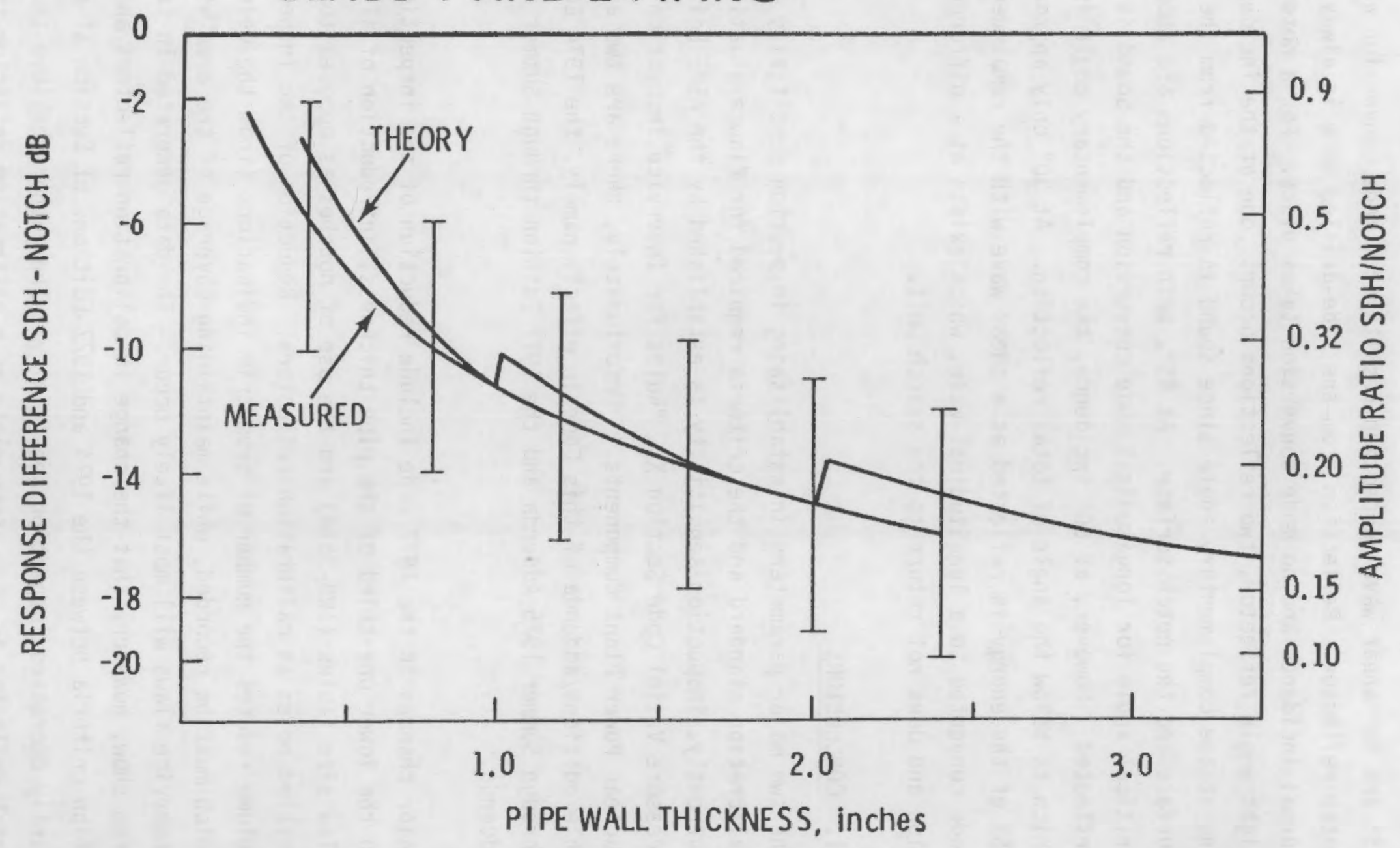

Figure 6. Measured and Theoretical Reduction in Ultrasonic Piping Inspection Sensitivity of the 1977 Edition of the ASME Code, Section XI (Notch), as compared to the 1974 Edition (Side Drilled Holes, SDH). 
$45^{\circ}$ and $60^{\circ}$ shear wave inspection results from mode conversion at the notch reflector. Reflection from the side-drilled hole is always at normal incidence and no mode conversion takes place. For a notch or right angle reflector, two reflections occur: one at the incident and one at the complementary angle since sound is reflected from the back surface and the notch surface. At $45^{\circ}$, both reflections are above the critical angle for longitudinal mode conversion and the sound is totally reflected. However, at $60^{\circ}$ incidence, the complementary angle is $30^{\circ}$, which is below the angle of total reflection. At $30^{\circ}$ only approximately $15 \%$ of the energy is reflected as a shear wave with the remainder being mode converted to a longitudinal wave, which exists at a different location and does not return to the search unit.

\section{CONCLUSIONS}

The two major parameters in establishing inspection sensitivity are the calibration standard and the criteria required for flaw evaluation. Currently, inspection sensitivity is established by the ASME Boiler and Pressure Vessel Code Section XI, "Rules for Inservice Inspection of Nuclear Power Plant Components." Unfortunately, there are two applicable editions/addenda of this code in effect; namely, the 1974 Edition through Summer 1975 Addenda and the 1977 Edition through Summer 1978 Addenda .

Major changes in the 1977 Code include reduction of the inspection volume to the lower one-third of the pipe thickness, introduction of allowable flaw size tables (IWB-3514) and the use of notches as opposed to side drilled holes as calibration reflectors. Reduction of the inspection volume reduces the number of geometric indications (from the weld crown) which must be recorded, while maintaining coverage of the area where inservice flaws will most likely occur. The data generated in this program show, however, that the change in calibration reflectors and evaluation criteria between the 1974 and 1977 Editions of Section XI significantly decreases inspection sensitivity. The authors believe that a notch reflector is more appropriate as a calibration reflector than a 
side drilled hole because it more closely approximates the physics of sound reflection from surface connected cracks than a side drilled hole. However, the authors believe this study shows that the 100\% reference level criteria required by the 1977 Edition of Section XI is not adequate to detect the minimum rejectable flaws referenced by said code.

The data produced ${ }^{(13)}$ by this program show that if detection of $90 \%$ of the flaws in this program is to be assured (with a $10 \%$ notch used as a calibration reflector), then a $20 \%$ reference level evaluation criteria is required.

As noted in the introduction to this report, increasing the inspection sensitivity will also significantly increase the numbers of geometric reflectors that are reported. Therefore, before any responsible increase in inspection requirements is considered, the impact of said requirements on inspection costs and personnel exposure versus increase in plant safety must be evaluated.

${ }^{13}$ The data produced by this program allow one to vary calibration reflectors (i.e., short flaw or long flaw and angle) and evaluation criteria and then calculate the percentage of flaws that would be detected. 



\section{APPENDIX I}

12 INCH DIAMETER TEST SAMPLE TYPICAL OF ALL PIPE SECTIONS

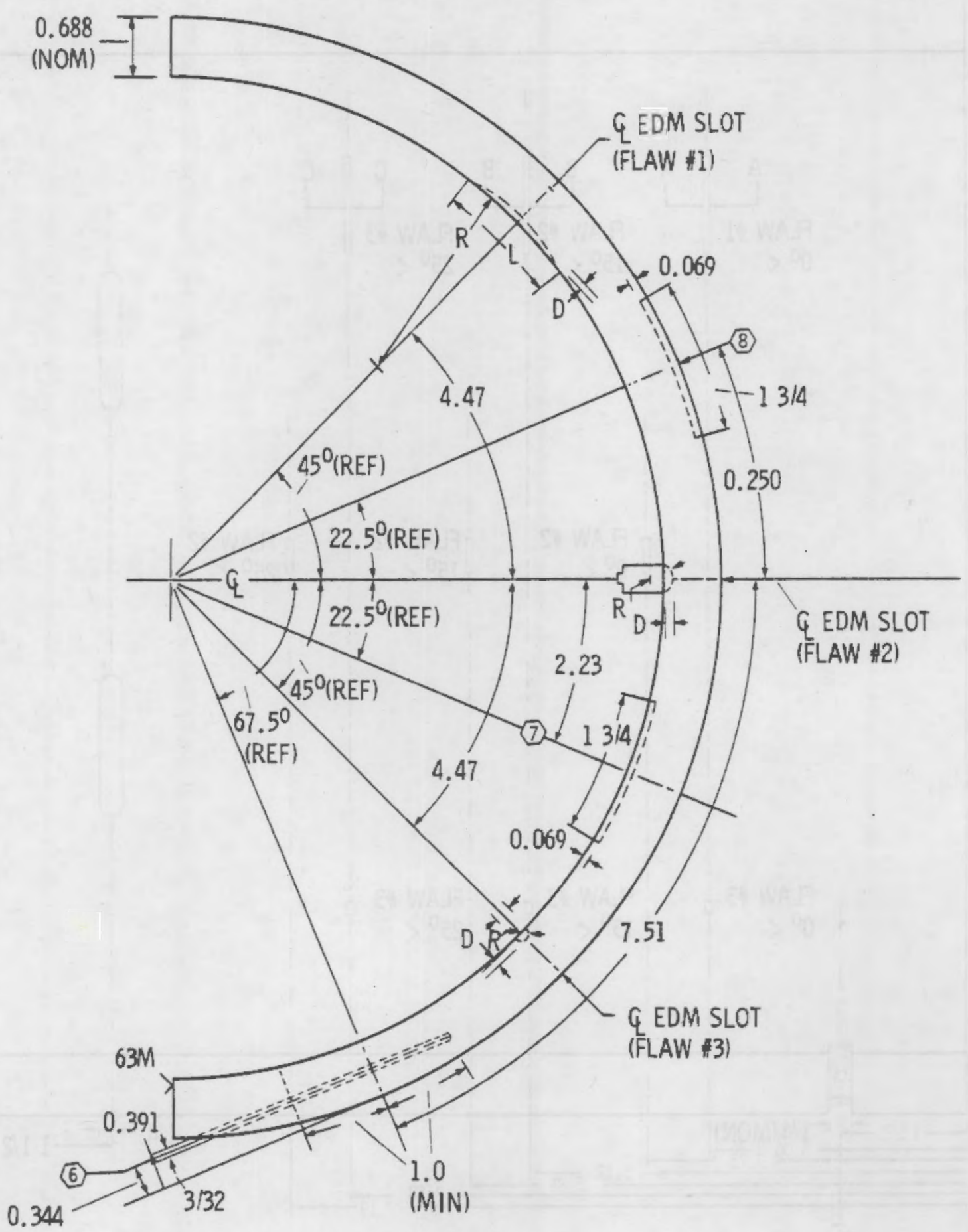




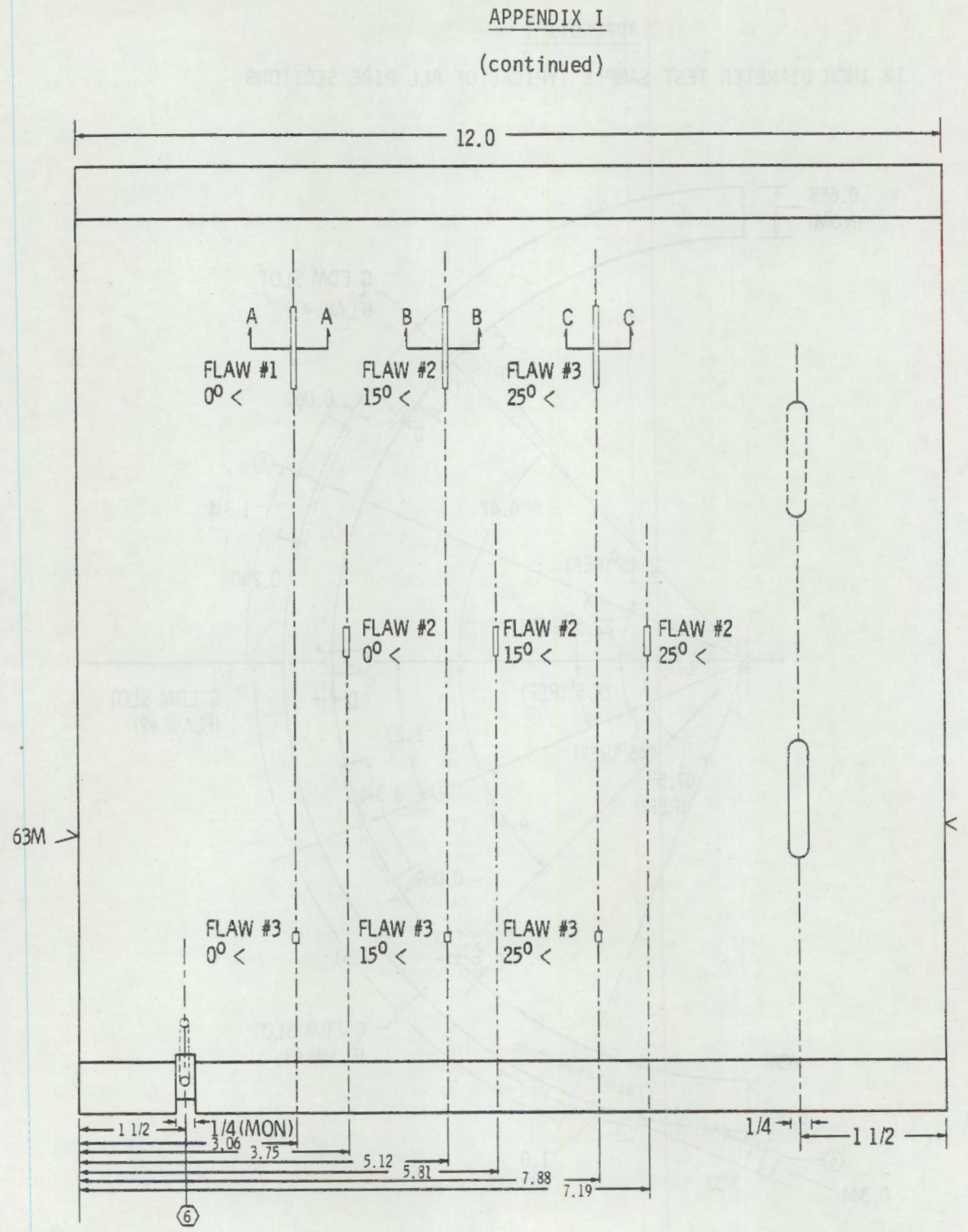




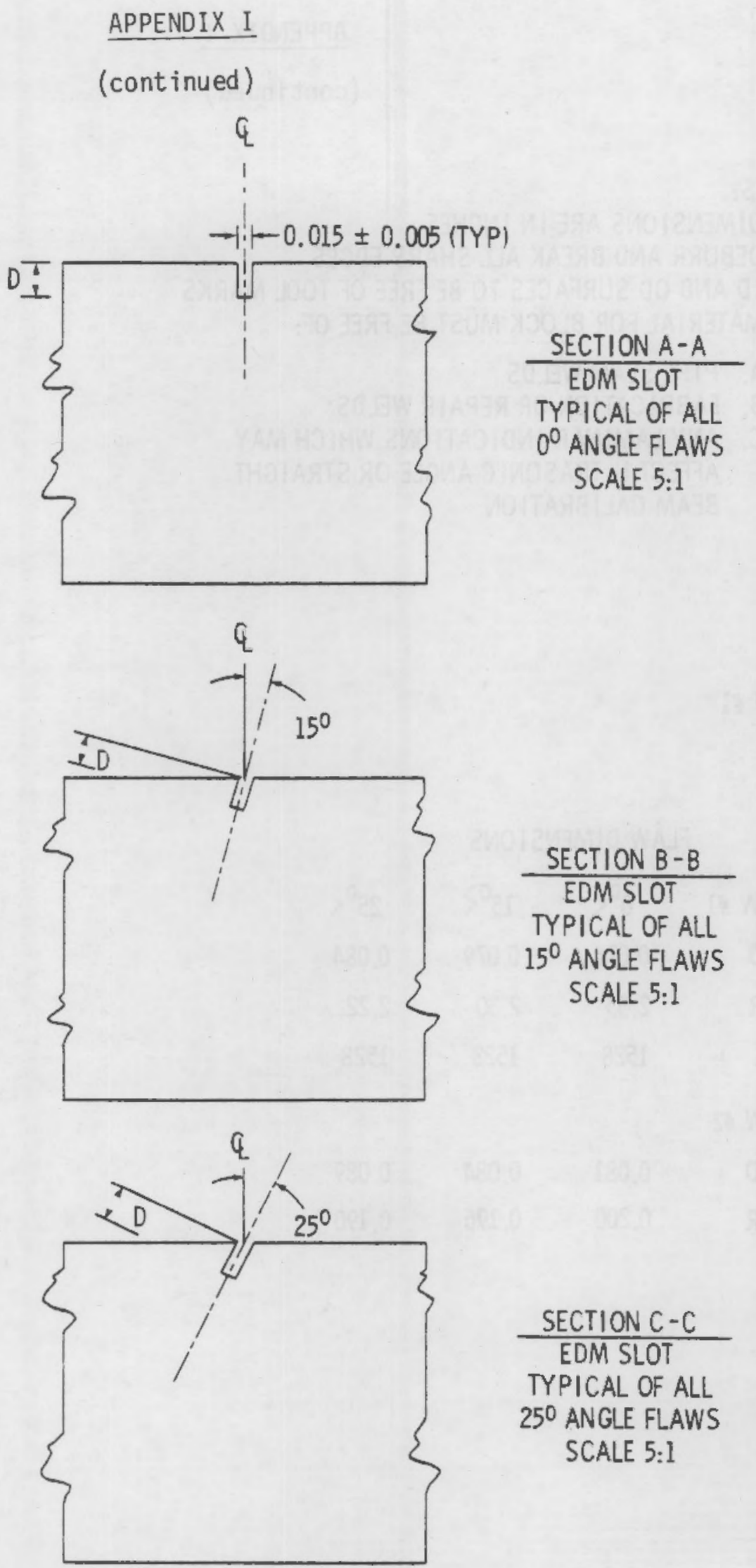




\section{APPENDIX I}

(continued)

NOTES:

(1) DIMENSIONS ARE IN INCHES

(2) DEBURR AND BREAK ALL SHARP EDGES

(3) ID AND OD SURFACES TO BE FREE OF TOOL MARKS

(4) MATERIAL FOR BLOCK MUST BE FREE OF:
A. PIPE SEAM WELDS
B. FABRICATION OR REPAIR WELDS
C. ANY LAMINAR INDICATIONS WHICH MAY AFFECT ULTRASONIC ANGLE OR STRAIGHT BEAM CALIBRATION

FLAW *1

FLAW DIMENSIONS

$\begin{array}{clll}\text { FLAW \#1 } & 0^{0}< & 15^{\circ}< & 25^{\circ}< \\ D & 0.076 & 0.079 & 0.084 \\ R & 2.35 & 2.30 & 2.22 \\ \text { L } & 1528 & 1528 & 1528\end{array}$

FLAW \#2

$\begin{array}{llll}D & 0.081 & 0.084 & 0.089 \\ R & 0.200 & 0.196 & 0.190\end{array}$




\section{APPENDIX II}

1974 Edition through Summer 1975 Addenda

Calibration Requirements

T-533 CALIBRATION REQUIREMENTS

T-533.2 Basic Calibration Hole

(a) The basic calibration hole shown in Fig. T-533(a) shall be drilled parallel to the contact surface of the basic calibration block or the component. The location, depth, and diameter of this hole shall be obtained from the table in Fig. T-533(a).

(b) However, other calibration reflectors may be used, provided equivalent responses to that from the basic calibration hole are demonstrated.

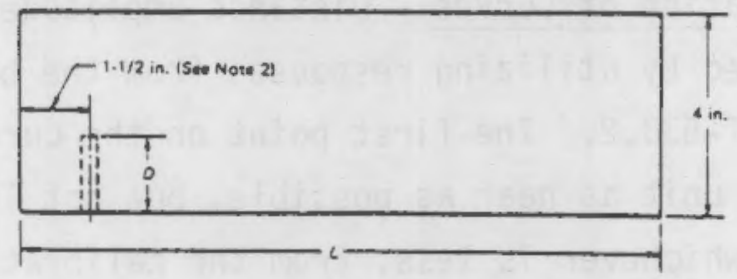

125

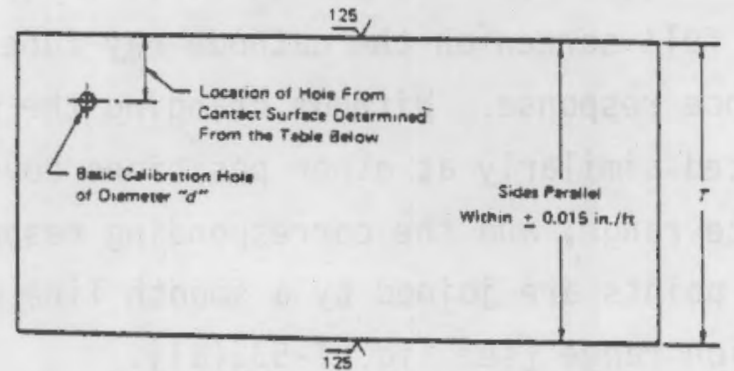

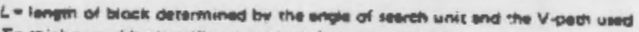

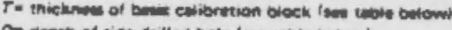

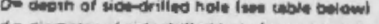

d- dismeter of side-dritind hole isee troble bellowt

i. nominet produetion maseriet thiekne:

Neminal Produrtion Material Thicknow $(t)$, in.

Up to 1 inct.

Oner 1 thru 2

Oven 2 thru 4

Over 4 thru 6

Over 8 thru 8

Over 10
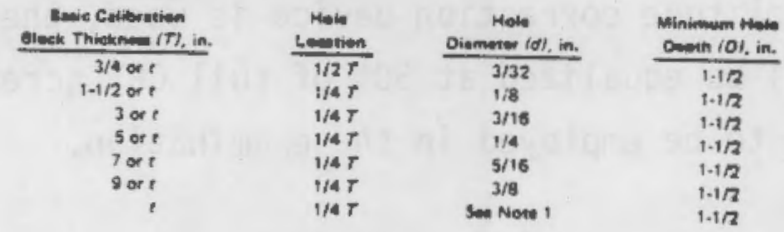

NOTES:

11) Foc exch increans in thicknew of 2 in., or a fraction thereof, the hole diemeter shell increen $1 / 16$ in.

(2) For block sizes over $J$ in, in thieknew (T), the distence from the hole to the and af the block thet be $1 / 2 \mathrm{~T}$

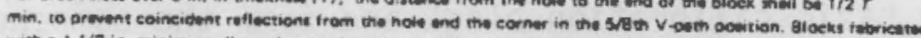

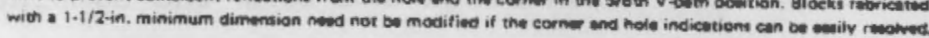

FG. T.533(a) BASIC CALIBRATON BLOCK 
T-535 ANGLE BEAM TECHNIQUE

T-535.1 Calibration of Equipment

(a) Frequency - The nominal frequency shall be $2.25 \mathrm{MHz}$ unless variables such as production material grain structure require the use of other frequencies to assure adequate penetration.

(b) Beam Angle - The beam angle in the production material shall be in the range of 40 to $75 \mathrm{deg}$., inclusive, with respect to the perpendicular to the entry surface.

(c) Distance-Amplitude Correction - Compensation for the distance traversed by the ultrasonic beam as it passes through the material is provided by the use of the curves shown by Fig. T-535(a) or electronically.

(1) Determination of Curves - Distance-amplitude correction curves shall be constructed by utilizing responses from the basic calibration hole described in T-533.2. The first point on the curve is obtained by placing the search unit as near as possible, but not less than $3 / 8 \mathrm{~V}$-path or $2 \mathrm{in.}(51 \mathrm{~mm})$, whichever is less, from the calibration hole and positioning from maximum response. The gain control is then set so this response is $75 \%$ of full screen on the cathode ray tube (CRT). This is the primary reference response. Without changing the gain, the search unit should be placed similarly at other positions covering the expected examination distance range, and the corresponding responses marked on the CRT screen. These points are joined by a smooth line whose length should cover the examination range [see Fig. T-535(a)].

(2) Electronic Distance-Amplitude Correction - If an electronic distance-amplitude correction device is used, the primary reference response shall be equalized at $50 \%$ of full CRT screen height over the distance range to be employed in the examination.

(d) Transfer Method - Transfer methods are used to correlate the responses from the basic calibration block and from the component. Transfer is accomplished by noting the difference between responses received 
from the same reference reflector in the basic calibration block and in the component and correcting for the difference.

The reference reflectors may be $V$ notches (which must subsequently be removed), an angle beam search unit acting as a reflector, of any other reflector which will aid in accomplishing the transfer.

(1) Vessels - The transfer method shall be used at least once for each $10 \mathrm{ft}(3048 \mathrm{~mm})$ of weld or less per plate and shall be performed at least twice for each type of welded joint.

(2) Piping - The transfer method shall be used, as a minimum, once for each welded joint for pipe sizes $10 \mathrm{in.}(254 \mathrm{~mm})$ in diameter and over, and once for each $5 \mathrm{ft}(1524 \mathrm{~mm})$ of weld for pipe less than $10 \mathrm{in}$. $(254 \mathrm{~mm})$ in diameter.

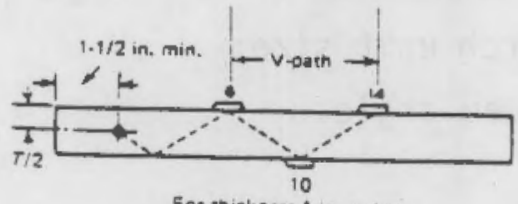

For thickness 1 in, or fous
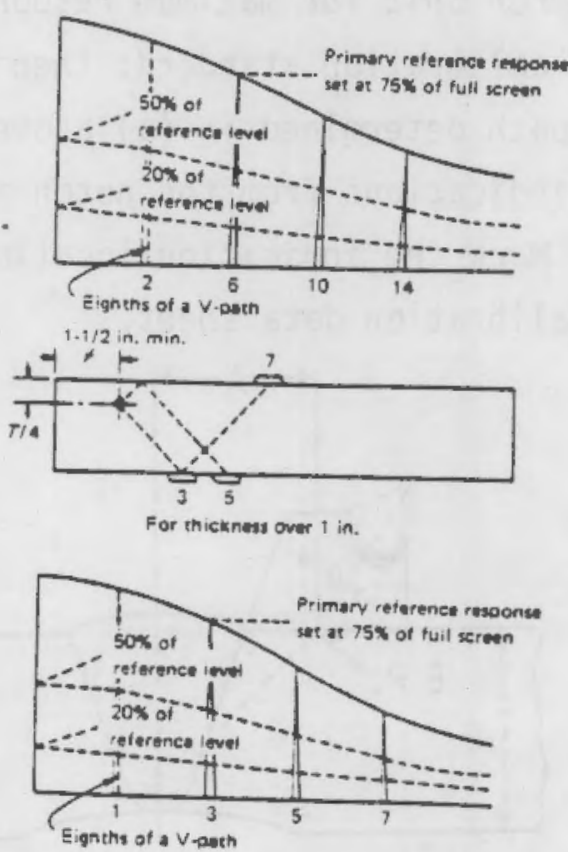

Figure T-535(a)

FIG. T-535(a) TYPICAL DISTANCE AMPLITUDE CORRECTION CURVE (ANGLE BEAM METHOD) (Distance in eighths of a $V$-path. For example, 14 is $\%$ of a V-path.) 


\section{III-3230 ANGLE BEAM CALIBRATION}

(a) Obtain the angle beam paths required in III-4420 and III-4430 on the sweep display. Variables such as weld preparation, weld crown width, or physical interference may preclude half- $V$ examination of the weld root as shown in Fig. III-3230-1. If these variables are such that the dimension A on Fig. III-3230 is greater than:

$$
\begin{aligned}
0.93 \mathrm{t} \text { for } 0 & =43 \text { to } 45 \mathrm{deg} . \\
1.6 \mathrm{t} \text { for } 0 & =58 \text { to } 60 \mathrm{deg} . \\
2.5 \mathrm{t} \text { for } 0 & =68 \text { to } 70 \mathrm{deg} .
\end{aligned}
$$

the beam path shall be increased at least one-half $V$. Alternately, the interference may be el iminated by one or more of the following:

(1) reducing the dimension of the wedge edge-to-beam entry point;

(2) reducing search unit size;

(3) increasing beam angle.

(b) Position the search unit for maximum response from the notch on the opposite side of the calibration standard; then position the search unit to obtain the metal path determined in (a) above. Adjust the sweep control to display the indications from the notch at convenient intervals on the sweep range. Mark the indication locations on the screen and record them on the calibration data sheet.

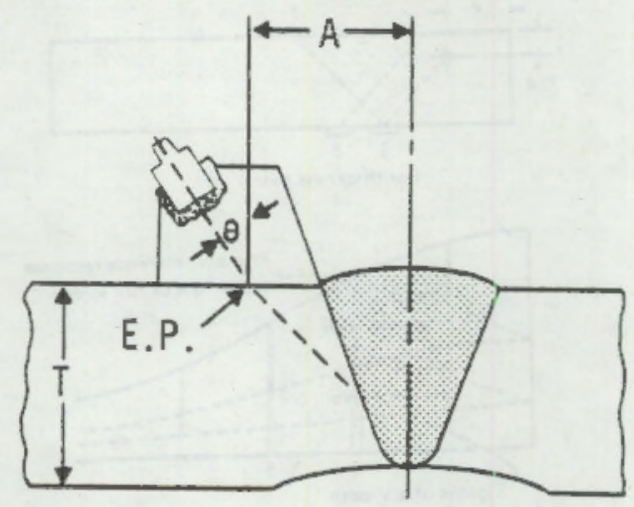

Figure III-3230-1. Physical Restrictions to the Weld Examination. 
(c) Sensitivity levels shall be established using the notch and shall be applicable to that region of the calibrated sweep length providing complete examination of the weld and heat affected zone (HAZ). To establish calibration, maximize the signal amplitude from the first notch included in the examination region of the sweep to $80 \%$ of full screen height (FSH). Without changing the gain control, determine the peak indication amplitudes from the remaining points in the examination region and construct a distance-amplitude correction (DAC) curve. This curve shall be the primary reference level.

(d) Where the examination technique is limited to the $1 / 2 \mathrm{~V}$ path, side drilled holes shall be used to obtain the slope and shape of the DAC curve. A minimum of two holes, each of the same diameter, located at $1 / 4 t$ and $3 / 4 t$, shall be placed in the end surfaces of the calibration standard. The holes shall be parallel to the length axis of the pipe calibration standard and generally conform to the arrangement shown in Fig. III-3230-2 (in course of preparation). The minimum hole length shall be 1-1/2 in. ( $38 \mathrm{~mm}$ ). Calibration shall be accomplished by constructing a OAC curve from the side drilled holes so that the maximum amplitude point is at $80 \%$ (FSH). Once the shape and slope are determined and marked on the screen, the curve shall be extrapolated $1 / 4$ t to cover the full examination thickness. Next, establish the sensitivity from the inside diameter (I.D.) surface notches by setting the indication amplitude at the level of the DAC curve. 



\section{APPENDIX III}

*NOTE: Ultrasonic inspections were made only at $-25,-15,0,15$ and 25 degrees. The lines drawn between these points were used to show flaw response trends and to differentiate between flaw response of inspection systems $A$ and $B$. 
4" DIAMETER CARBON STEEL

TRANSDUCER $=.25^{\prime \prime}$ DIA.

BEAM ANGLE $=45^{\circ}$

$1 / 2$ V BEAM PATH
APPENDIX III

CALL PAGES

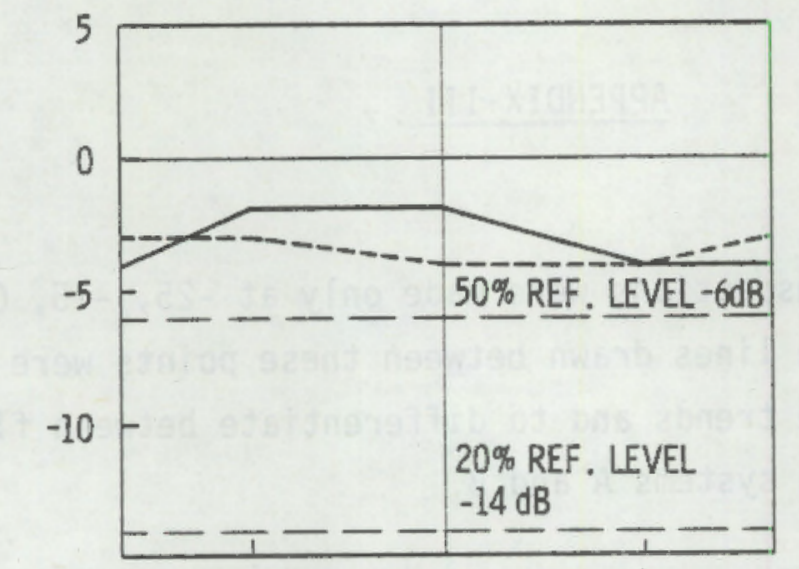

SHORT FLAW

ASPECT RATIO $=0.5$

MEDIUM FLAW

ASPECT RATIO $=0.25$

$50 \%$ REF. LEVEL

$-10$
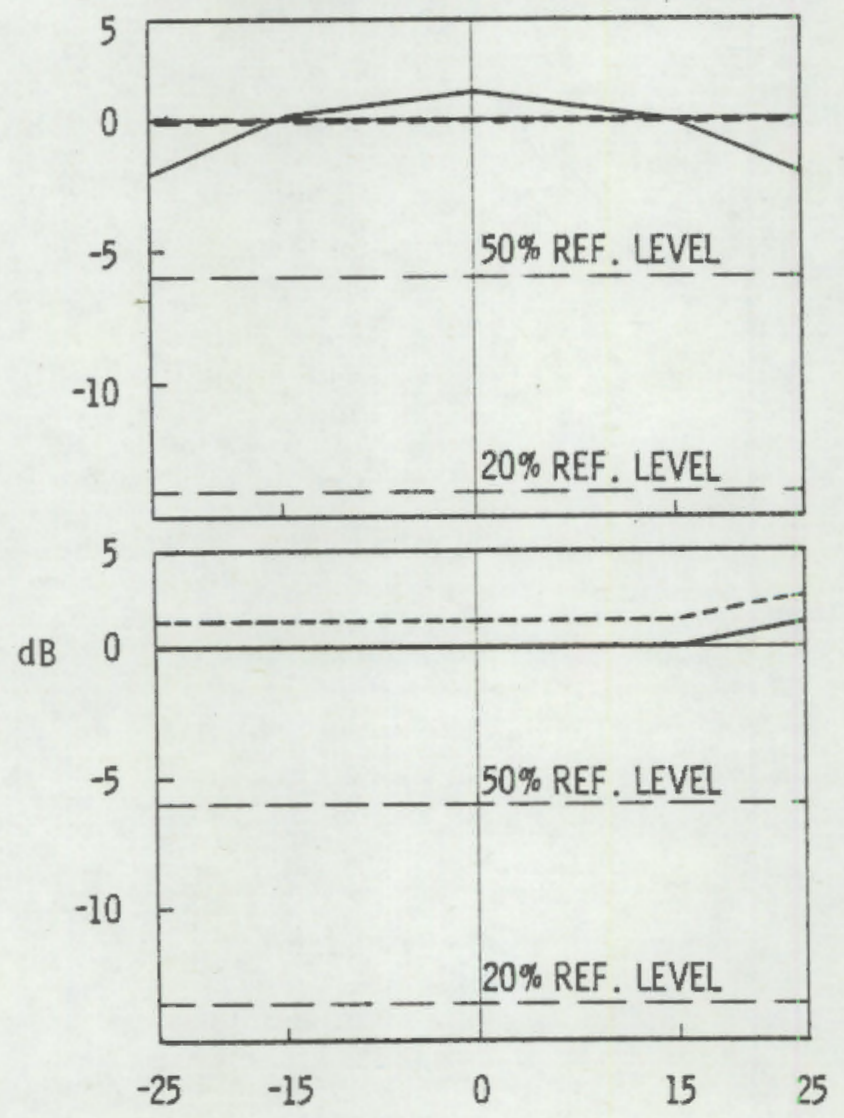

LONG FLAW

ASPECT RATIO $=0.05$

FLAW ANGLE

INSTRUMENT A

INSTRUMENT B 
4" DIAMETER CARBON STEEL

TRANSDUCER $=.5^{\prime \prime}$ DIA.

BEAM ANGLE $=45^{\circ}$

$1 / 2 \vee$ BEAM PATH

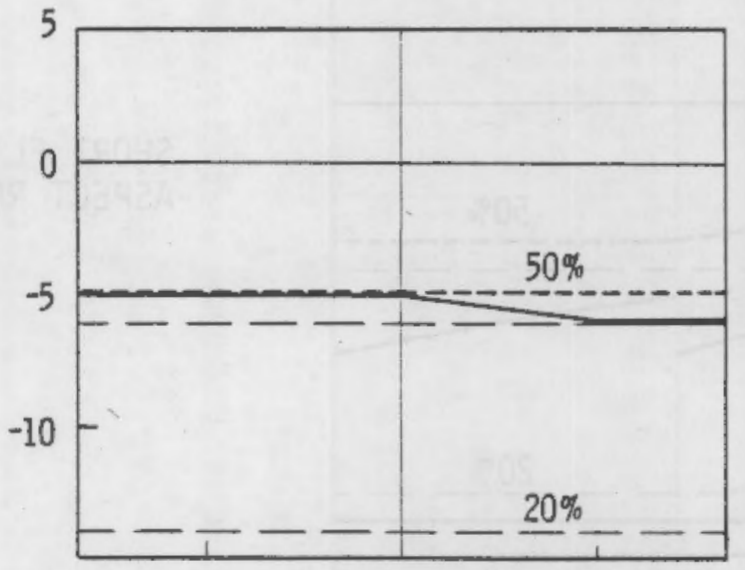

SHORT FLAW

ASPECT RATIO $=0.5$

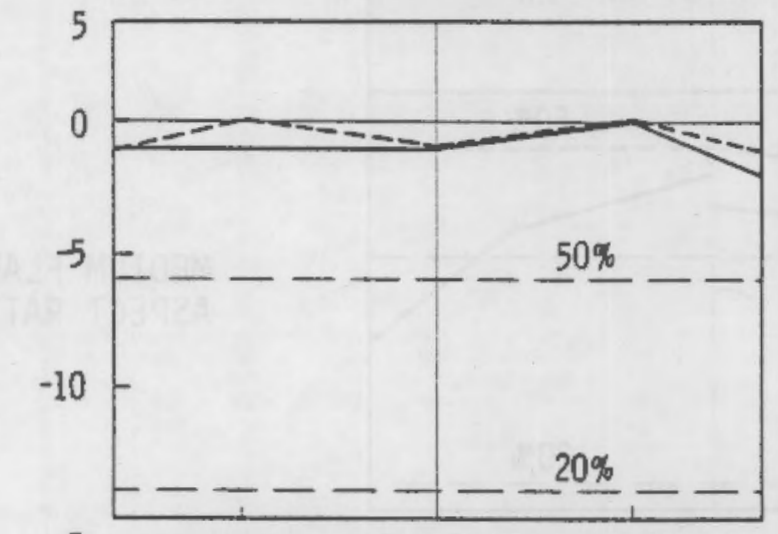

MEDIUM FLAW

ASPECT RATIO $=0.25$

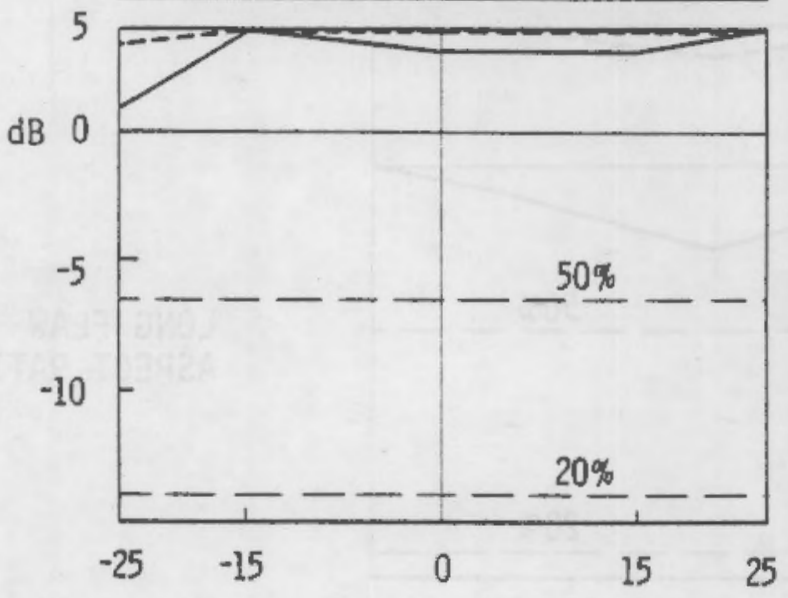

LONG FLAW

ASPECT RATIO $=0.05$

FLAW ANGLE

INSTRUMENT A

INSTRUMENT B 
4" DIAMETER CARBON STEEL

TRANSDUCER $=.25^{\prime \prime}$ DIA.

BEAM ANGLE $=45^{\circ}$

$3 / 2$ V BEAM PATH

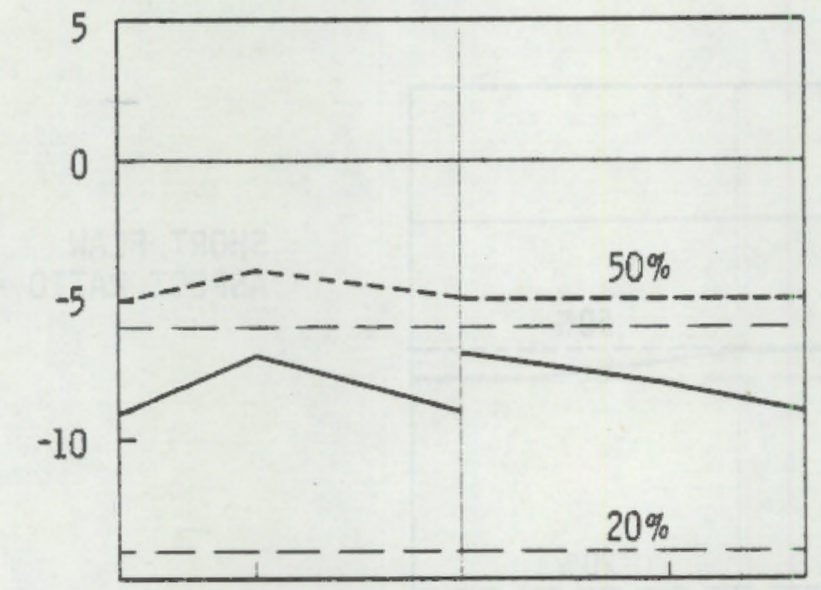

SHORT FLAW

ASPECT RATIO $=0.5$
MEDIUM FLAW

ASPECT RATIO $=0.25$
LONG FLAW

ASPECT RATIO $=0.05$

FLAW ANGLE 
4" DIAMETER CARBON STEEL

TRANSDUCER $=.5^{\prime \prime}$ DIA.

BEAM ANGLE $=45^{\circ}$

$3 / 2 \vee$ BEAM PATH

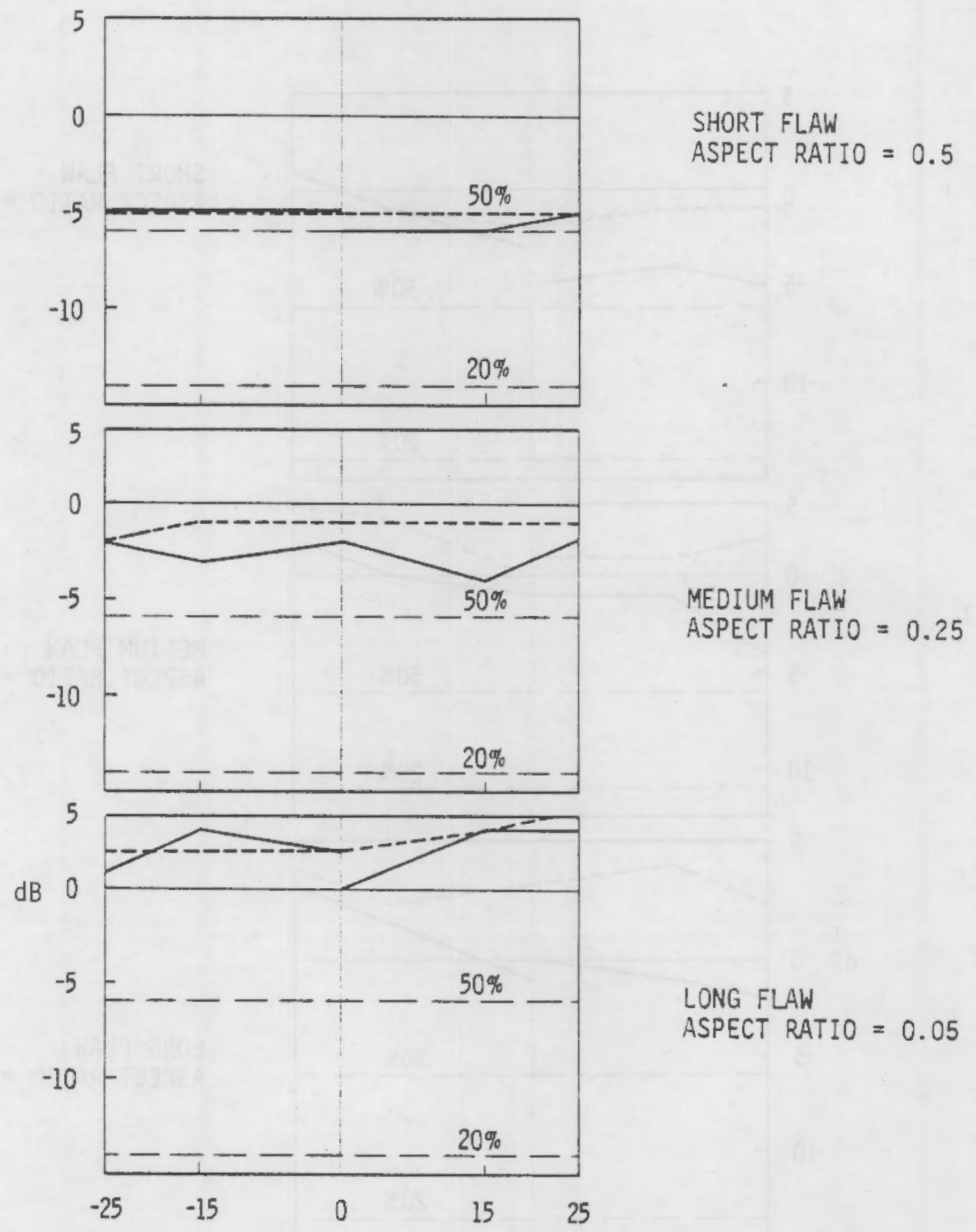

FLAW ANGLE

INSTRUMENT A

INSTRUMENT B 
4" DIAMETER CARBON STEEL

TRANSDUCER $=.25^{\prime \prime}$ DIA.

BEAM ANGLE $=60^{\circ}$

$1 / 2 \vee$ BEAM PATH

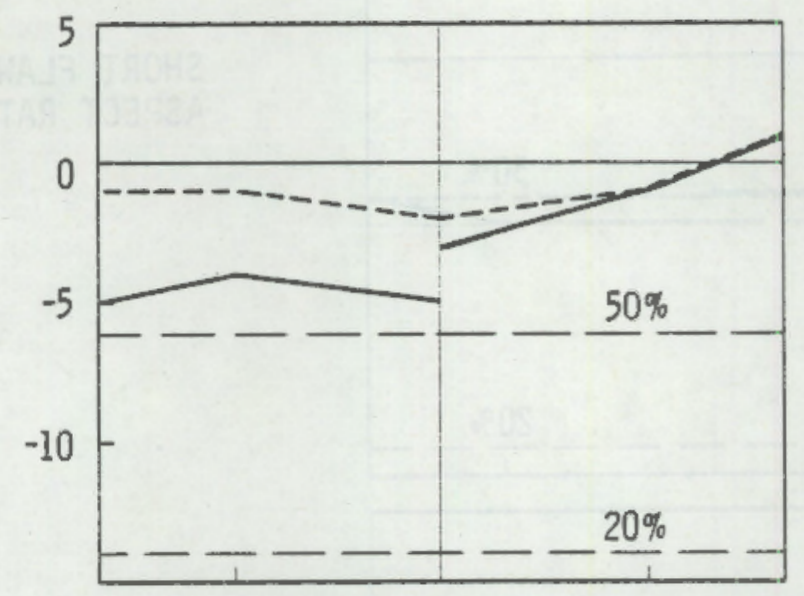

SHORT FLAW

ASPECT RATIO $=0.5$

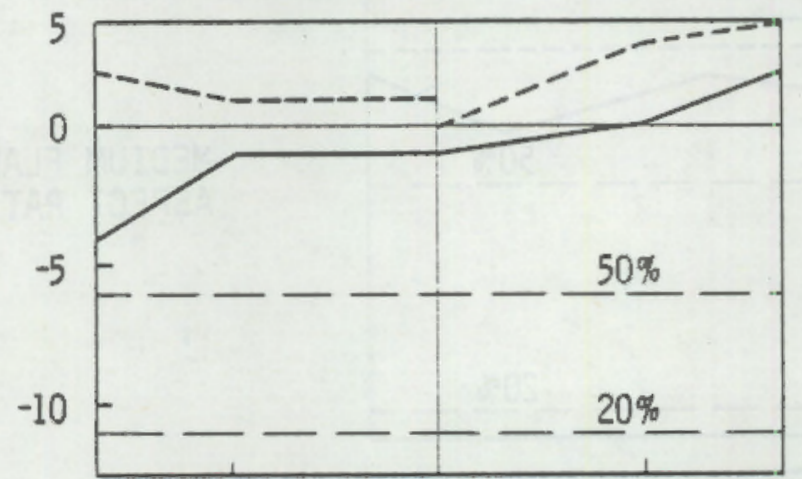

MEDIUM FLAW

ASPECT RATIO $=0.25$

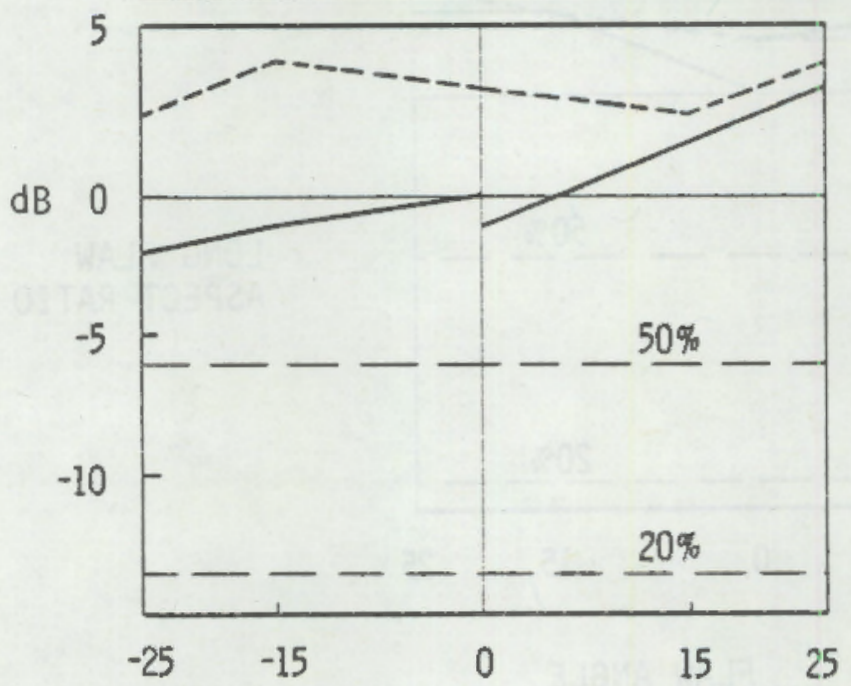

LONG FLAW

ASPECT RATIO $=0.05$

FLAW ANGLE 
4" DIAMETER CARBON STEEL

TRANSDUCER $=.5^{\prime \prime}$ DIA.

BEAM ANGLE $=60^{\circ}$

$1 / 2$ V BEAM PATH

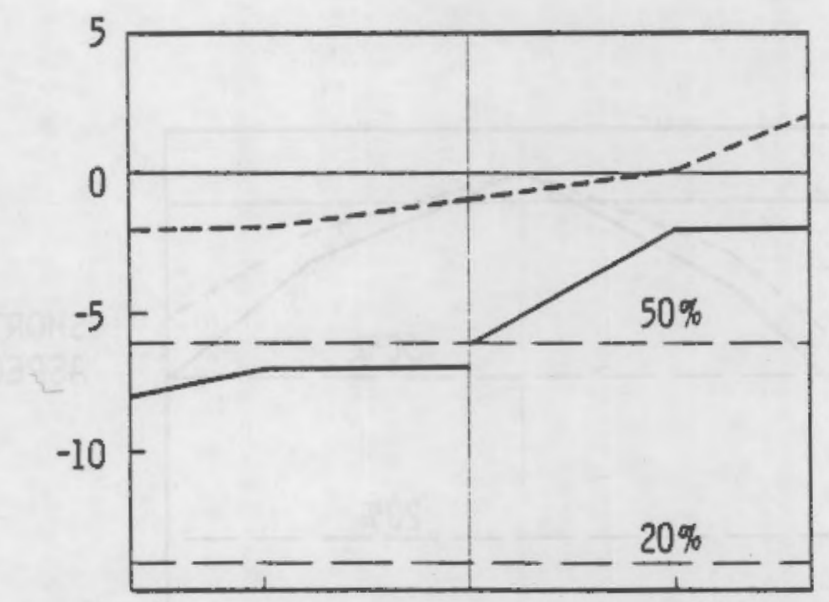

SHORT FLAW

ASPECT RATIO $=0.5$

MEDIUM FLAW

ASPECT RATIO $=0.25$

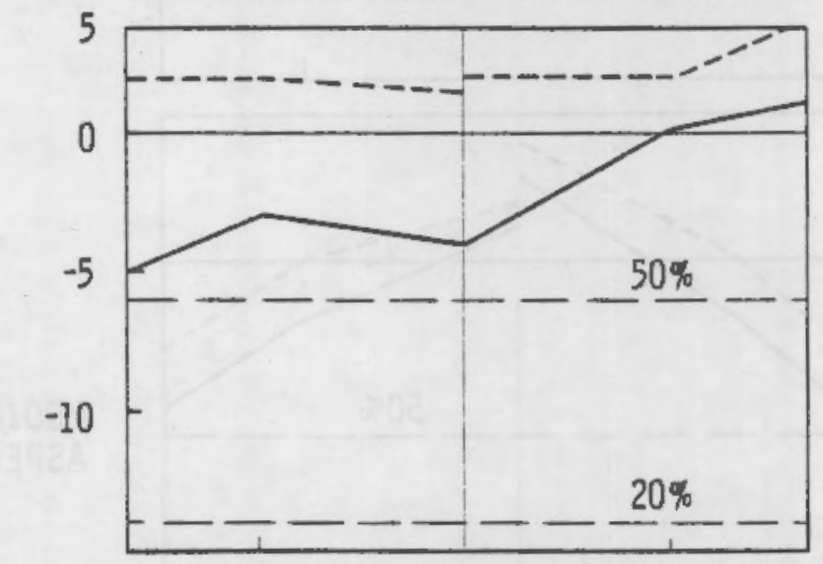

$$
\text { ASPECT RATIO }=0.25
$$

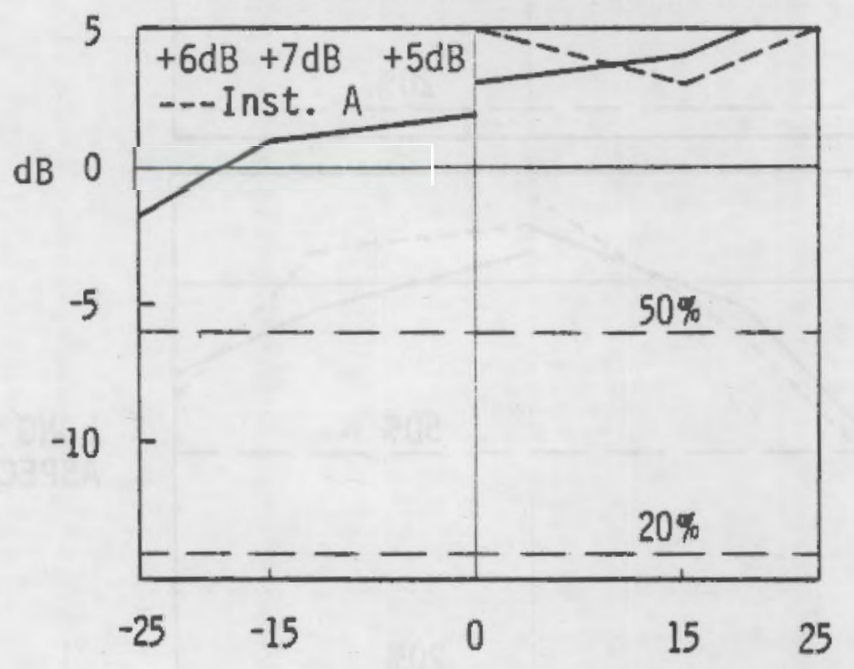

LONG FLAW

ASPECT RATIO $=0.05$

FLAW ANGLE 
12" DIAMETER $304 \mathrm{~S} / \mathrm{S}$

TRANSDUCER $=.25^{\prime \prime}$ DIA.

BEAM ANGLE $=45^{\circ}$

$1 / 2 \vee$ BEAM PATH

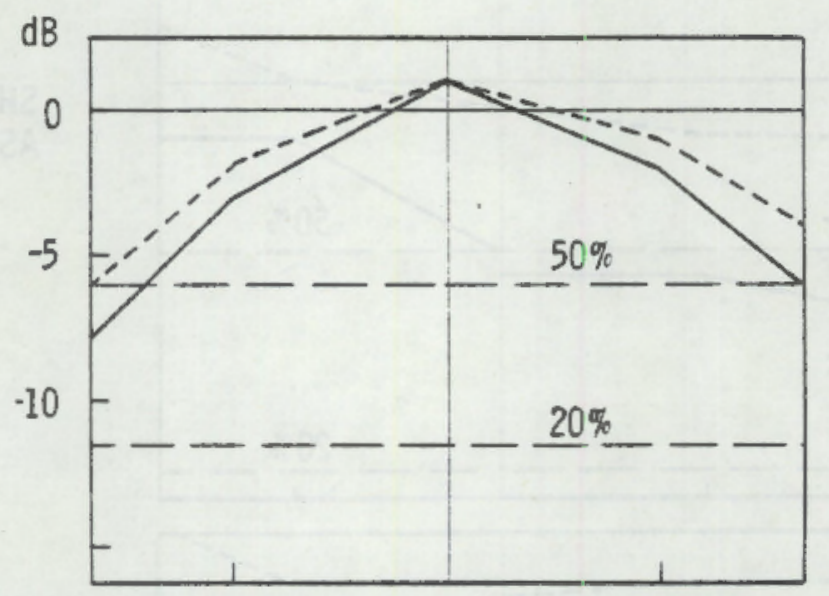

SHORT FLAW

ASPECT RATIO $=0.5$

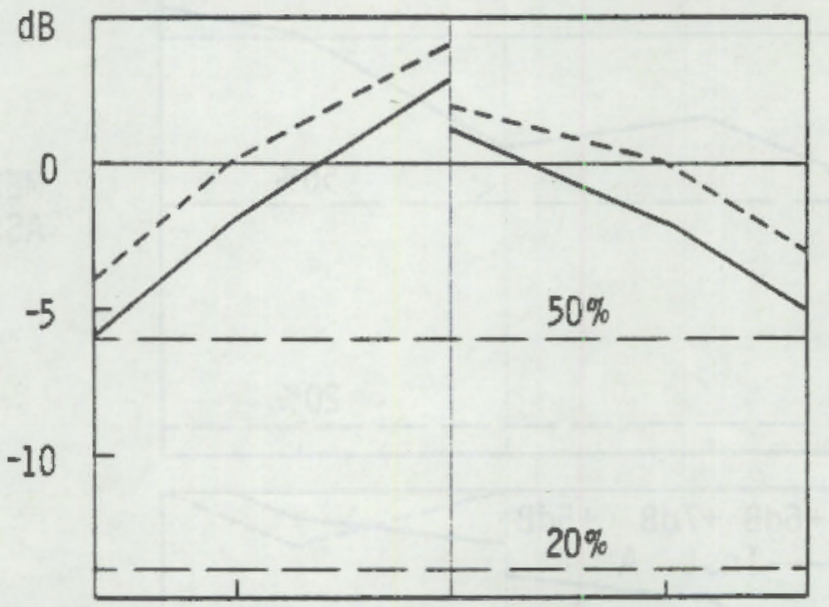

MEDIUM FLAW

ASPECT RATIO $=0.25$

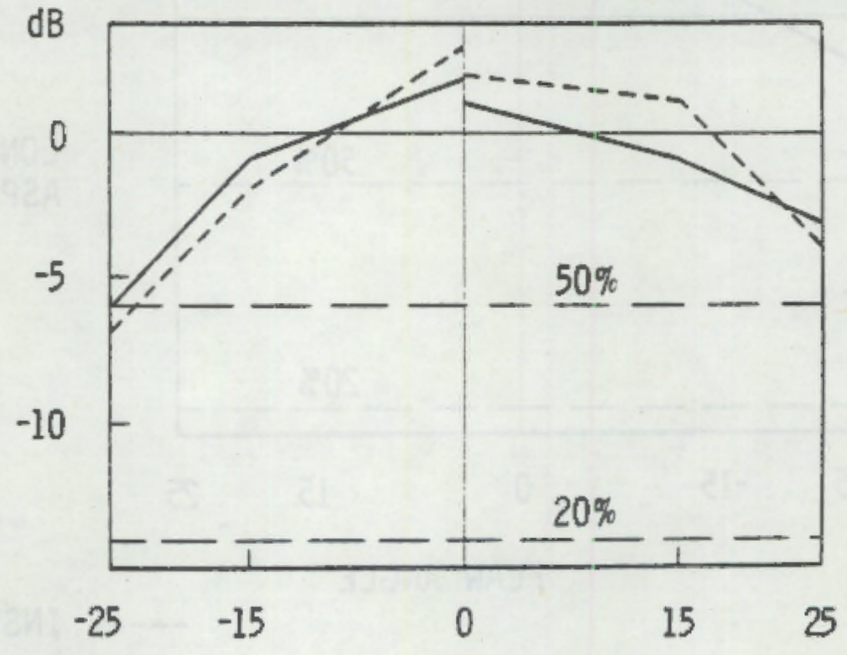

LONG FLAW

ASPECT RATIO $=0.05$

FLAW ANGL.E

III-8 
12" DIAMETER $304 \mathrm{~S} / \mathrm{S}$

TRANSDUCER $=.5 "$ DIA.

BEAM ANGLE $=45^{\circ}$

$1 / 2 \checkmark$ BEAM PATH

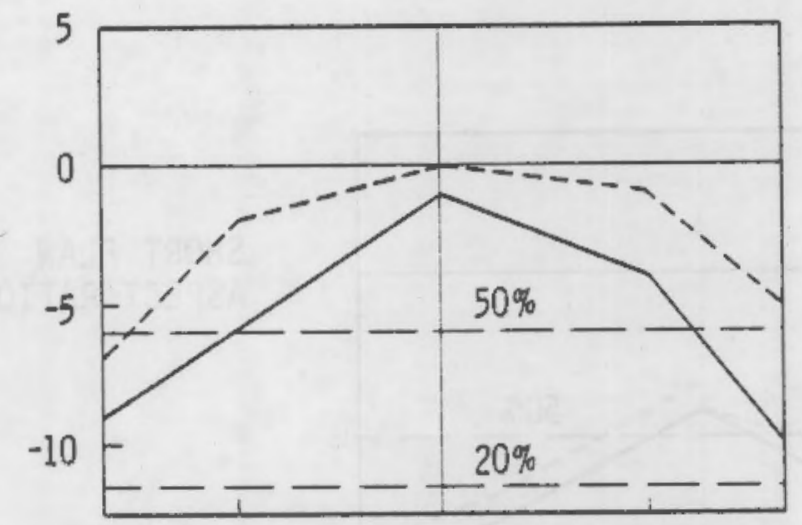

SHORT FLAW

ASPECT RATIO $=0.5$

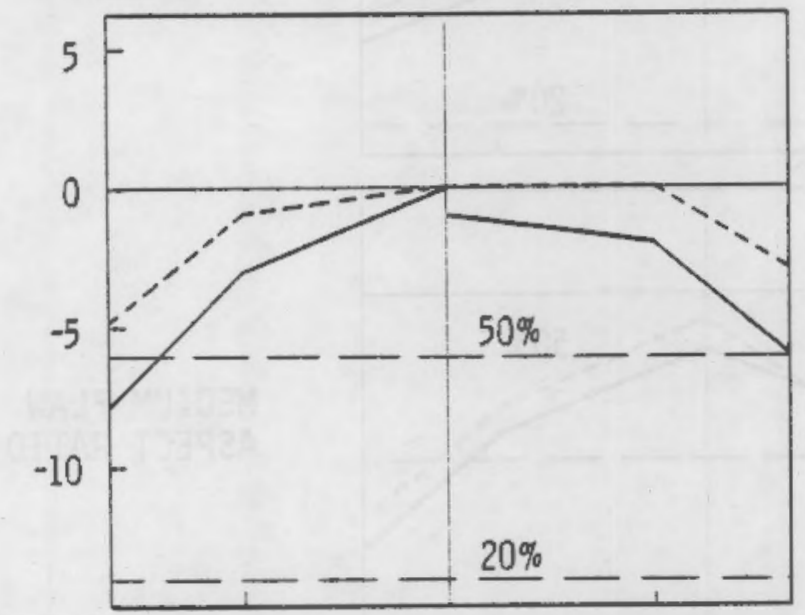

MEDIUM FLAW

ASPECT RATIO $=0.25$

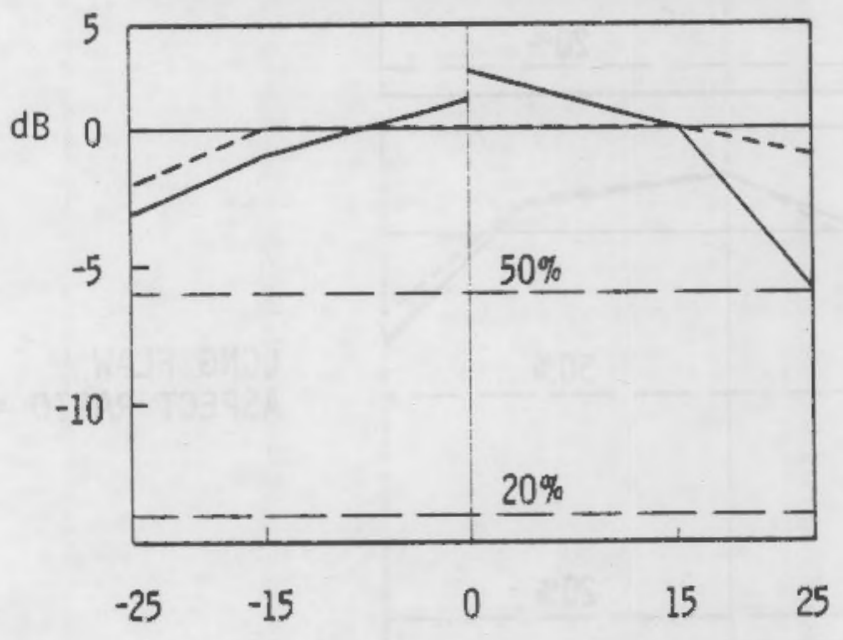

LONG FLAW

ASPECT RATIO $=0.05$

FLAW ANGLE 
12" DIAMETER $304 \mathrm{~S} / \mathrm{S}$

TRANSDUCER $=1 "$ DIA.

BEAM ANGLE $=45^{\circ}$

$1 / 2 \vee$ BEAM PATH

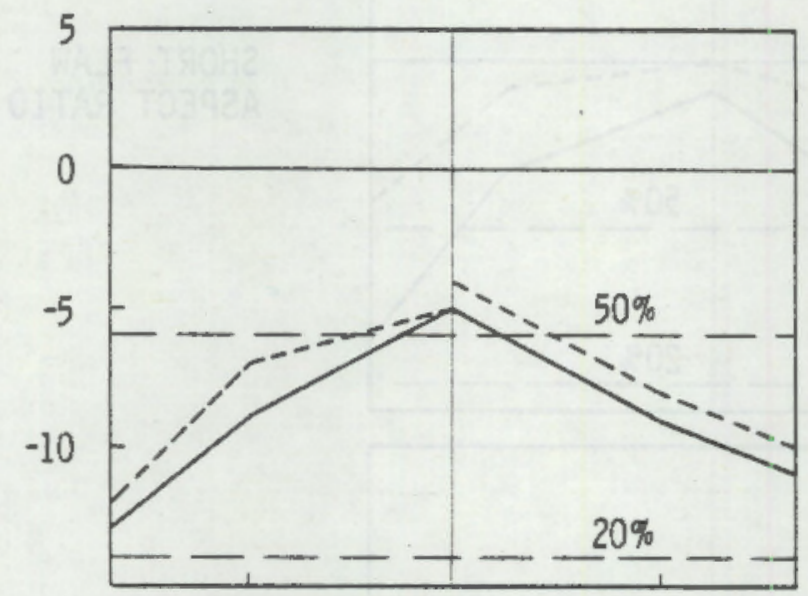

SHORT FLAW

ASPECT RATIO $=0.5$

MEDIUM FLAW

ASPECT RATIO $=0.25$
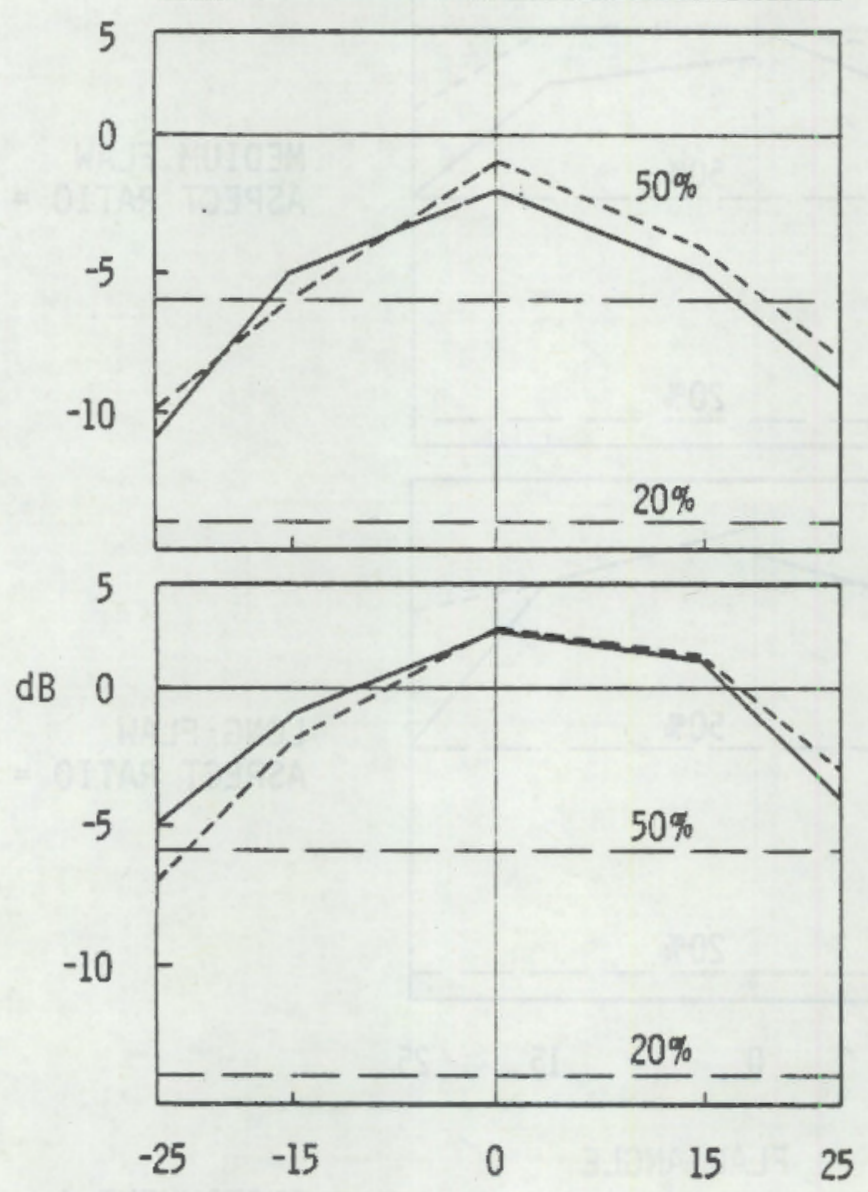

LONG FLAW

ASPECT RATIO $=0.05$

FLAW ANGLE 
12" DIAMETER $304 \mathrm{~S} / \mathrm{S}$

TRANSDUCER $=.25^{\prime \prime}$ DIA.

BEAM ANGLE $=45^{\circ}$

$3 / 2 \vee$ BEAM PATH

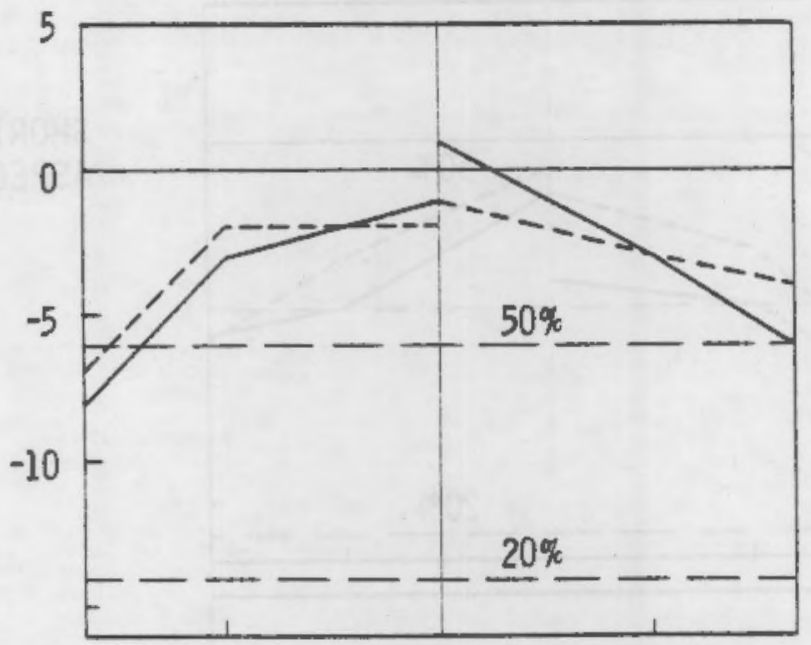

SHORT FLAW

ASPECT RATIO $=0.5$

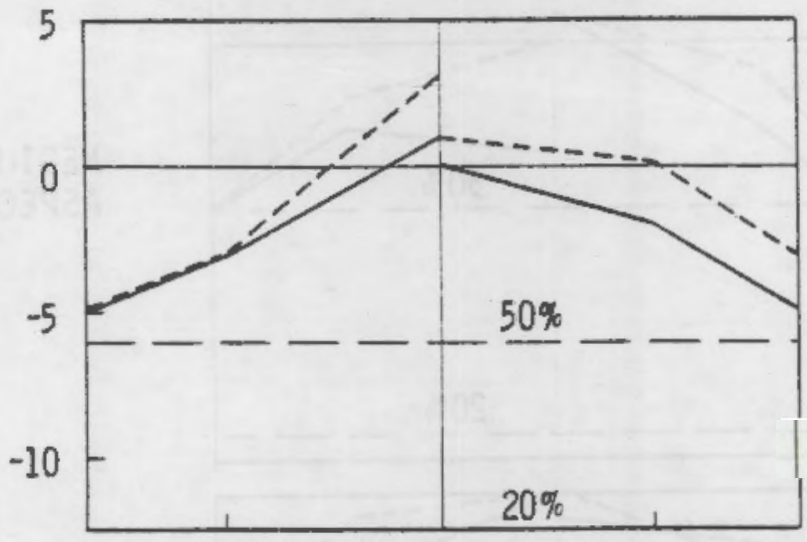

MEDIUM FLAW

ASPECT RATIO $=0.25$

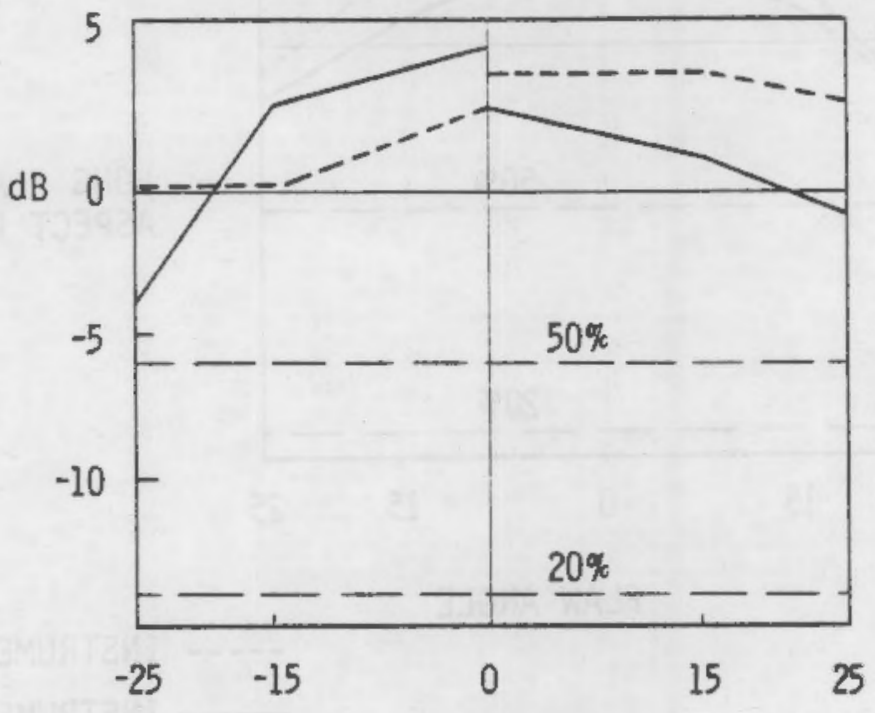

LONG FLAW

ASPECT RATIO $=0.05$

FLAW ANGLE

II I-11

---- INSTRUMENT A

INSTRUMENT B 
12" DIAMETER $304 \mathrm{~S} / \mathrm{S}$

TRANSDUCER $=.5^{\prime \prime}$ DIA.

BEAM ANGLE $=45^{\circ}$

$3 / 2 \checkmark$ BEAM PATH

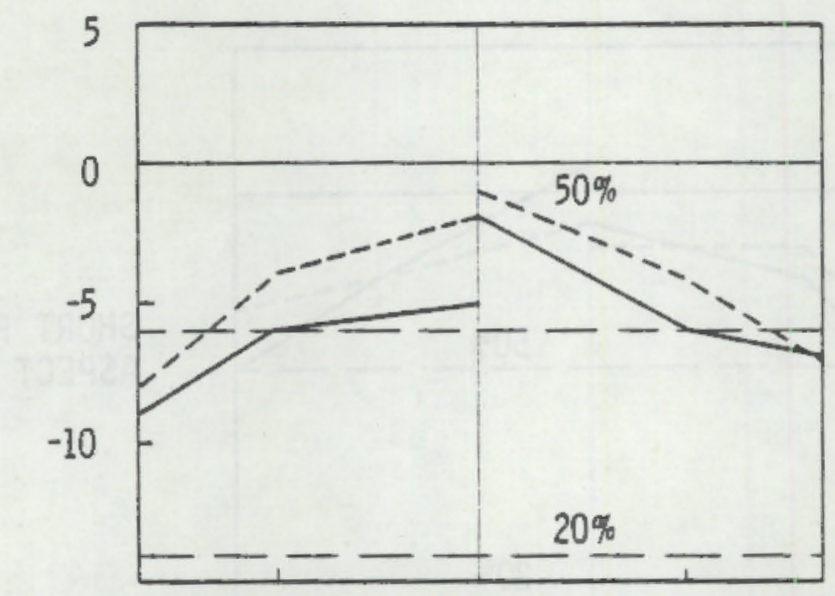

SHORT FLAW

ASPECT RATIO $=0.5$

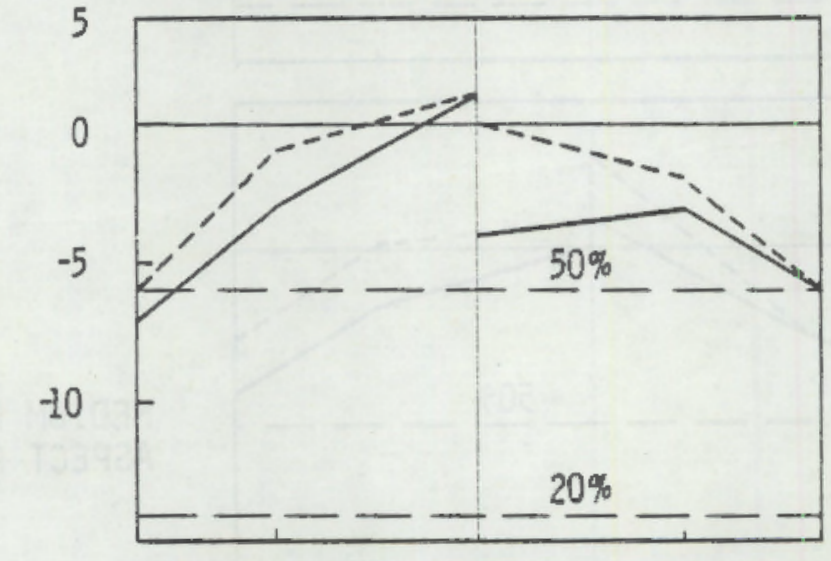

MEDIUM FLAW

ASPECT RATIO $=0.25$

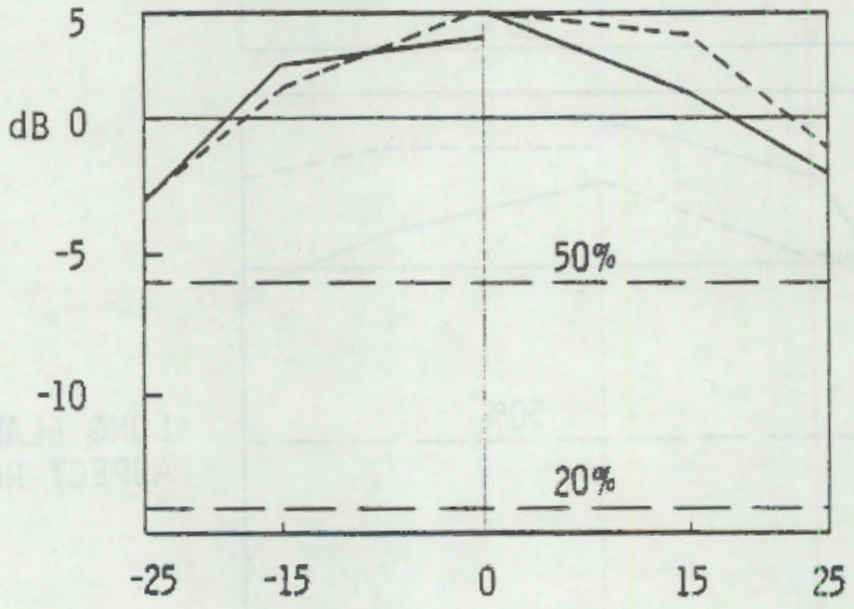

LONG FLAW

ASPECT RATIO $=0.05$

FLAW ANGLE

INSTRUMENT A

INSTRUMENT B 
12" DIAMETER $304 \mathrm{~S} / \mathrm{S}$

TRANSDUCER $=1 "$ DIA.

BEAM ANGLE $=45^{\circ}$

$3 / 2$ V BEAM PATH

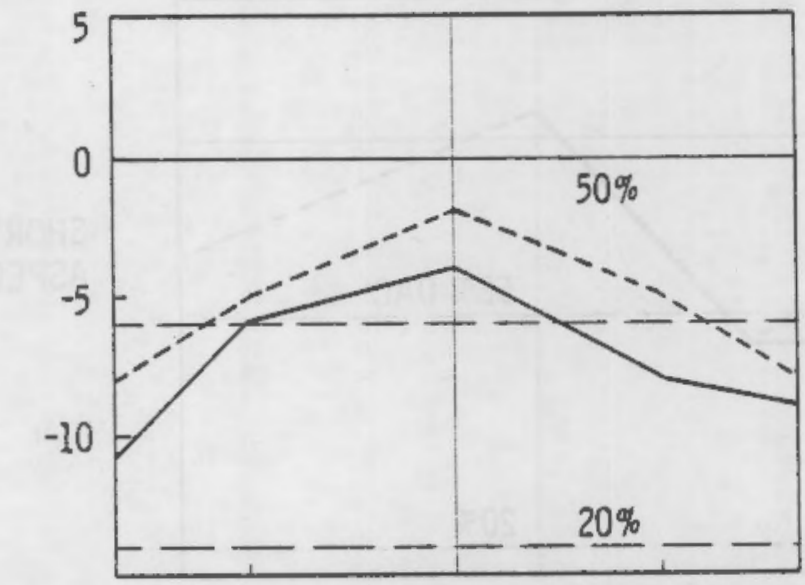

SHORT FLAW

ASPECT RATIO $=0.5$

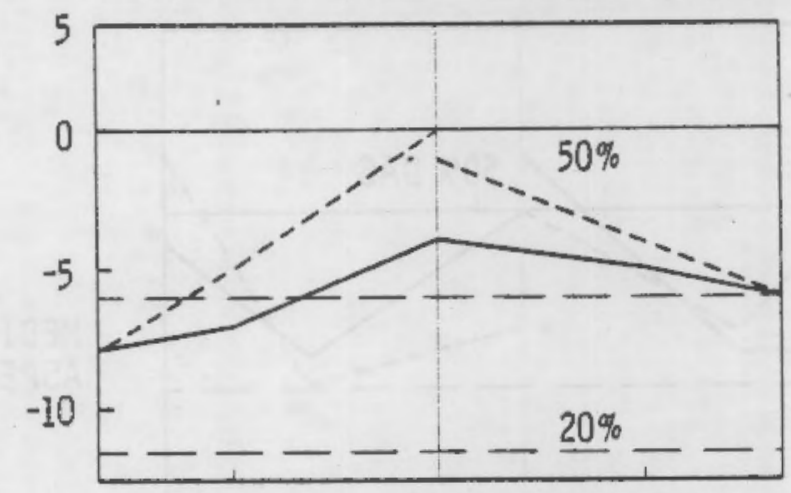

MEDIUM FLAW

ASPECT RATIO $=0.25$

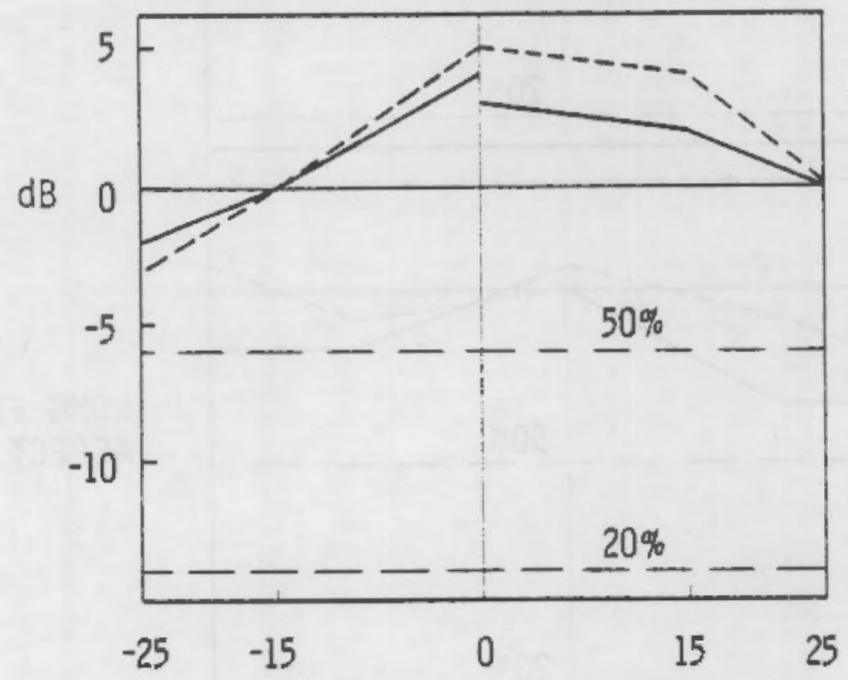

LONG FLAW

ASPECT RATIO $=0.05$

FLAW ANGLE

INSTRUMENT A

INSTRUMENT $B$ 
12 " DIAMETER $304 \mathrm{~S} / \mathrm{S}$

TRANSDUCER $=.25^{\prime \prime}$ DIA.

BEAM ANGLE $=60^{\circ}$

$1 / 2 \vee$ BEAM PATH
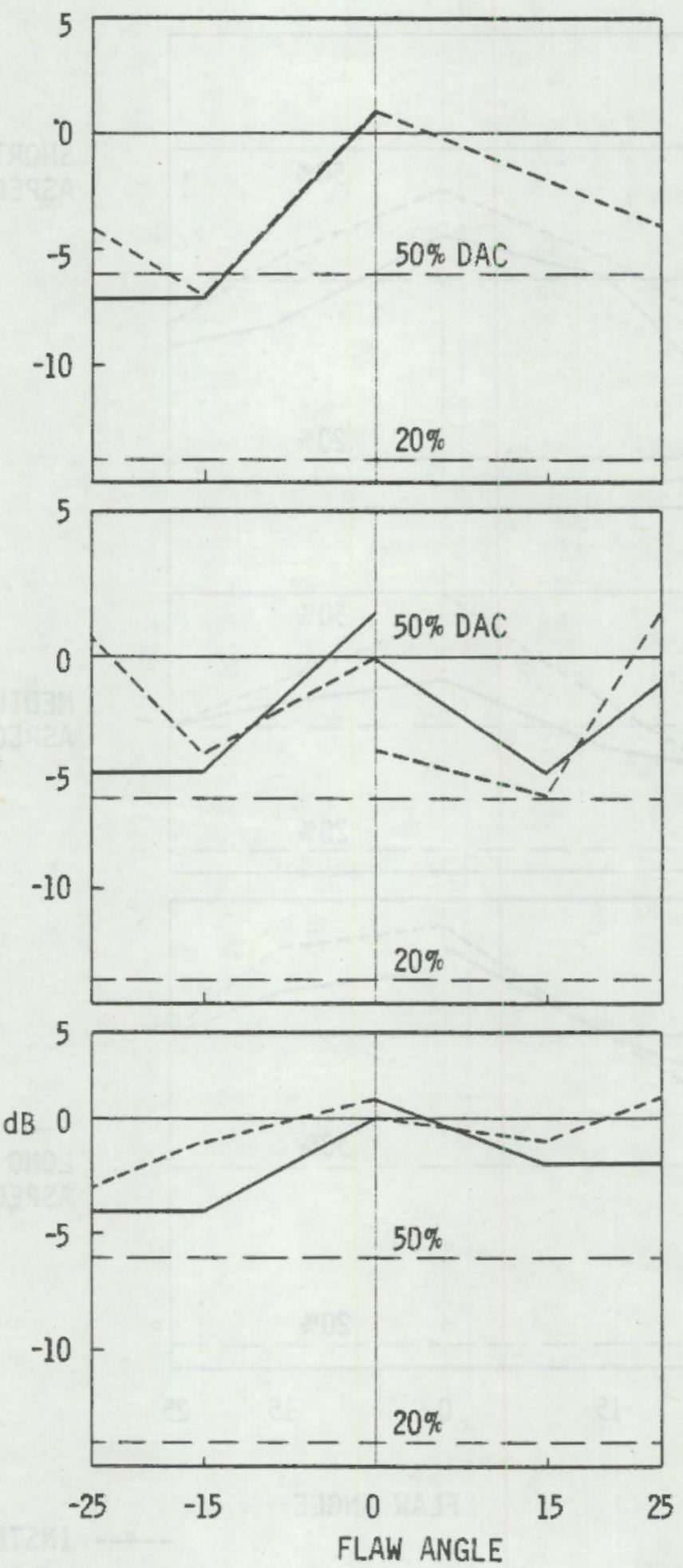

-.-- INSTRUMENT A

INSTRUMENT B 
12" DIAMETER $304 \mathrm{~S} / \mathrm{S}$

TRANSDUCER $=.5^{\prime \prime}$ DIA.

BEAM ANGLE $=60^{\circ}$

$1 / 2 \checkmark$ BEAM PATH
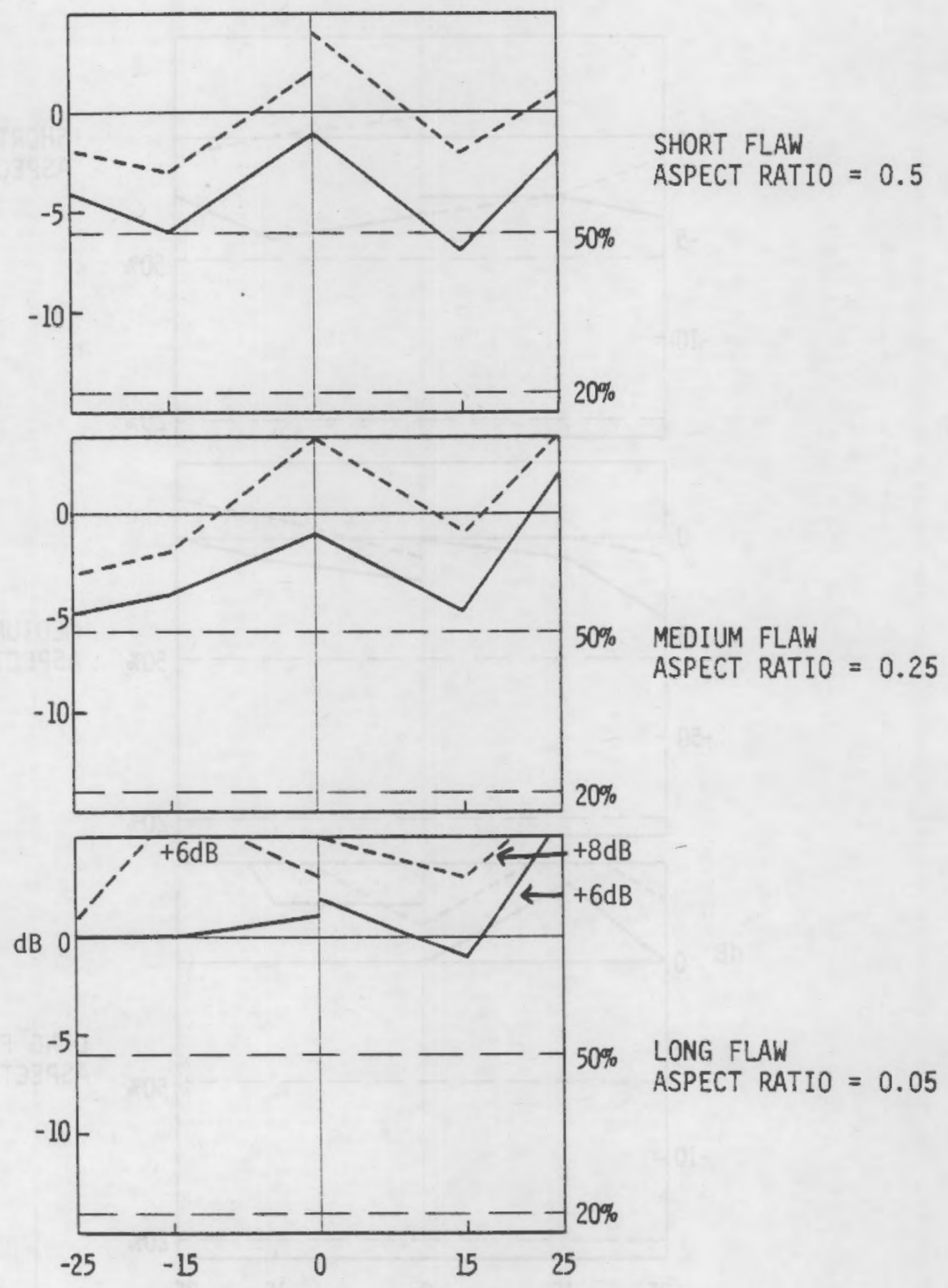

FLAW ANGLE 
12" DIAMETER $304 \mathrm{~S} / \mathrm{S}$

TRANSDUCER $=1 "$ DIA.

BEAM ANGLE $=60^{\circ}$

$1 / 2 \checkmark$ BEAM PATH
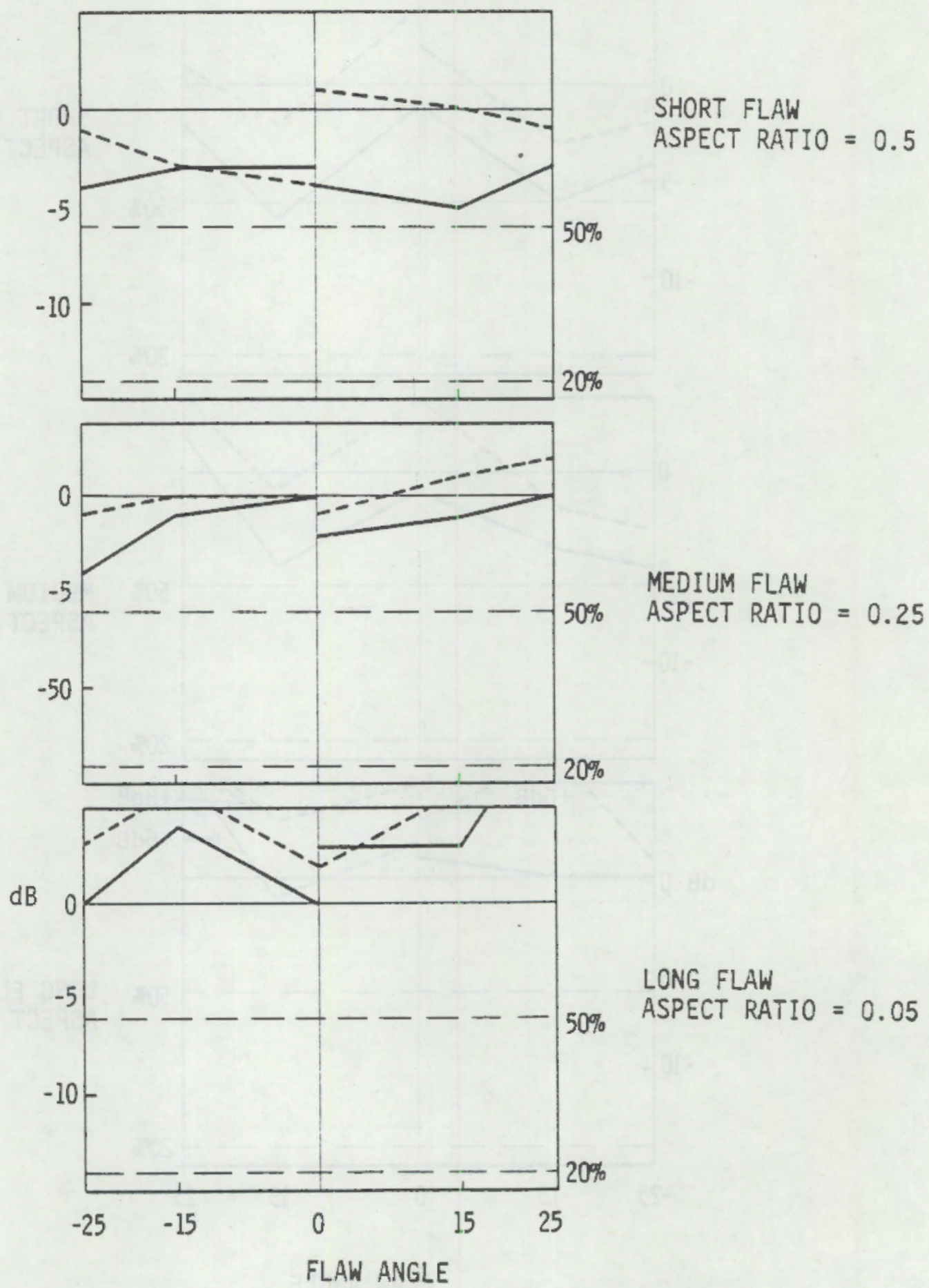

INSTRUMENT A

INSTRUMENT B 
20" DiAMETER CARBON STEEL

TRANSDUCER $=.25^{\prime \prime}$ DIA.

BEAM ANGLE $=45^{\circ}$

$1 / 2 \checkmark$ BEAM PATH
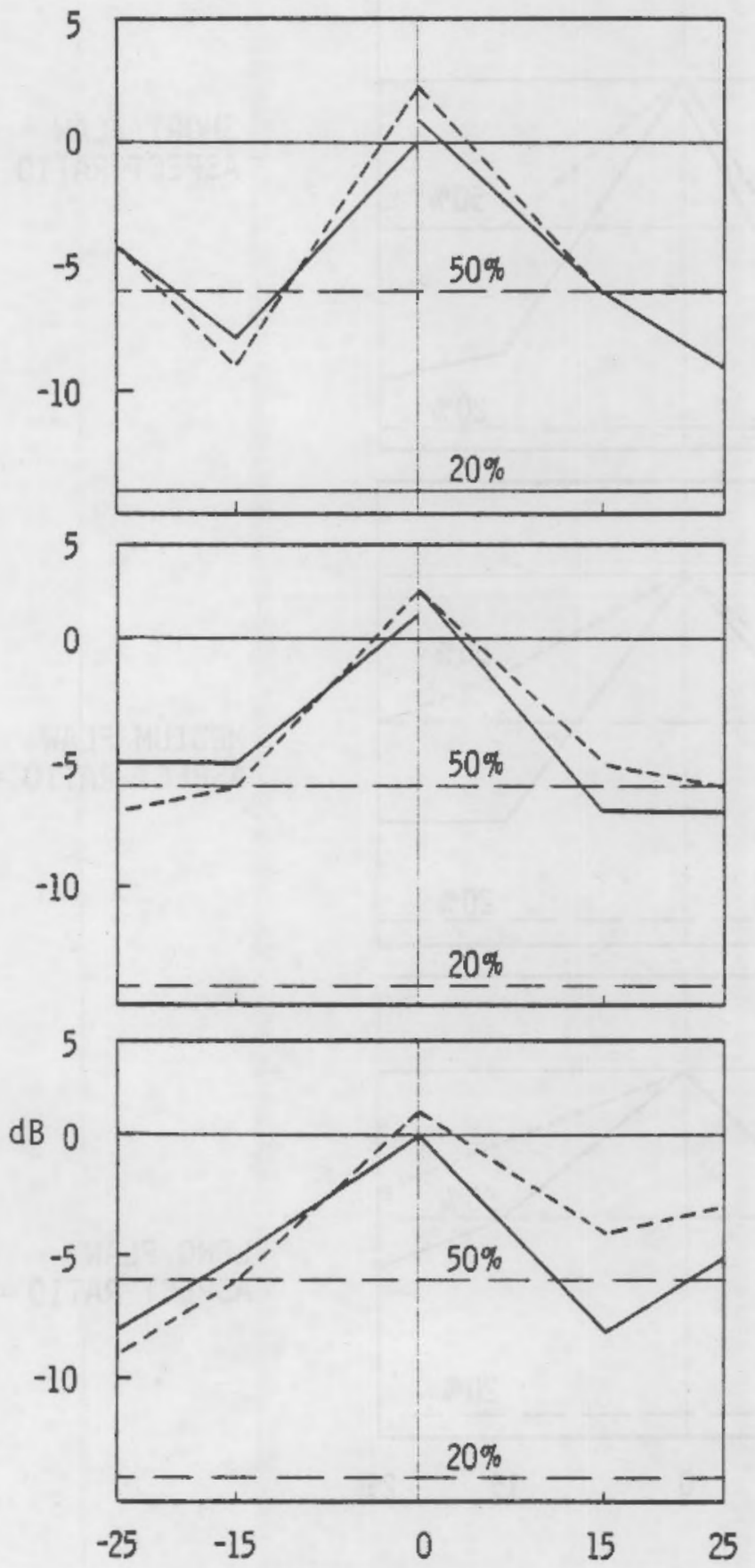

SHORT FLAW

ASPECT RATIO $=0.5$

MEDIUM FLAW

ASPECT RATIO $=0.25$
LONG FLAW

ASPECT RATIO $=0.05$

\section{FLAW ANGLE}


20" DIAMETER CARBON STEEL

TRANSDUCER $=.5^{\prime \prime}$ DIA.

BEAM PATH $=45^{\circ}$

$1 / 2$ V BEAM PATH

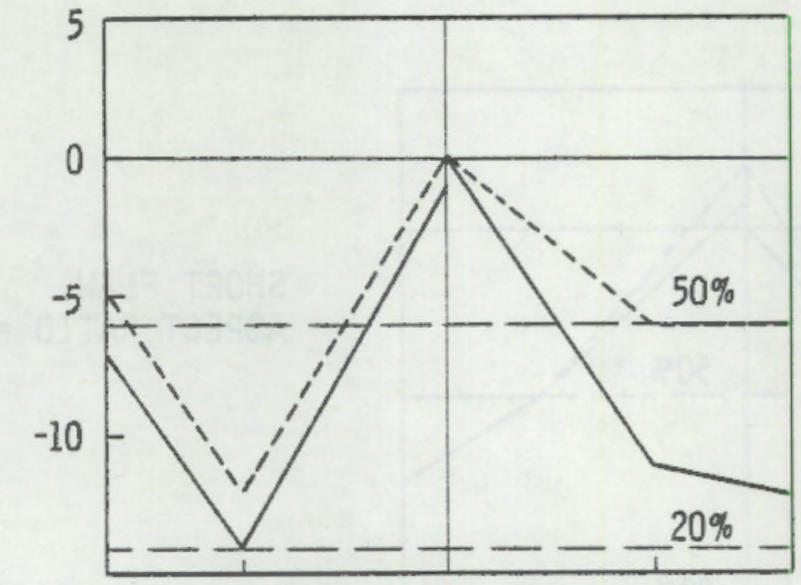

SHORT FLAW

ASPECT RATIO $=0.5$

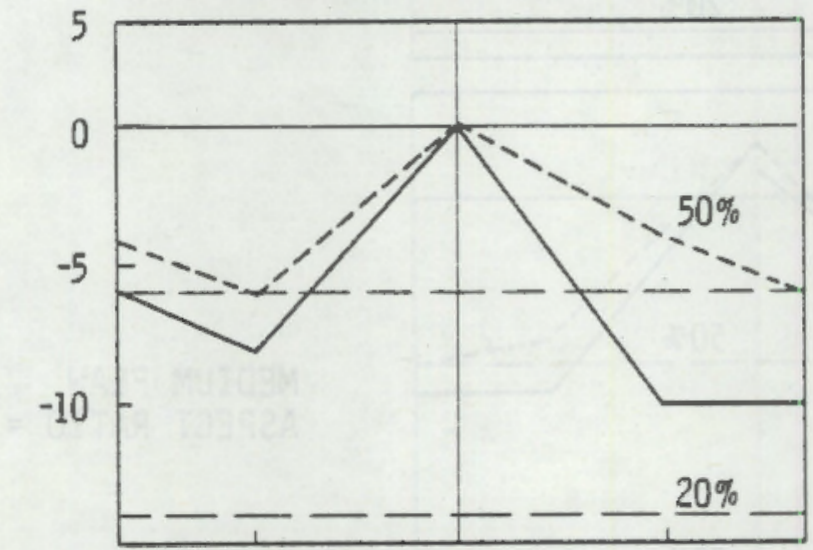

MEDIUM FLAW

ASPECT RATIO $=0.25$

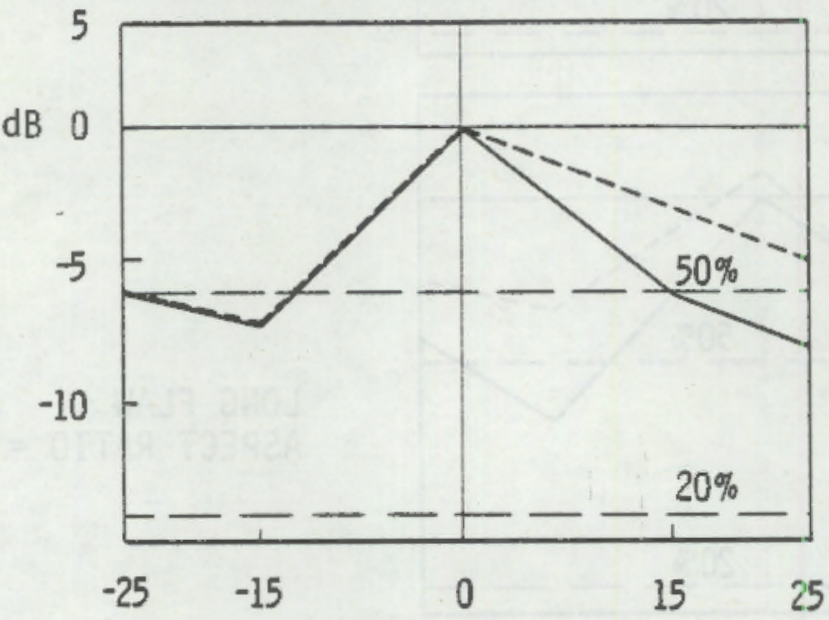

LONG FLAW

ASPECT RATIO $=0.05$

FLAW ANGLE

INSTRUMENT A

INSTRUMENT $B$ 
20" DIAMETER CARBON STEEL

TRANSDUCER $=1 "$ DIA.

BEAM ANGLE $=45^{\circ}$

$1 / 2$ V BEAM PATH

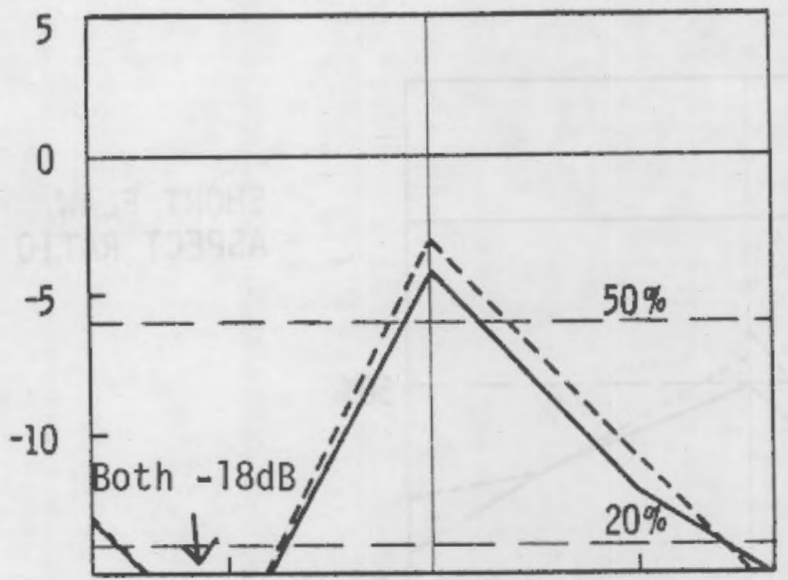

SHORT FLAW

ASPECT RATIO $=0.5$

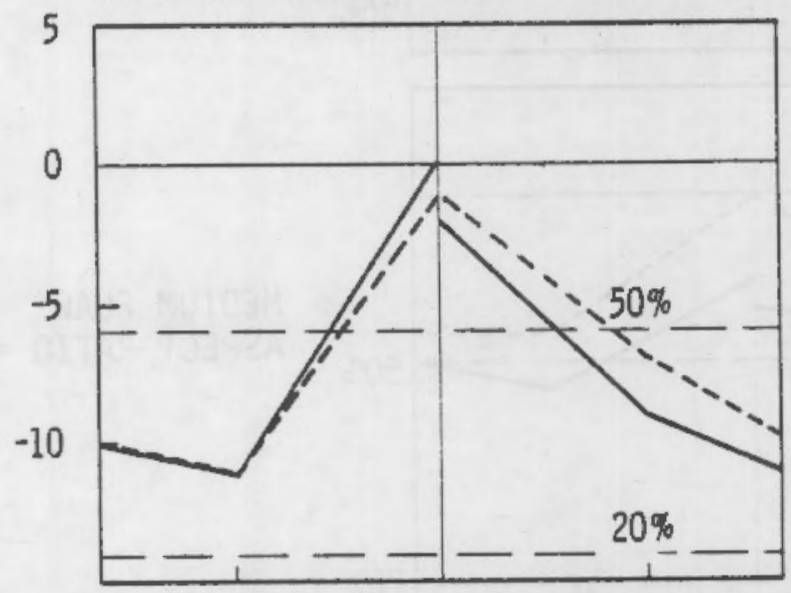

MEDIUM FLAW

ASPECT RATIO $=0.25$

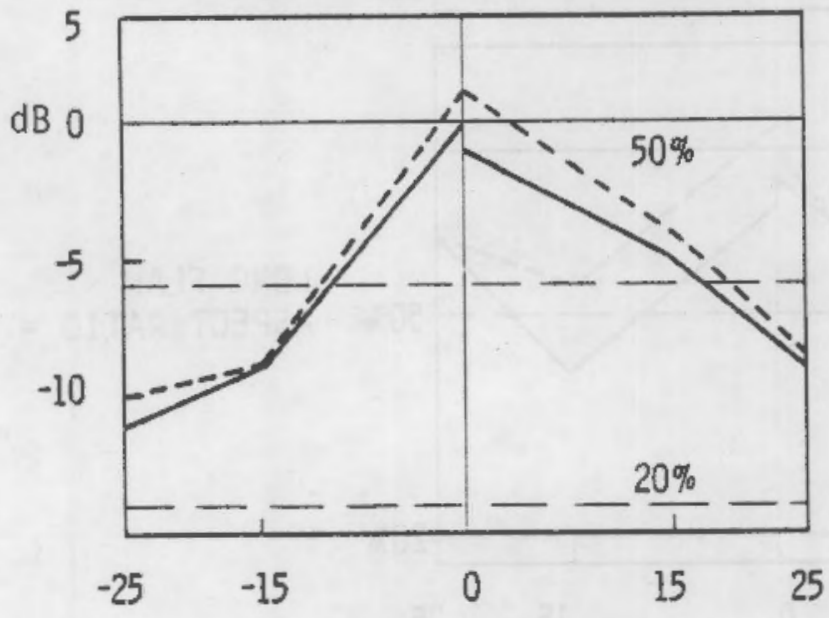

LONG FLAW

ASPECT RATIO $=0.05$

FLAW ANGLE

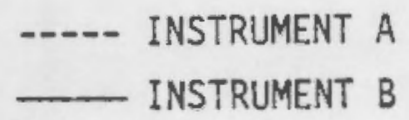


20" DIAMETER CARBON STEEL

TRANSDUCER $=.25^{\prime \prime}$ DIA.

BEAM ANGLE $=45^{\circ}$

$3 / 2 \vee$ BEAM PATH
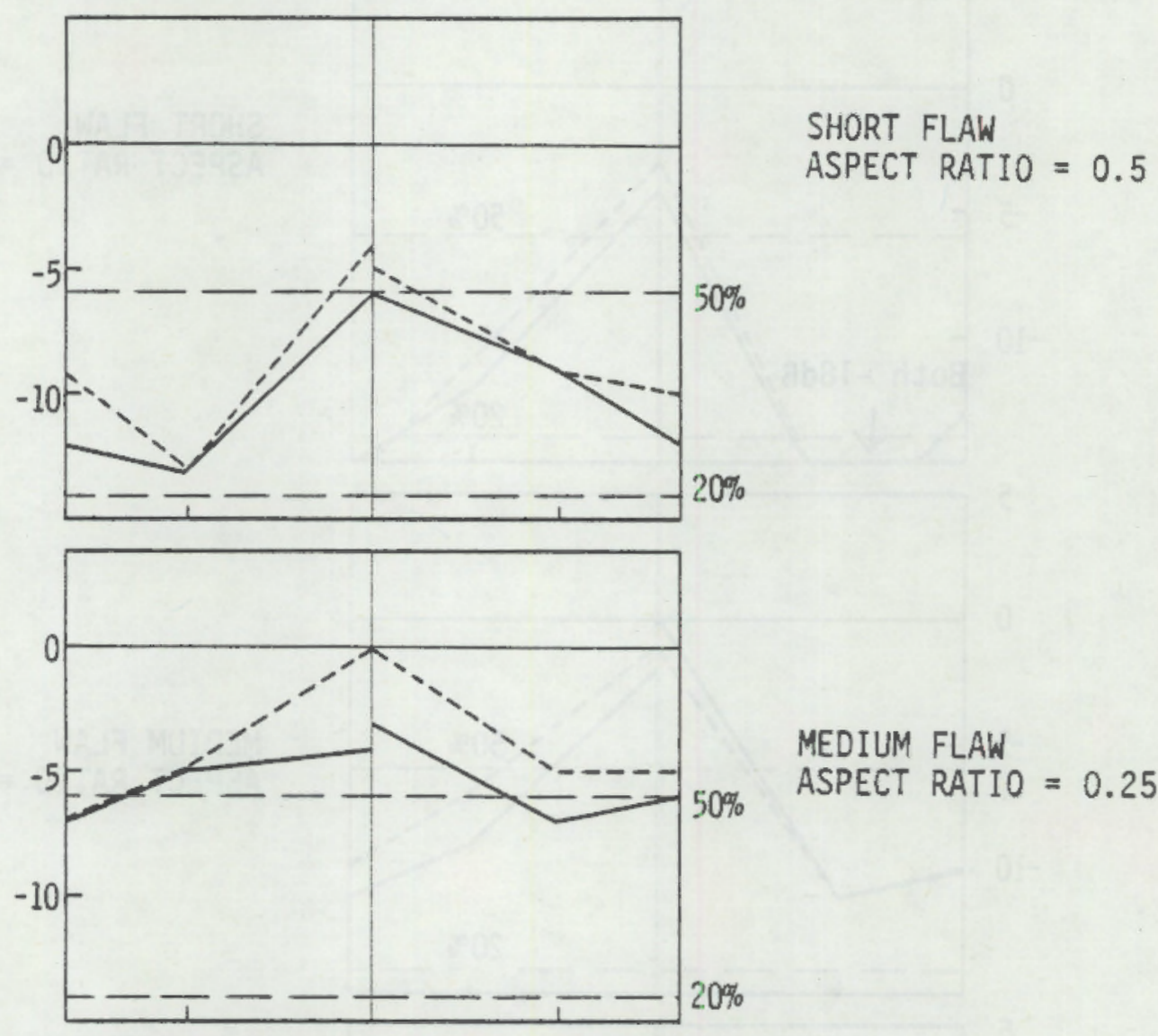

MEDIUM FLAW

ASPECT RATIO $=0.25$

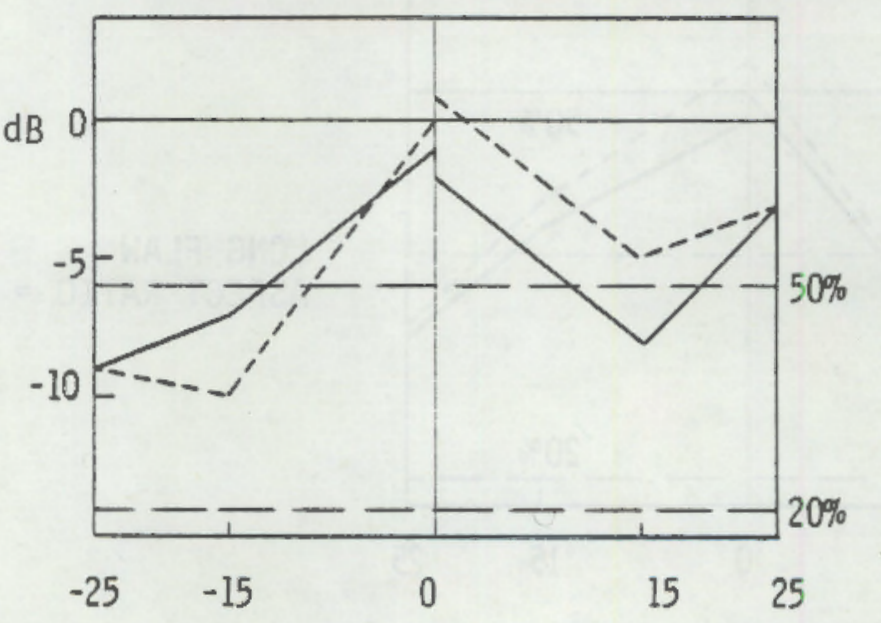

LONG FLAW

ASPECT RATIO $=0.05$

FLAW ANGLE 
20" DIAMETER CARBON STEEL

TRANSDUCER $=.5^{\prime \prime}$ DIA.

BEAM ANGLE $=45^{\circ}$

$3 / 2$ V BEAM PATH

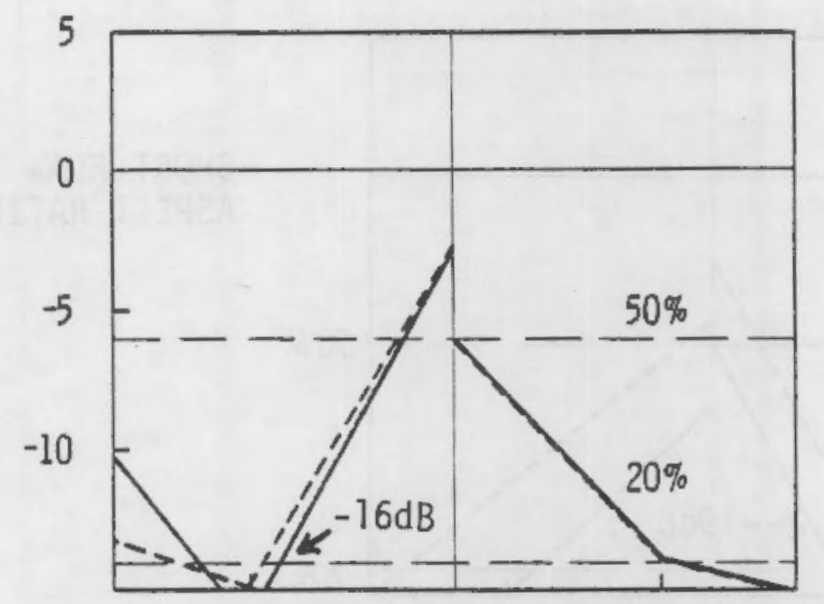

SHORT FLAW

ASPECT RATIO $=0.5$

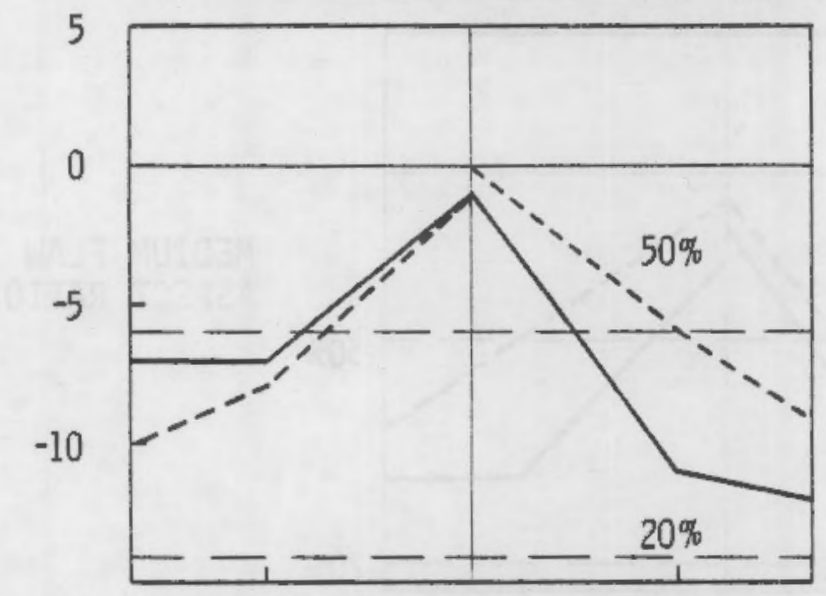

MEDIUM FLAW

ASPECT RATIO $=0.25$

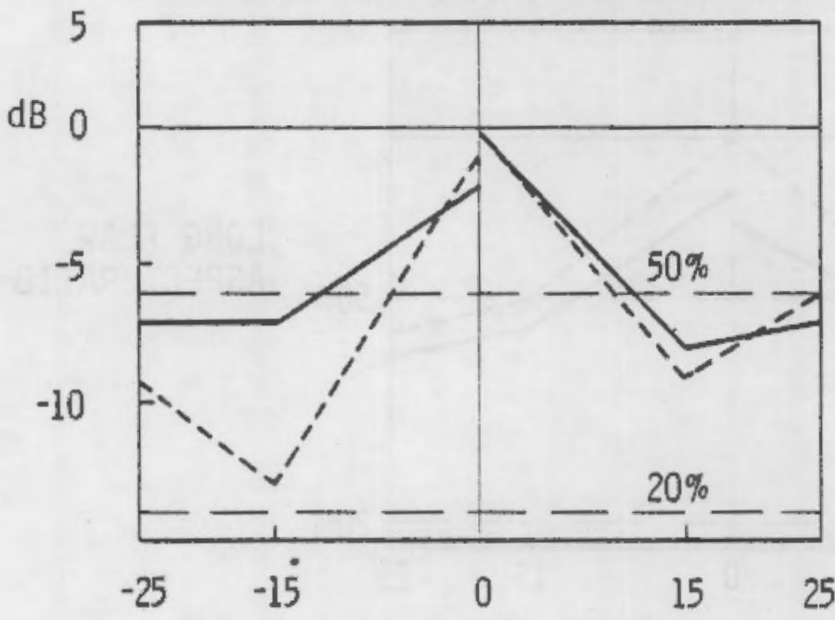

LONG FLAW

ASPECT RATIO $=0.05$

FLAW ANGLE 
20" DIAMETER CARBON STEEL

TRANSDUCER $=1 "$ DIA.

BEAM ANGLE $=45^{\circ}$

$3 / 2 \checkmark$ BEAM PATH

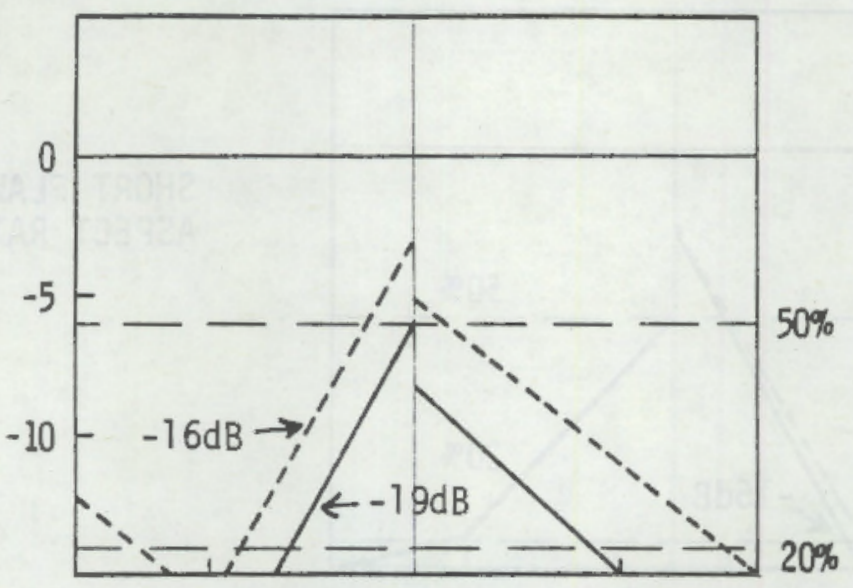

SHORT FLAW

ASPECT RATIO $=0.5$

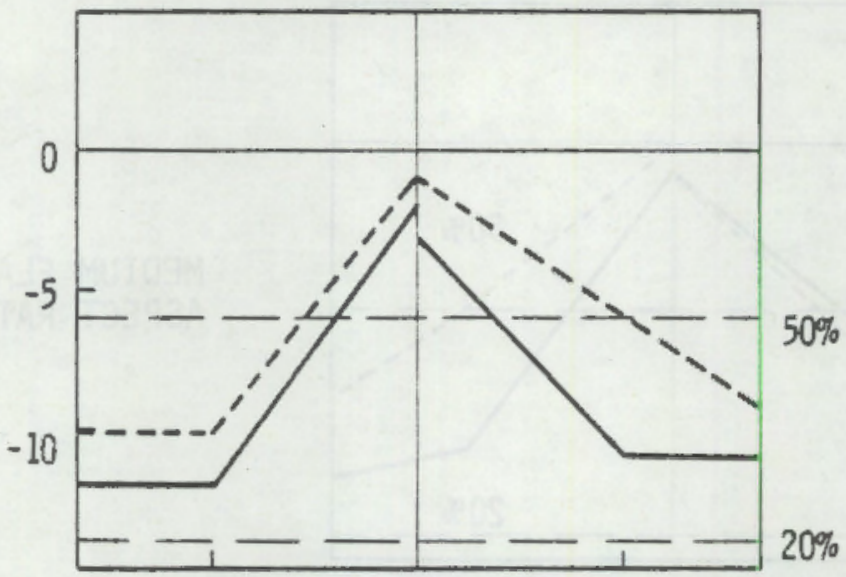

MEDIUM FLAW

ASPECT RATIO $=0.25$

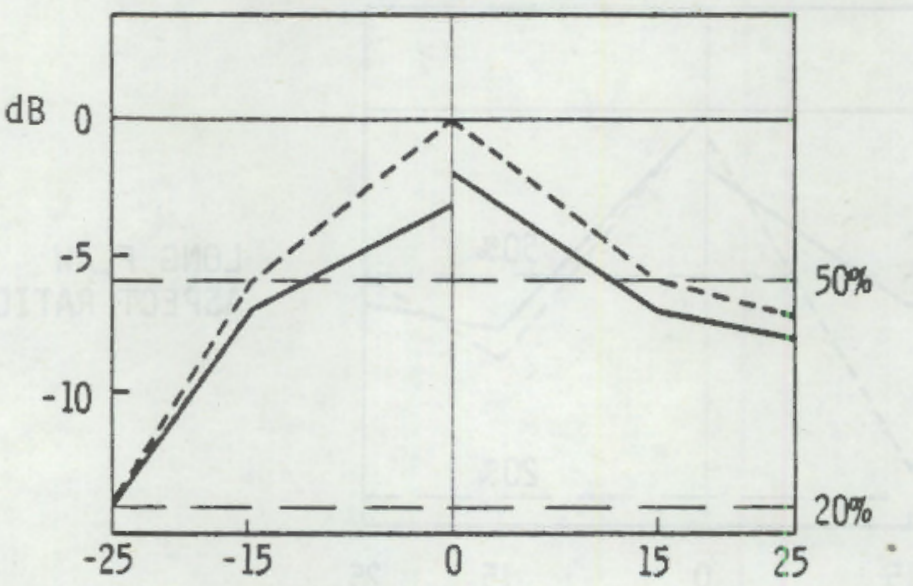

LONG FLAW

ASPECT RATIO $=0.05$

FLAW ANGLE

INSTRUMENT A

INSTRUMENT B 
20" DIAMETER CARBON STEEL

TRANSDUCER $=.25^{\prime \prime}$ OIA.

BEAM ANGLE $=60^{\circ}$

$1 / 2 \checkmark$ BEAM PATH

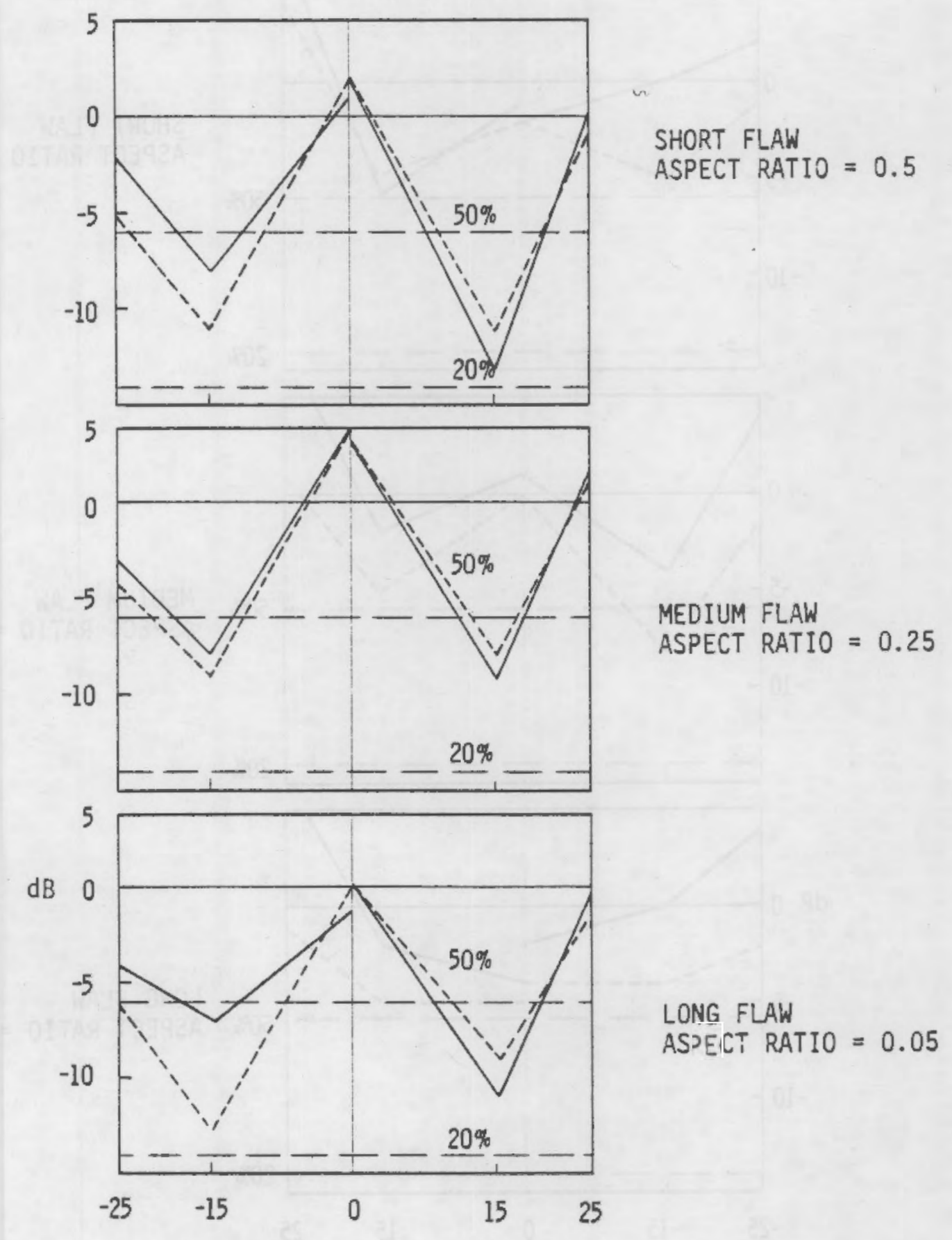

FLAW ANGLE

----- INSTRUMENT A INSTRUMENT B 
20 " DIAMETER CARBON STEEL

TRANSDUCER $=.5^{\prime \prime}$ DIA.

BEAM ANGLE $=60^{\circ}$

$1 / 2 \vee$ BEAM PATH
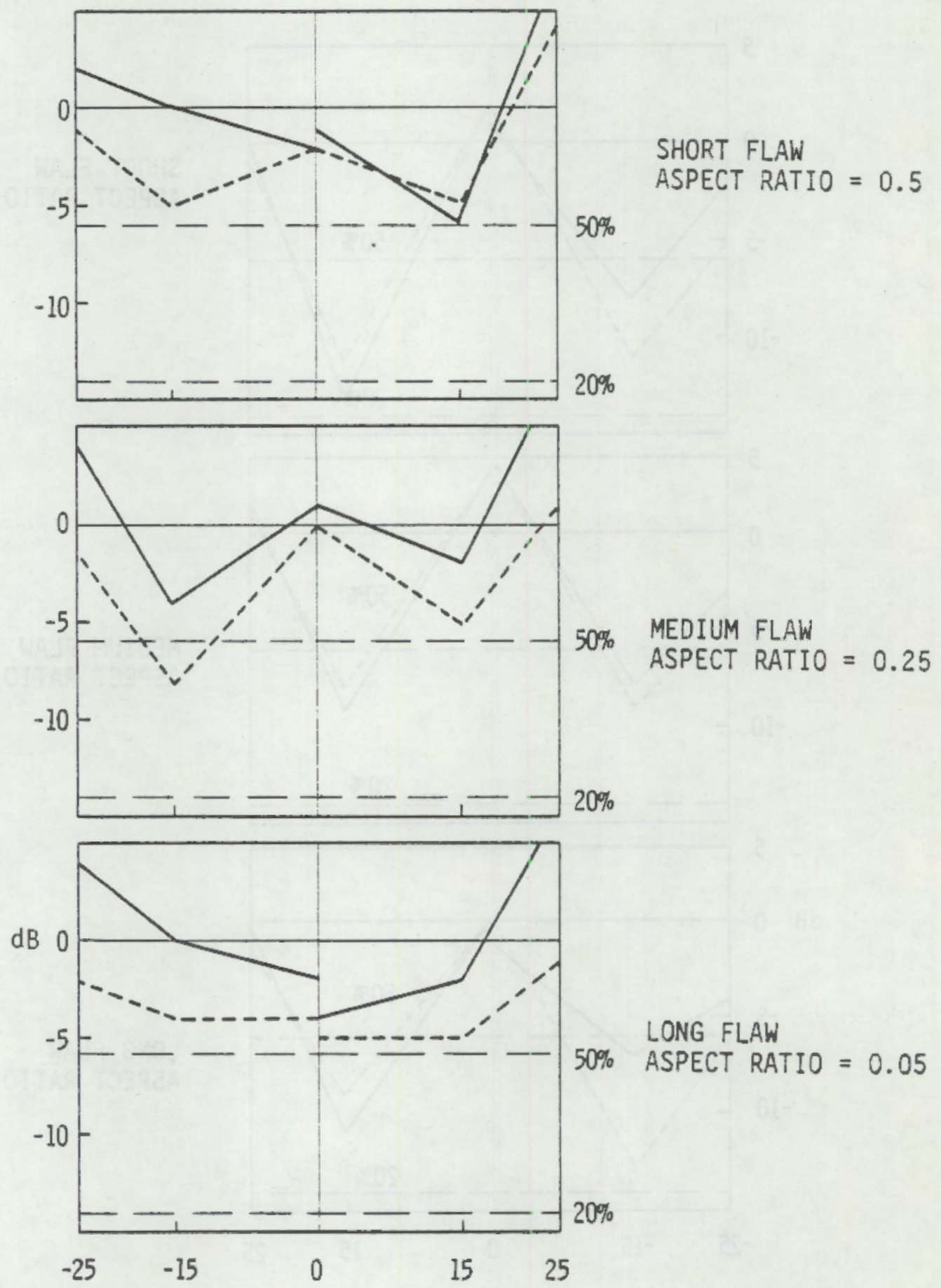

FLAW ANGLE

-..-- INSTRUMENT A

INSTRUMENT $B$ 
20" DIAMETER CARBON STEEL

TRANSDUCER $=l "$ DIA.

BEAM ANGLE $=60^{\circ}$

$1 / 2 \mathrm{~V}$ BEAM PATH

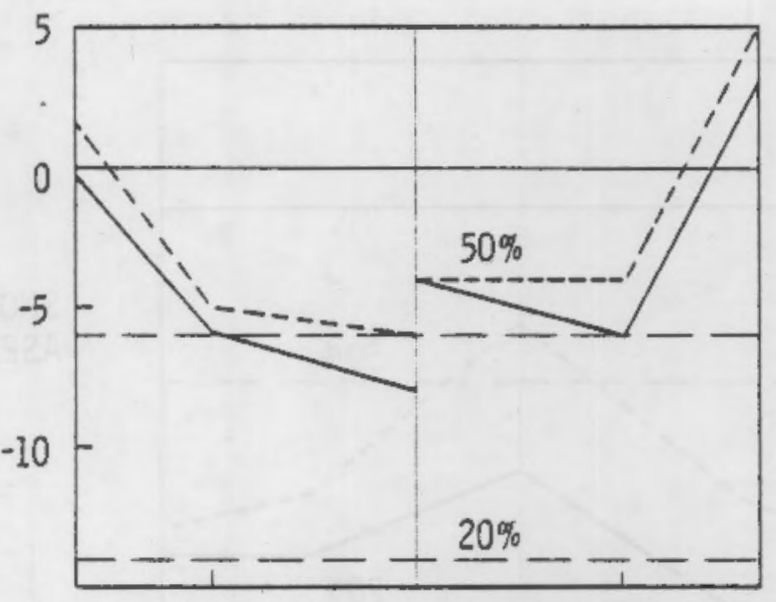

SHORT FLAW

ASPECT RATIO $=0.5$

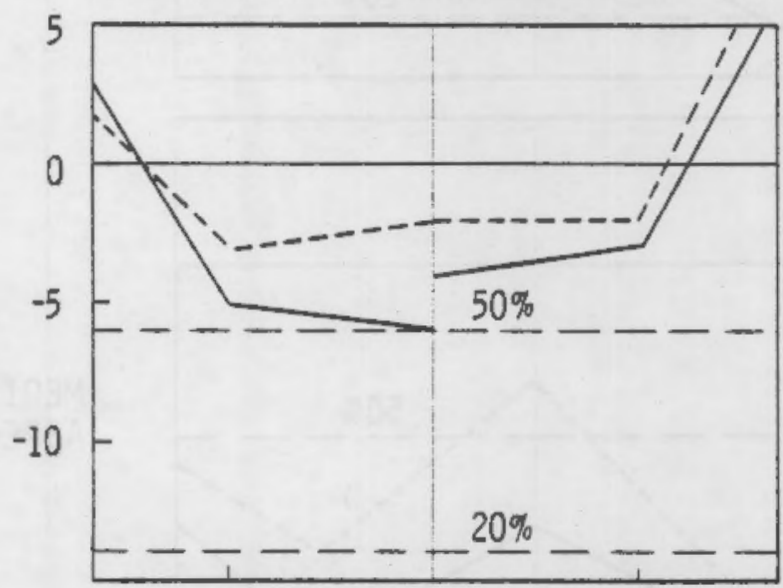

MEDIUM FLAW

ASPECT RATIO $=0.25$

$\mathrm{dB}$

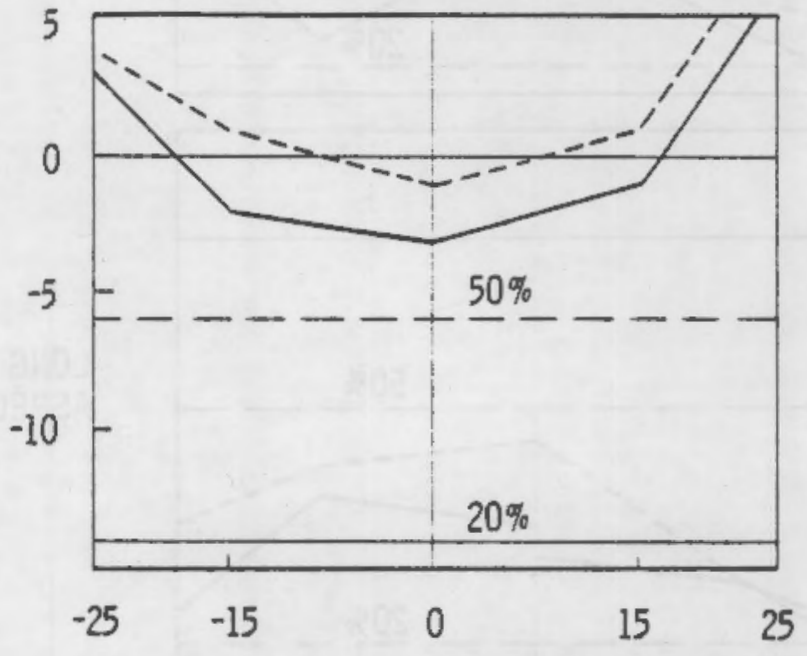

LONG FLAW

ASPECT RATIO $=0.05$

FLAW ANGLE 
20" DIAMETER $304 \mathrm{~S} / \mathrm{S}$

TRANSDUCER $=.25^{\prime \prime}$ DIA.

BEAM ANGLE $=45^{\circ}$

$1 / 2 \checkmark$ BEAM PATH

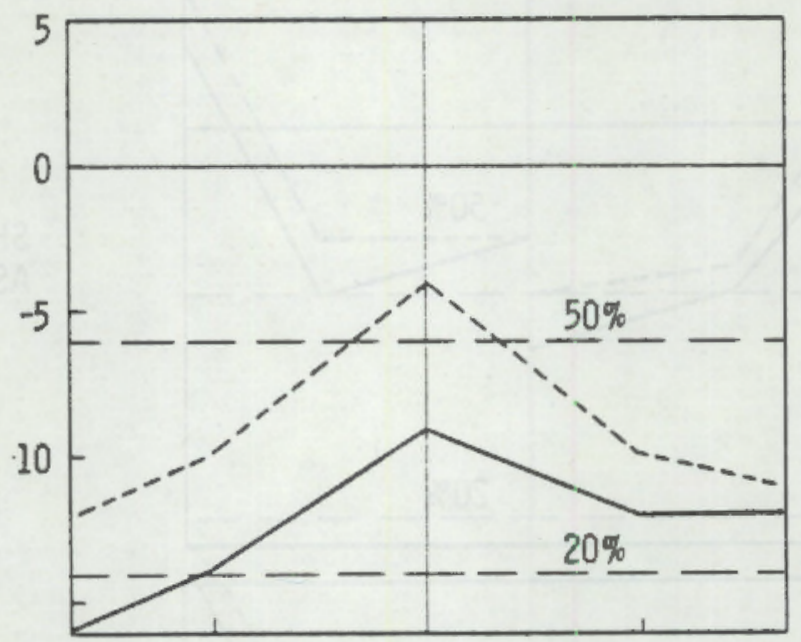

SHORT FLAW

ASPECT RATIO $=0.5$

MEDIUM FLAW

ASPECT RATIO $=0.25$
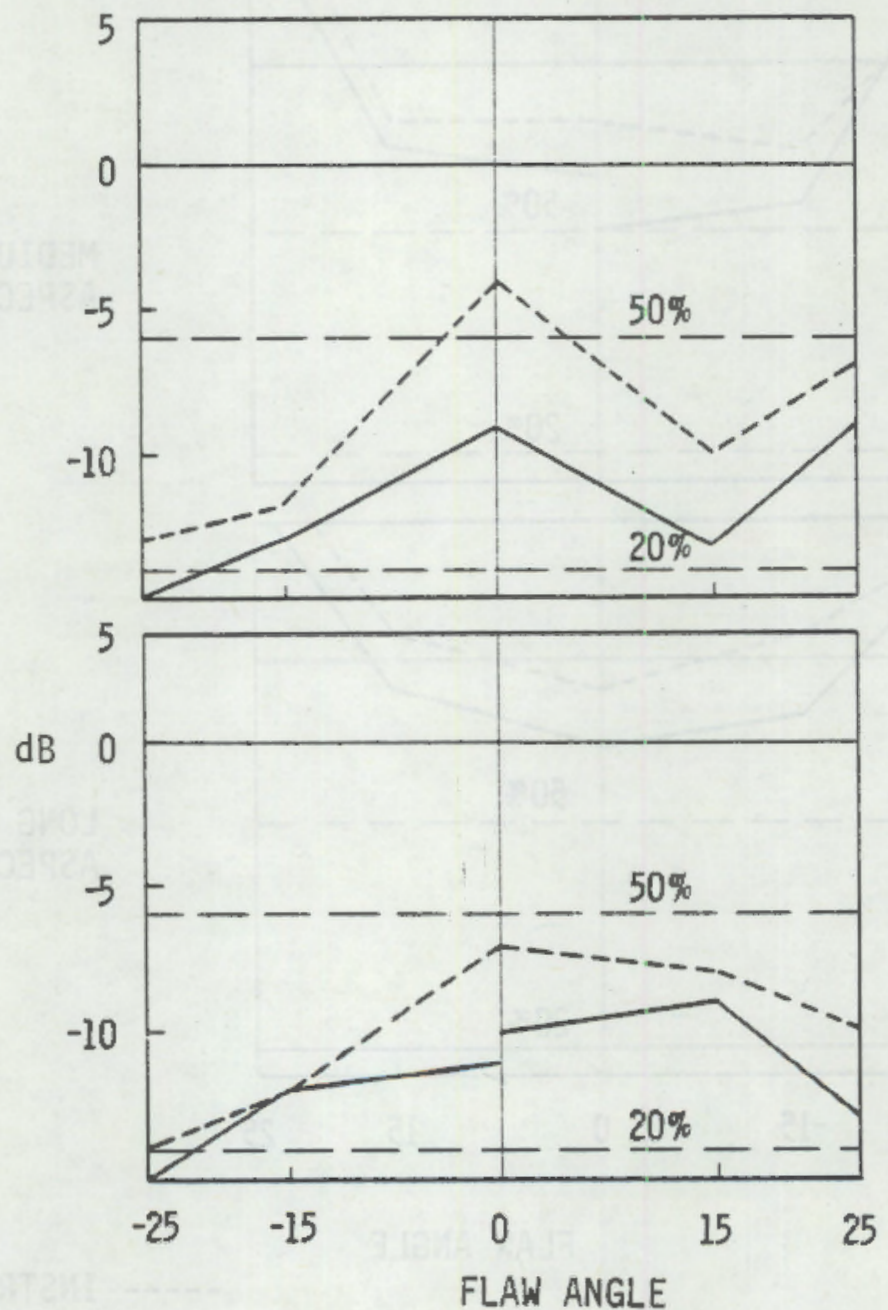

LONG FLAW

ASPECT RATIO $=0.05$

-..-- INSTRUMENT A

INSTRUMENT $B$ 
20" DIAMETER $304 \mathrm{~S} / \mathrm{S}$

TRANSDUCER $=.5^{\prime \prime}$ DIA.

BEAM ANGLE $=45^{\circ}$

$1 / 2$ V BEAM PATH

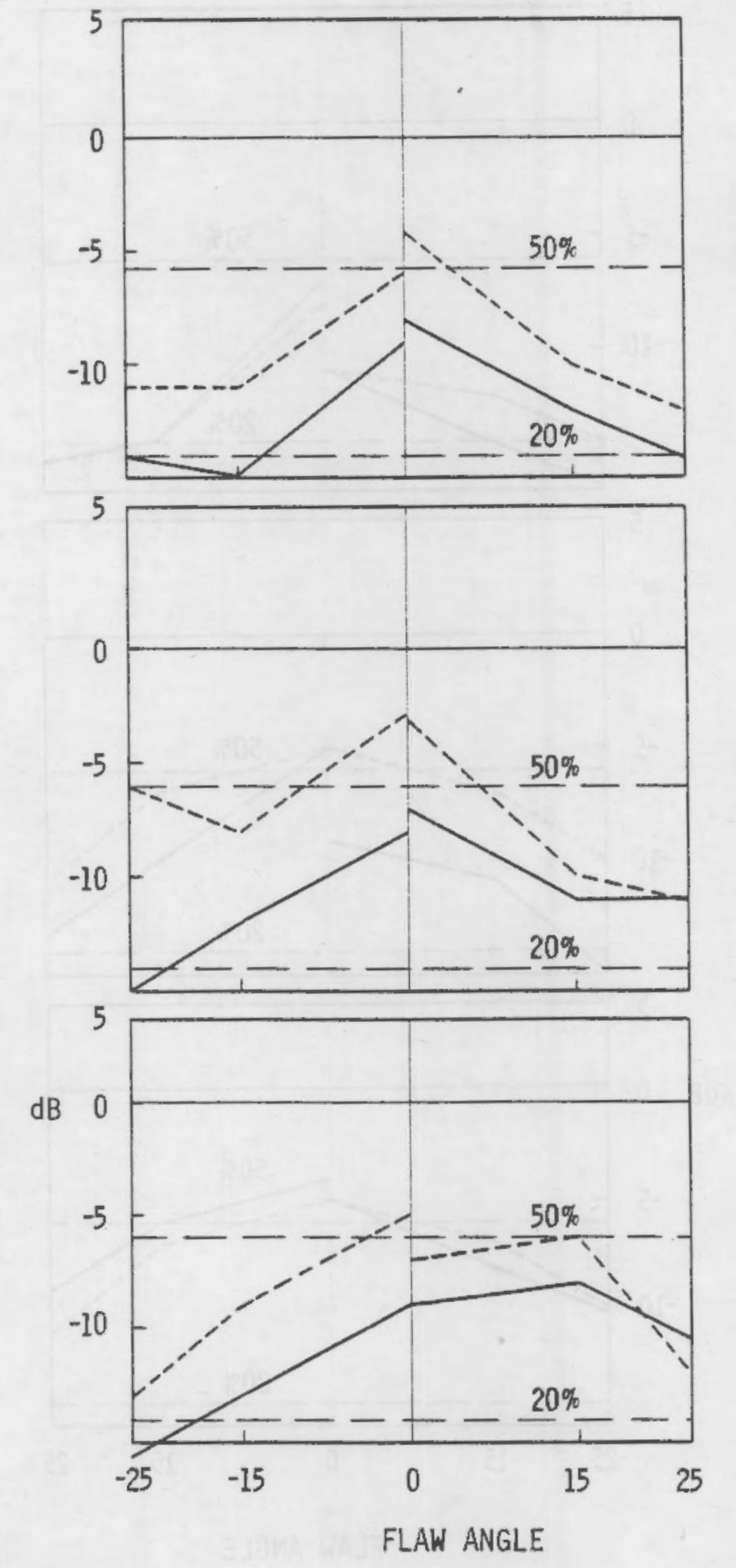

SHORT FLAW

ASPECT RATIO $=0.5$

MEDIUM FLAW

ASPECT RATIO $=0.25$

LONG FLAW

ASPECT RATIO $=0.05$ 
20" DIAMETER $304 \mathrm{~S} / \mathrm{S}$

TRANSDUCER $=1 "$ DIA.

BEAM ANGLE $=45^{\circ}$

$1 / 2 \checkmark$ BEAM PATH

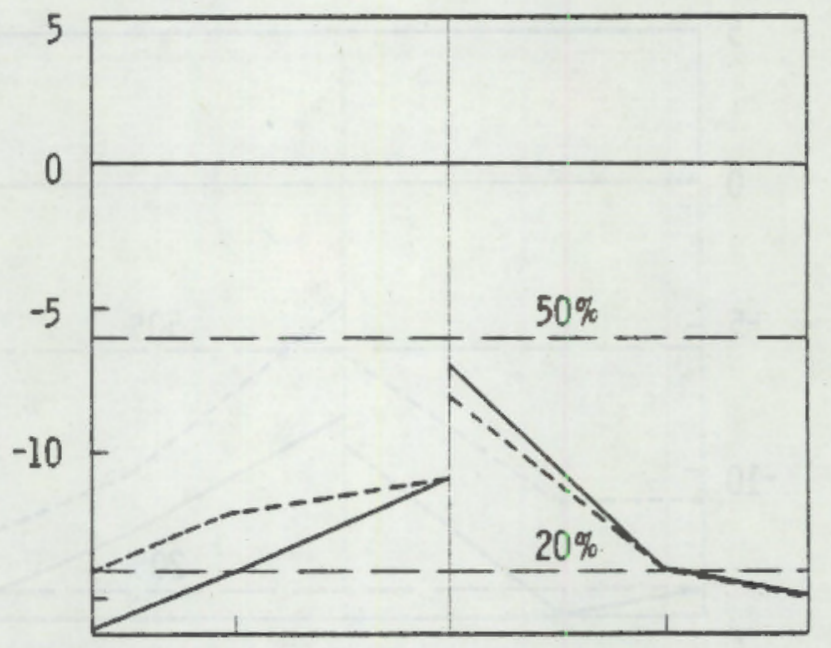

SHORT FLAW

ASPECT RATIO $=0.5$

MEDIUM FLAW

ASPECT RATIO $=0.25$
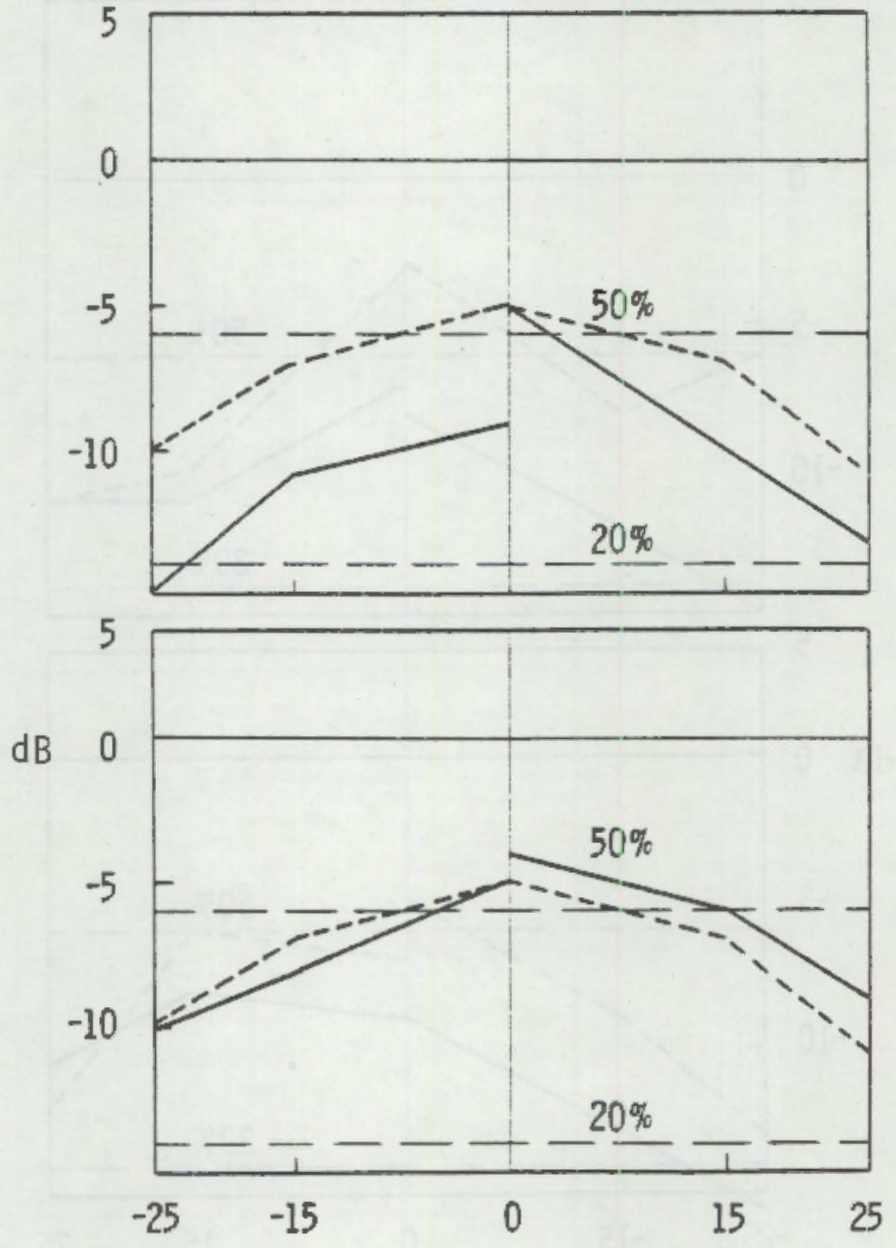

LONG FLAW

ASPECT RATIO $=0.05$

FLAW ANGLE 
20" DIAMETER $304 \mathrm{~S} / \mathrm{S}$

TRANSDUCER $=.25^{\prime \prime}$ DIA .

BEAM ANGLE $=60^{\circ}$

$1 / 2 \checkmark$ BEAM PATH

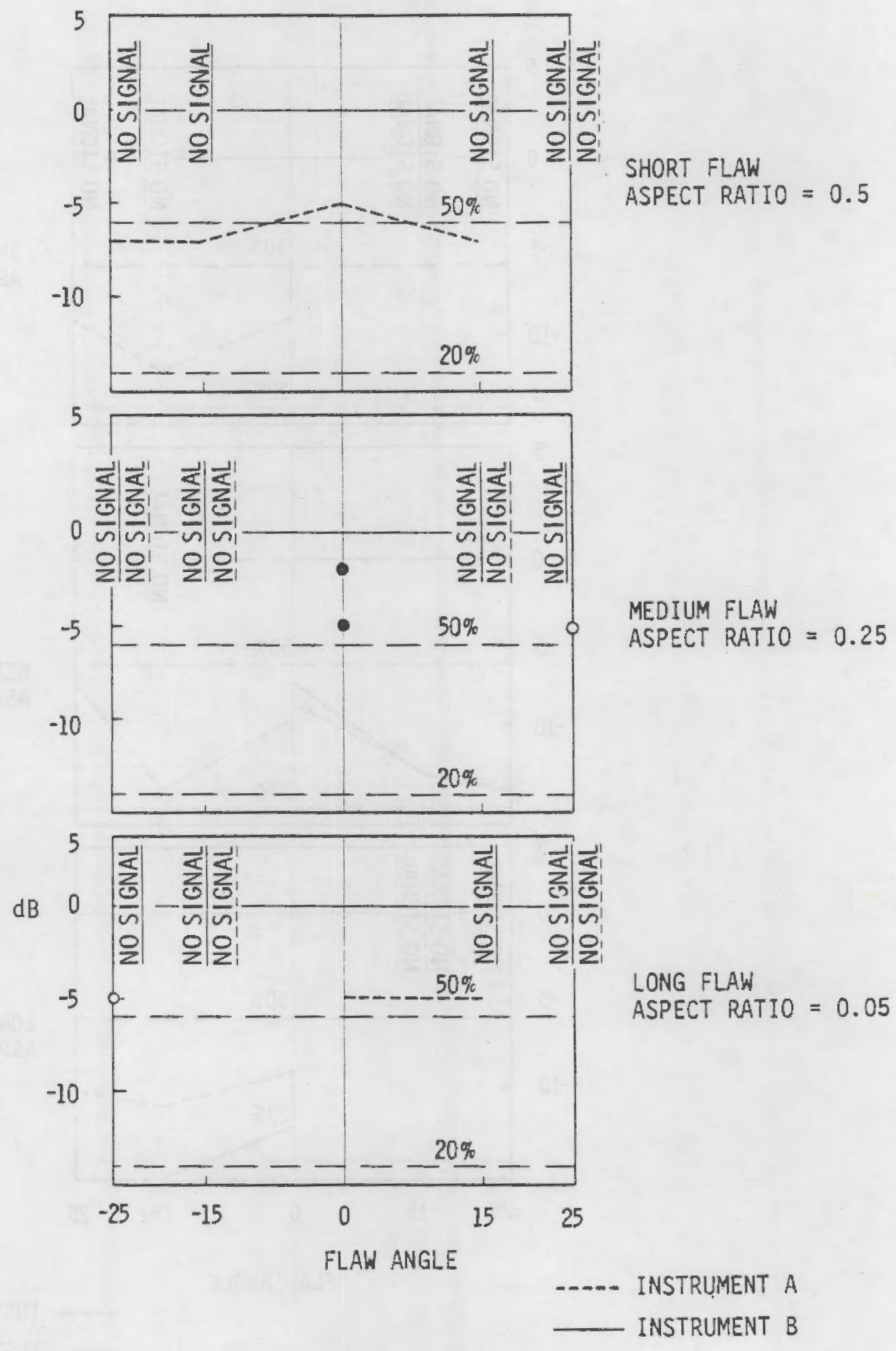


20" DIAMETER $304 \mathrm{~S} / \mathrm{S}$

TRANSDUCER $=.5^{\prime \prime}$ DIA.

BEAM ANGLE $=60^{\circ}$

$1 / 2$ V BEAM PATH

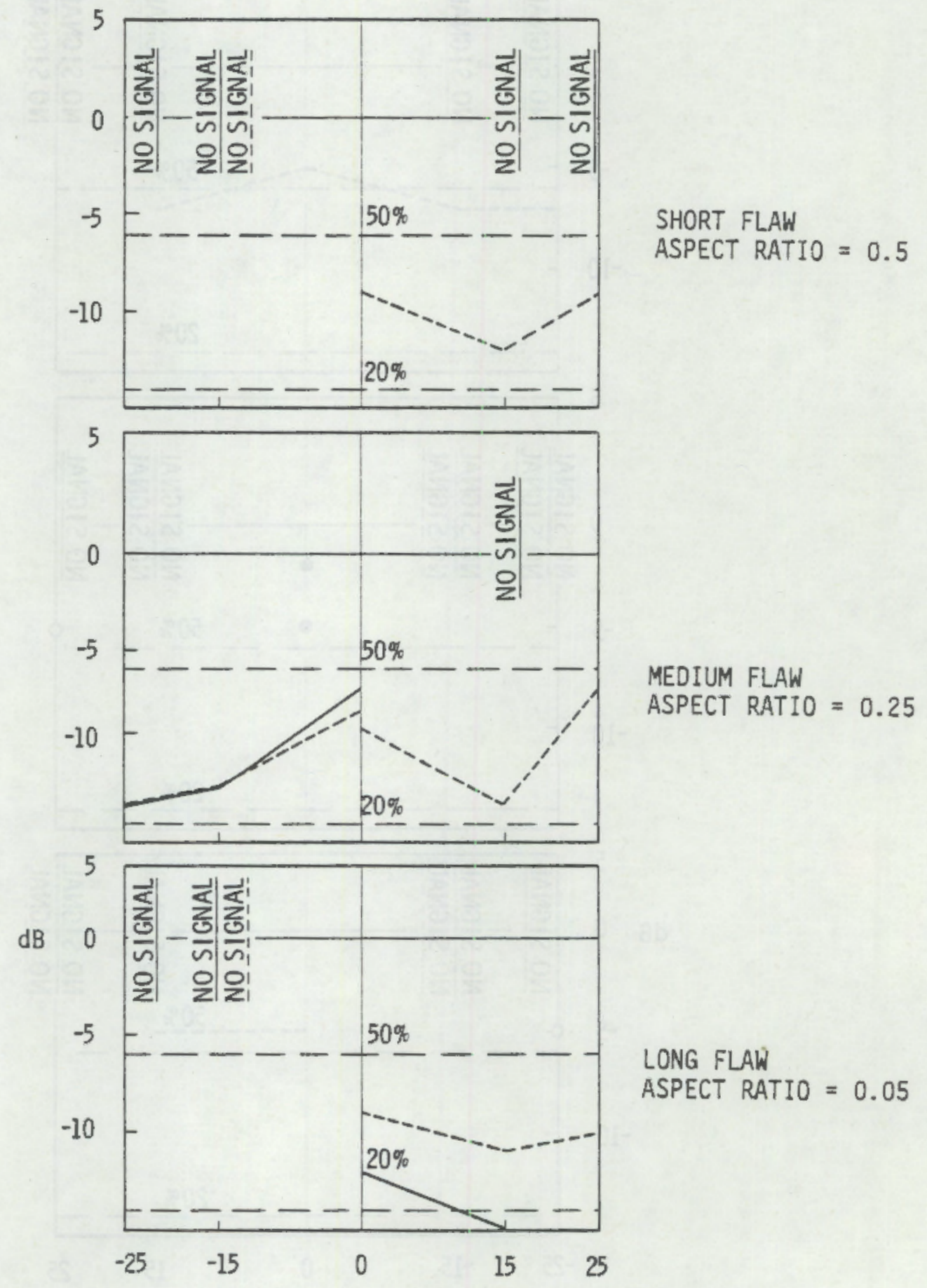

FLAW ANGLE

III -30 
20" DIAMETER $304 \mathrm{~S} / \mathrm{S}$

TRANSDUCER $=1$ " DIA.

BEAM ANGLE $=60^{\circ}$

$1 / 2$ V BEAM PATH

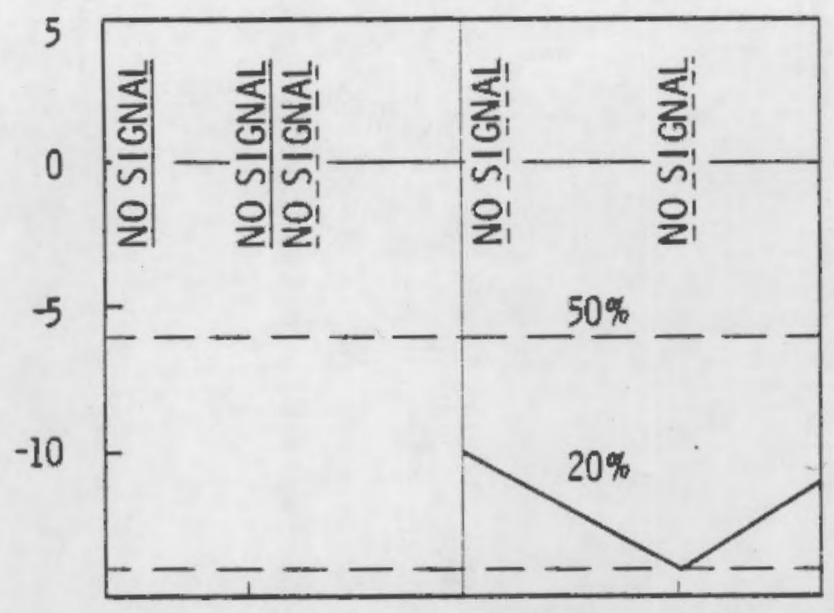

SHORT FLAW

ASPECT RATIO $=0.5$

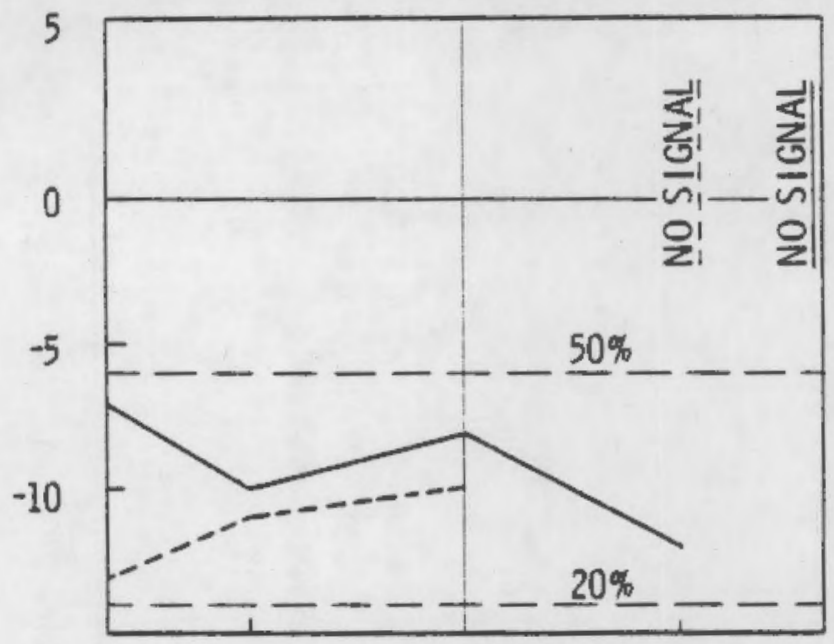

MEDIUM FLAW

ASPECT RATIO $=0.25$

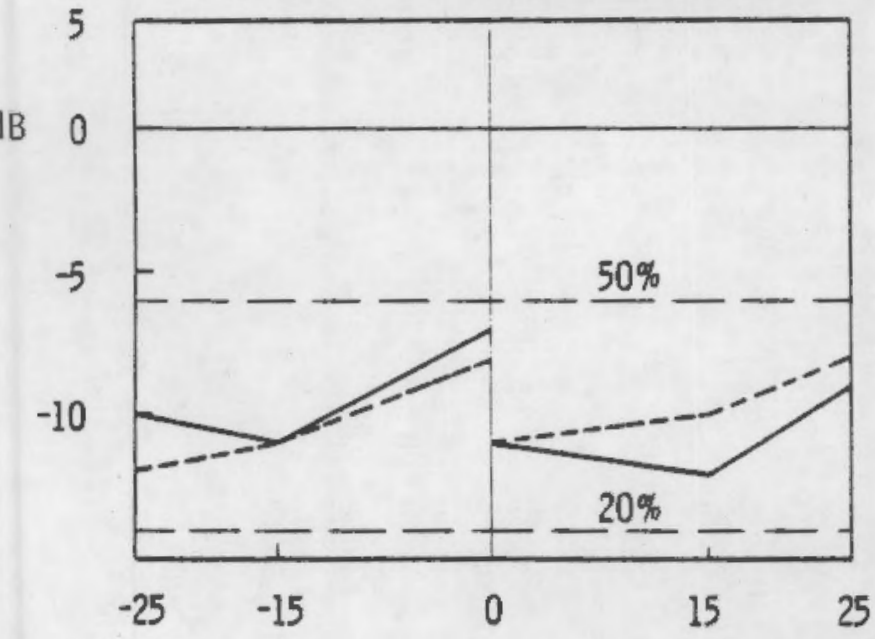

LONG FLAW

ASPECT RATIO $=0.05$

FLAW ANGLE

INSTRUMENT A

INSTRUMENT B 

NUREG/CR-1957

PNL-3692

\section{DISTRIBUTION}

No. of

Copies

Offsite

A. A. Churm

DOE Patent Division

9800 S. Cass Avenue

Argonne, IL 60439

U.S. Nuclear Regulatory Commission Division of Technical Information and Document Control

7920 Norfolk Avenue

Bethesda, MD 20014

2 OOE Technical Information Center

5 U.S. Nuclear Regulatory Commission Materials Engineering Branch

Oivision of Engineering

Washington, DC 20555

Martin Hum

Jim Kennedy

B. D. Liaw

G. Johnson

C. Y. Cheng
No. of

Copies

Onsite

48 Pacific Northwest Laboratory

F. L. Becker

S. Bush

G. J. Posakony

G. P. Selby

T. T. Taylor (37)

Publishing Coordination (2)

Technical Information (5) 


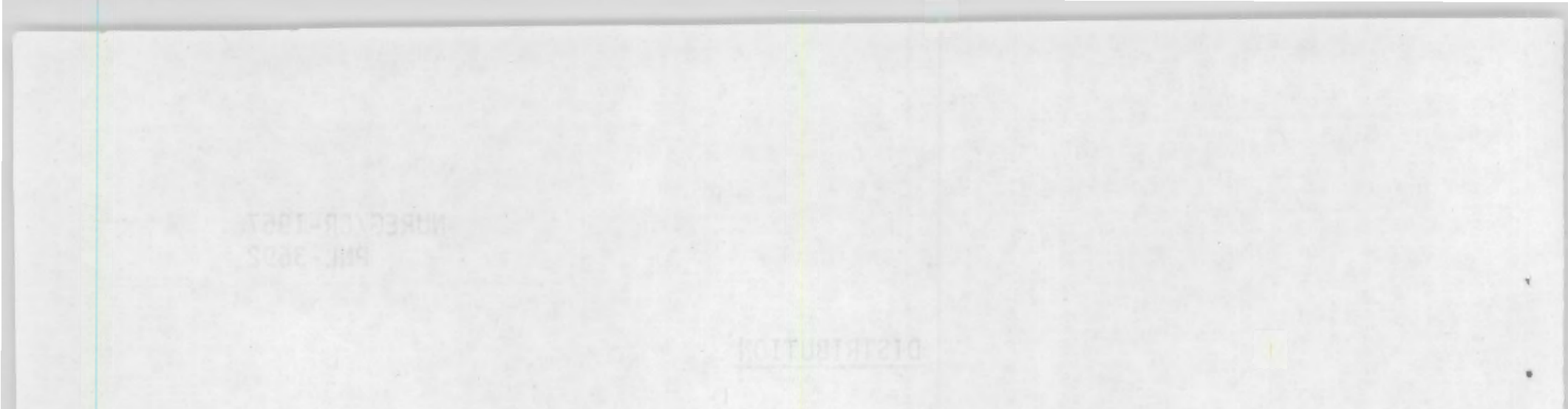


NRC FORM 335

(7).77)

Evaluation of ASME Section XI Reference Level

,

Sensitivity for Initiation of Ultrasonic Inspection

Examination

7. AUTHORIS)

T.T. Taylor, G.P. Selby

9. PERFORIMING ORGANIZATION NAME AND MAILING ADORESS (Include Zip Code)

Pacific Northwest Laboratory

Richland, WA 99352

2. SPONSORING ORGANIZATION NAME AND MAILING ADDRESS (Include $Z$ ip Code)

Division of Engineering

Office of Nuclear Reactor Regulation

U.S. Nuclear Regulatory Commission

Washington, DC 20555
1. REPORT NUMBER (Assigned bY DDC)

NUREG/CR-1957

PNL-3692

2. (Leave biank)

3. RECIPIENT'S ACCESSION NO

5. DATE REPORT COMPLETED \begin{tabular}{l|l}
\hline MONTH & YEAR \\
\hline
\end{tabular}

February 1981

DATE REPORT ISSUED

\begin{tabular}{l|l}
\hline MONTH & YEAR \\
\hline
\end{tabular}

April 1981

6. (Leave blank).

8. (Leave blank)

10. PROJECT/TASK/WORK UNIT NO

11. CONTRACT NO

FIN B2157

13. TYPE OF REPORT

PERIOD COVERED (/nc/usive dates)

15. SUPPLEMENTARY NOTES

14. (Leave olank)

16. ABSTRACT (200 words or less)

This report evaluates the change in inspection sensitivity resulting in major changes of ASME Boiler and Pressure Vessel Code Section XI between 1974 and 1977 Editions. It was found that the inspection sensitivity resulting from requirements of the 1977 Edition of Section XI were not adequate to detect minimum flaws referenced by same code.

\begin{tabular}{|c|l|}
\hline $\begin{array}{c}\text { 19. SECURITY CLASS (This report) } \\
\text { UnClaSS if ied }\end{array}$ & 21 NO OF PAGES \\
\hline $\begin{array}{c}\text { 20. SECURITY CLASS (This page) } \\
\text { UnClass if ied }\end{array}$ & $\begin{array}{c}\text { 22. PRICE } \\
\text { S }\end{array}$ \\
\hline
\end{tabular}




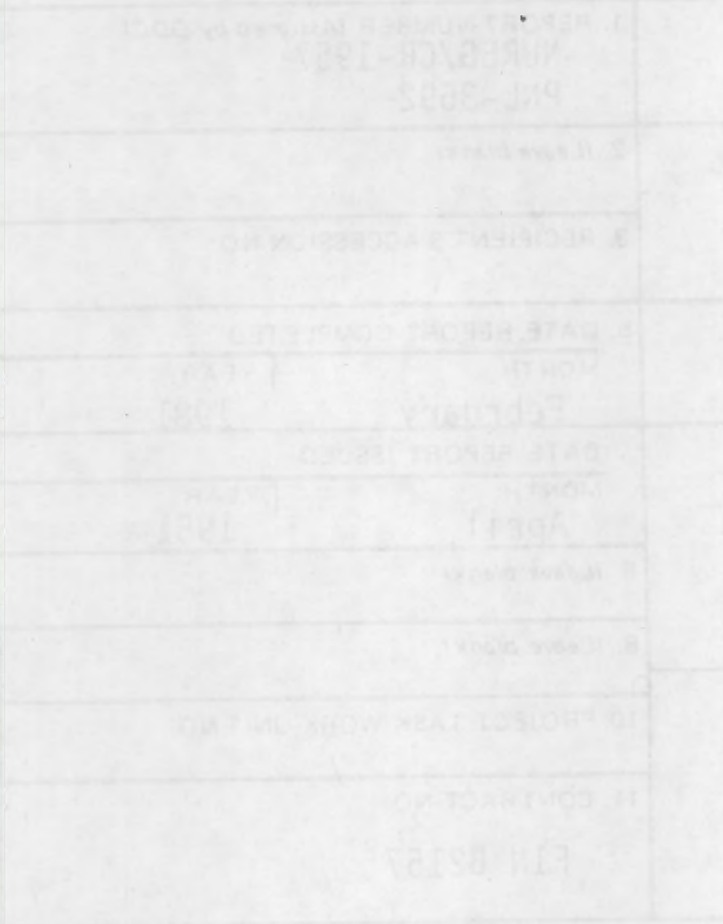

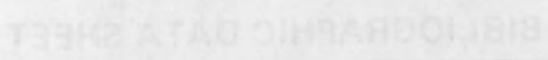

,

$\checkmark$ 